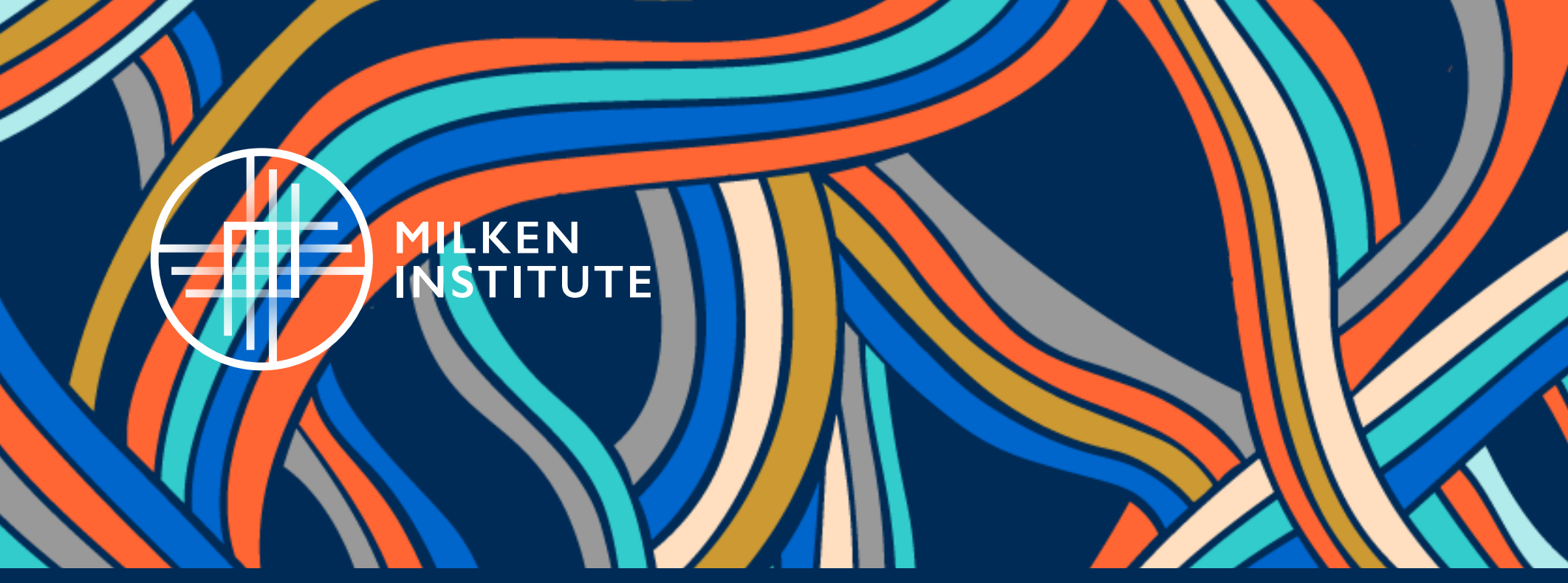

\title{
Reducing the Cost and Risk of Dementia
}

Recommendations to Improve Brain Health and Decrease Disparities

NORA SUPER, RAJIV AHUJA, AND KEVIN PROFF

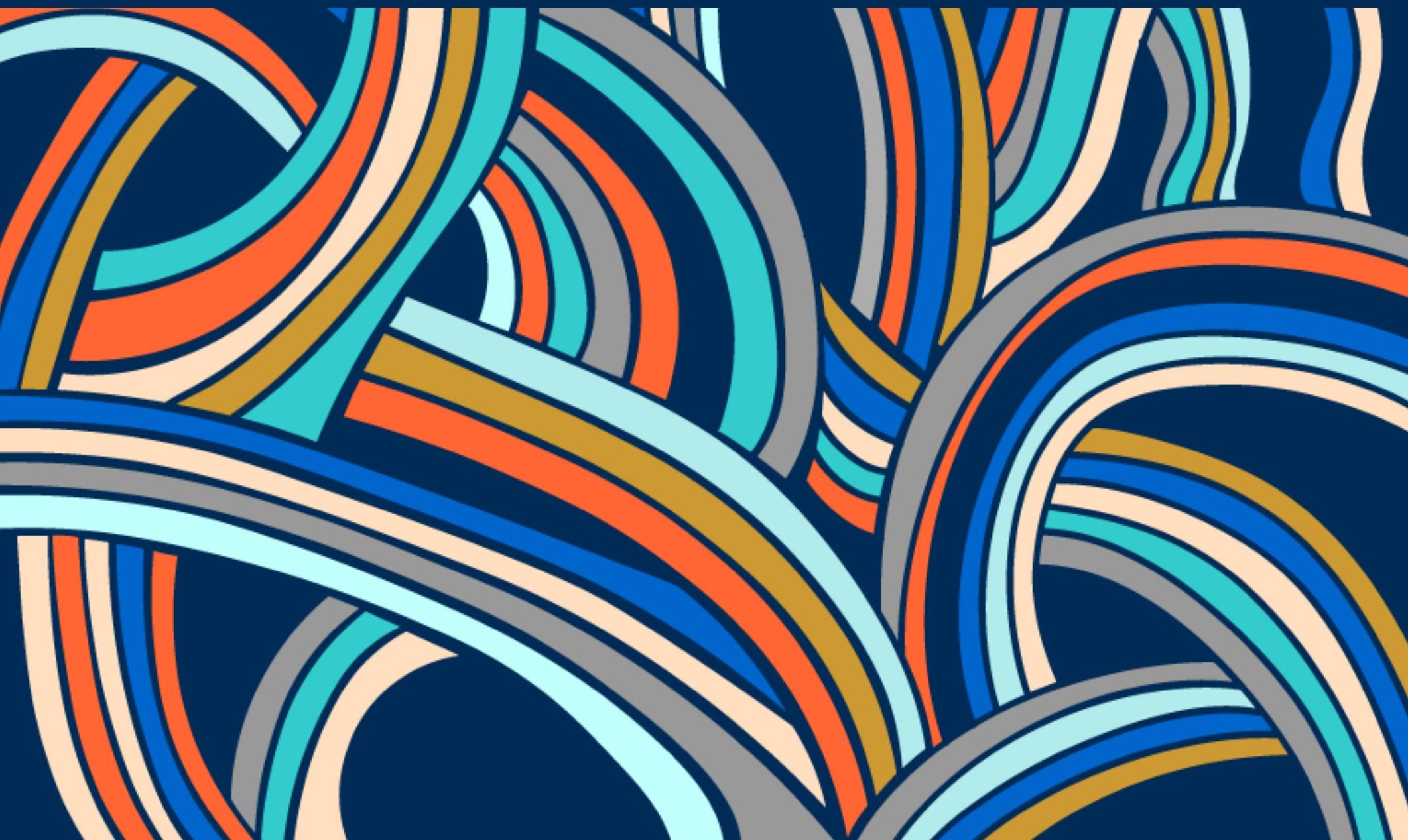




\section{CONTENTS}

\begin{tabular}{ll}
1 & Foreword \\
\hline 2 & Introduction \\
\hline 3 & Overview \\
\hline 9 & Goal \#1: Promote Strategies to Maintain and Improve Brain Health for \\
& All Ages, Genders, and Across Diverse Populations \\
\hline
\end{tabular}

16 Goal \#2: Increase Access to Cognitive Testing and Early Diagnosis

22 Goal \#3: Increase Opportunities for Diverse Participation in Research and Prioritize Funding to Address Health Disparities

29 Goal \#4: Build a Dementia-Capable Workforce Across the Care Continuum

38 Goal \#5: Establish Services and Policies that Promote Supportive Communities and Workplaces for People with Dementia and Their Caregivers

46 Endnotes

59 Supporting Organizations

60 Acknowledgments

61 About the Authors 


\section{FOREWORD}

by Sarah Lenz Lock, SVP, Policy \& Brain Health, AARP and Executive Director, Global Council on Brain Health, and Jill Lesser, Board Member, UsAgainstAlzheimer's and President, WomenAgainstAlzheimer's

Empowering people to live healthier lives with sharper minds is one of AARP's most important strategic priorities. It serves a triple bottom line by helping people live their best lives, maintaining older Americans' contributions to their communities, and reducing health-care costs. With this shared goal and a dedication to eradicating dementia globally, UsAgainstAlzheimer's is committed to disrupting the status quo, accelerating towards an effective means of prevention, treatment, and a cure for Alzheimer's by 2025 , and giving a voice to the 5.8 million Americans living with Alzheimer's disease and their 16 million caregivers.

Both of our organizations are pleased to collaborate with the Milken Institute Center for the Future of Aging and others in the Brain Health Partnership to support policies that will reduce the risks of cognitive decline and dementia as we age. We have come together because dementia is one of the greatest public health challenges of our time, and the diseases that cause it must be eradicated. Unfortunately, developing a pharmacological, disease-modifying intervention for Alzheimer's and related dementias has proven more challenging than we have ever expected. Indeed, this immense challenge is why AARP, on its 60th anniversary, invested an unprecedented $\$ 60$ million in the Dementia Discovery Fund-to develop innovative treatments for dementia and urge others to do the same. And while our commitment to a cure is unwavering, we believe tremendous opportunity lies in widening our view and addressing dementia on multiple fronts.

A healthy brain is essential for vital, productive aging. But too many people think that dementia is an inevitable part of the aging process. This report demonstrates the impact and burden dementia places on our families and country, but it also shows us that dementia is not a normal part of aging, and that we have the power to change the trajectory. "Reducing the Cost and Risk of Dementia" makes a significant contribution to our mutual goals by clearly defining the nature, scope, and dimensions of the challenges that dementia poses and providing the steps we need to take to address them.
We should not underestimate the enormous value of simply maintaining brain health as long as possible. If we can delay onset of dementia by even five years, we could reduce the incidence of the diseases causing dementia by half. Imagine the value of five more years of healthy living, sharp minds, and purposeful, productive aging to individuals and their families. Imagine what our families and our health-care systems could do with the \$145 billion we would have saved in 2019 on the direct care costs of dementia if we had already cut the incidence rate in half. This report helps us imagine a better future and provides evidence to show that cutting both the costs and risks of dementia is very possible.

Understanding the problem is only half of the solution. This report exposes the economic burdens associated with dementia and who bears them, and quantifies the societal challenges ahead of us-which are particularly acute for women, African Americans, Hispanics, lowincome older Americans, and people with intellectual and developmental disabilities. It confirms that we must double-down on efforts for increased scientific rigor, particularly for research that helps us better understand how to reduce disparities. It outlines solutions as well, showing us the steps within our control to reduce the cost and risk of dementia. The five goals set forth in this report are designed to improve brain health and decrease disparities, and provide clear recommendations on how we can move forward towards a future where we can all live longer, healthier lives.

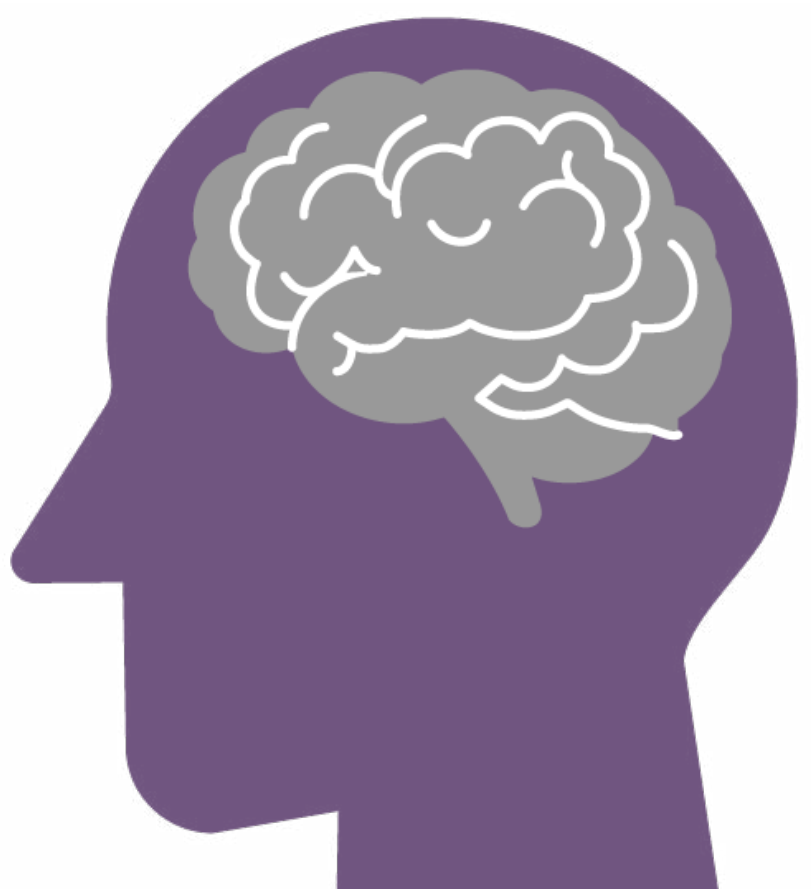




\section{INTRODUCTION}

Increased longevity is perhaps one of the greatest success stories of our modern public health system. People around the globe are living longer than ever before thanks to major medical and public health advances and greater access to health care. Sixty-five-year-olds living in developed countries today can expect to live another 19 years on average-that's age 83 for men and 86 for women.

But along with this success comes one of our greatest challenges to healthy longevity. As we age, the risk of neurodegenerative disease increases dramatically. Neurodegenerative diseases are characterized by a progressive deterioration of brain function, with a significant consequent decrease in quality of life for those living with the disease and for their families and loved ones. Alzheimer's disease is by far the most common type of neurodegenerative disease, affecting millions of people worldwide.

Our research determined 7.2 million Americans today live with Alzheimer's disease or other dementias. Alzheimer's disease is the most common cause of dementia and accounts for 60 to 80 percent of all cases, which means nearly 5.8 million people are currently living with Alzheimer's disease in the US. Of those living with Alzheimer's, 81 percent are age 75 and older. ${ }^{1}$ With increased lifespans over the past century, the number of people living with dementia is expected to rise significantly. This research projects that over the next 20 years, the total number of those living with Alzheimer's disease or other dementias in the US is expected to approximately double from 7.2 million to nearly 13 million, with 8.5 million women and 4.5 million men.

At the Milken Institute, we strive to catalyze practical solutions to global challenges. That is why we are putting forward new ideas to reduce the cost and risk of dementia. This report updates previously published data from our 2016 "The Price Women Pay for Dementia: Strategies to Ease Gender Disparity and Economic Costs" report, and expands our analysis to include the value of brain health and the effects of dementia on diverse communities. The report includes actionable recommendations centered around five primary goals:

\section{Goal 1: Promote strategies to maintain and improve brain health for all ages, genders, and across diverse populations}

\section{Goal 2: Increase access to cognitive screening and early diagnosis}

\section{Goal 3: Increase opportunities for diverse participation in research and prioritize funding to address health disparities}

\section{Goal 4: Build a dementia-capable workforce across the care continuum}

\section{Goal 5: Establish services and policies that promote supportive communities and workplaces for people with dementia and their caregivers}

Years of investment and research in Alzheimer's disease and related dementias are now sowing seeds of hope. Scientists today have a more complete understanding of how the brain works and its complex and dynamic relationship with the rest of our body systems. We are seeing data emerge that confirm a role for interventions that may delay or possibly prevent cognitive decline. New research is focusing on ways to improve and maintain our brain health through prevention and risk reduction strategies. ${ }^{2}$ We have to work harder to find new ways to improve brain health, especially for women and minority populations who are at greater risk for developing dementia, though we don't fully know why. We do understand more about how to improve the lives of those currently living with dementia than many of us realize. ${ }^{3}$ As evidence emerges, we are in a prime position to act, but time is of the essence. In a field that can often look grim, there is hope. The time to act is now.

Since our last report, new information is available regarding the underlying causes of dementia and the 
economic and social costs based on gender, race, and ethnicity. Below are some key developments:

\section{- Our understanding of the causes of dementia continues}

to grow. Dementia is no longer thought of as a disease with a singular cause, but rather the result of different neurobiological pathways and processes that lead to the expression of dementia. Aging is still the leading risk factor for dementia and cognitive decline. The older we are, the more risk we face for developing dementia, though new research shows us that dementia is not inevitable as we age. Recent approaches to diagnosing and treating dementia address these numerous biological processes and pathways, and integrate them into the care continuum.

\section{- Multiple biomedical failures have caused us to re-} evaluate our approach to treating dementia. Historically, biomedical research has focused on the amyloid plaques, or clumps between nerve cells (neurons) in the brain-a defining hallmark of Alzheimer's disease. Several highprofile Phase III drug trials were discontinued after leading researchers and biopharmaceutical companies concluded that targeting beta-amyloid in plaque does not result in clinical improvement. Building upon these biomedical findings and recognizing that there are no current treatments to modify the underlying disease, several multi-pronged interventions have been identified to prevent or delay the transition from preclinical (asymptomatic) Alzheimer's disease to more advanced stages of the disease. ${ }^{4}$ These interventions include, but are not limited to, anti-amyloid immunotherapies, modifiable lifestyle factors, and treatment of co-occurring medical conditions. And while genetic risks to brain health are inherited, there is new scientific evidence that adherence to a healthy lifestyle may counteract a genetic risk for Alzheimer's disease. ${ }^{5} \mathrm{New}$ research released during the Alzheimer's Association International Conference showed that addressing four or five healthy lifestyle factors, including a healthy diet, exercise, stopping smoking, light to moderate alcohol intake, and engaging in cognitively stimulating activities, reduced risk of Alzheimer's by 60 percent. $^{6}$

\section{- Gender disparities still prevail in the incidence and} impact of dementia. It is well documented that women have a higher lifetime risk of developing dementia. Previously, researchers posited that this is because women live longer than men, but new data have unveiled key discoveries about the differences between men's and women's brains, and how they age. ${ }^{7}$ Moreover, women typically take on greater caregiver responsibilities than men. ${ }^{8}$ Women caregivers are more likely to be impacted financially and leave their jobs or miss work to care for a family member. ${ }^{9}$ And research demonstrates that spousal caregivers may be at a higher risk of cognitive impairment or dementia than non-caregivers. ${ }^{10}$

\section{- We increasingly understand the disparate impacts} of dementia on diverse communities. Specific minority populations have a higher lifetime risk of developing dementia. According to AARP, older African Americans have the highest risk of dementia, followed by American Indians/Alaska Natives, and Latinos. ${ }^{11}$ These minority populations also experience a greater economic impact from dementia, both as patients and caregivers. The African American Network Against Alzheimer's asserts that "while African Americans make up 13.6 percent of the US population, they bear one-third of the nation's total costs of Alzheimer's and other dementias." Unfortunately, in spite of this disparity, these individuals often receive delayed diagnosis or inadequate treatment. ${ }^{12}$

People with intellectual and developmental disabilities (IDD) have a similar prevalence of dementia as the general population. However, people with Down syndrome have a higher prevalence of dementia at middle and early elderly ages. ${ }^{13}$ People living with IDD and dementia also often have unique caregiving needs. ${ }^{14}$

To build on this new research and understanding of dementia, we analyzed data, conducted interviews, and hosted consensus-building sessions with thought leaders, experts, industry stakeholders, and advocates to develop actionable recommendations to improve brain health and reduce disparities. The remainder of this report details these recommendations and the evidence to support them.

\section{OVERVIEW}

Dementia is not a specific disease. According to the National Institutes of Health (NIH), dementia is the "loss of thinking, remembering, and reasoning ... that interferes with a person's daily life and activities." ${ }^{15}$ There are many causes for dementia, but Alzheimer's disease is the most common and accounts for 60 to 80 percent of all 
cases. ${ }^{16}$ Dementia is a term for a group of progressive, neurodegenerative diseases that impact memory and cognitive skills. Even though dementia is more common in older adults, scientists emphatically assert that it is not a normal part of aging.

\section{Populations Impacted}

According to our projections, over the next 20 years, the total prevalence of Alzheimer's disease and related dementias in the US is expected to approximately double from 7.2 million to nearly 13 million, with 8.5 million women and 4.5 million men expected to develop dementia by 2040 (see Table 1).

Age is still the greatest risk factor for dementia. Our risk of developing dementia doubles every five years after we turn $65 .{ }^{18}$ In 2019, 81 percent of people with Alzheimer's disease are age 75 and older. In the US, many of us will live until age 85 , and about one-quarter will live past 90. ${ }^{19}$ Dementia will impact this 85 -year-old age group significantly moving forward. By the time we turn 85 , we will have nearly a one in three chance of developing dementia. ${ }^{20}$ And by 2050, more than half of all people 65 and older with Alzheimer's disease will be older than $85 .{ }^{21}$

More women than men develop dementia, and the difference is significant. Gender is one of the most established determinants for developing dementia. By 2020, roughly 4.7 million women in the US are projected to have dementia, which represents nearly two-thirds of all people living with dementia (see Figure 1).
Table 1: Population Reporting Dementia by Gender (Thousands)

\begin{tabular}{|cccc|c|}
\hline \multicolumn{5}{c|}{2019} \\
\cline { 1 - 3 } Prevalence & $\begin{array}{c}\text { Treated } \\
\text { Prevalence }\end{array}$ & $\begin{array}{c}\text { Adult Day } \\
\text { Care }\end{array}$ & $\begin{array}{c}\text { Nursing } \\
\text { Home }\end{array}$ & \\
\cline { 1 - 3 } $4,620.0$ & $1,201.2$ & 38.4 & 492.5 & Women \\
\cline { 1 - 3 } $2,580.0$ & 877.2 & 26.3 & 254.4 & Men \\
\hline $7,200.0$ & $2,078.4$ & 64.8 & 746.9 & Total \\
\hline
\end{tabular}

\begin{tabular}{|cccc|c|}
\multicolumn{5}{c|}{2040} \\
\cline { 1 - 3 } Prevalence & $\begin{array}{c}\text { Treated } \\
\text { Prevalence }\end{array}$ & $\begin{array}{c}\text { Adult Day } \\
\text { Care }\end{array}$ & $\begin{array}{c}\text { Nursing } \\
\text { Home }\end{array}$ & \\
\cline { 1 - 4 } $8,458.1$ & $2,230.8$ & 71.3 & 920.0 & Women \\
\cline { 1 - 3 } $4,509.3$ & $1,547.1$ & 48.7 & 442.0 & Men \\
\hline $12,967.3$ & $3,777.9$ & 120.0 & $1,362.0$ & Total \\
\hline
\end{tabular}

Source: Milken Institute, 2019. ${ }^{17}$

Note: Figures are rounded to the nearest tenth, so may not add up to the rounded total.

Figure 1: Increasing Dementia Prevalence by Gender (2015-2040)

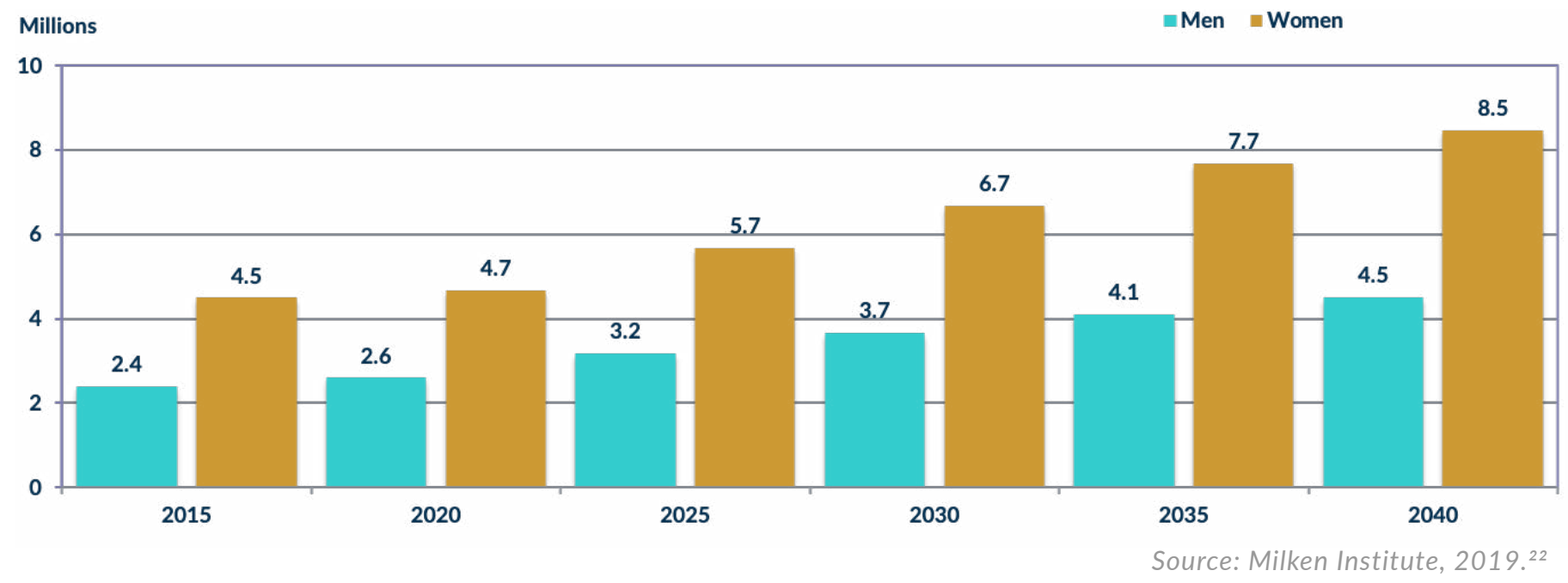


Dementia is expected to impact people of color even more significantly and disproportionately in the future. Dementia disproportionately impacts certain minority groups such as African Americans and Latinos, which will likely increase over the next few decades. While our analysis did not project prevalence by race or ethnicity, research by Kevin Matthews et al. projects that from 2020 to 2060, the number of African Americans and Latinos with dementia will grow by nearly 200 percent and 440 percent, respectively. ${ }^{23}$ In contrast, non-Hispanic whites are projected to experience 69 percent growth in people living with dementia. Hispanic Americans are projected to have the most significant increase in people living with dementia due to population growth over the next four decades.

Family caregivers provide the vast majority of dementia care, and they also experience direct negative impacts on their health and finances. As cognition declines, people living with dementia often need help with a broad range of activities of daily living such as eating, dressing, and housekeeping. After receiving a diagnosis of Alzheimer's disease, people live, on average, four to eight years, with some living as long as 20 years. ${ }^{24}$ Eighty-three percent of caregiving in the US comes from family members, friends, or other unpaid caregivers. ${ }^{25}$ In 2018, more than 16 million Americans served as caregivers to people with dementia, providing an estimated 18.5 billion hours of unpaid care. ${ }^{26}$ These caregivers provide as much as 80 percent of the necessary long-term support and services. ${ }^{27}$

Many dementia caregivers are themselves growing older and are physically and financially vulnerable. One in four dementia caregivers is 65 or older, which is significantly higher than non-dementia caregivers. ${ }^{28}$ Although 60 percent of dementia caregivers are employed, their median household income is less than $\$ 60,000 .{ }^{29}, 30$ Caregivers of people living with dementia spend the most time providing help and report the highest degree of physical strain compared with those caring for people with other conditions. ${ }^{31}$

Women are disproportionately impacted, not only by the disease itself but because they bear the majority of the responsibility for providing caregiving services. Older women, in particular, provide the majority of care to spouses, parents, parents-in-law, friends, and neighbors. The majority of dementia caregivers are women (58 percent) and are around age 54 on average, which is about six years older than non-dementia caregivers. ${ }^{32}$

Caregivers take on many roles on behalf of their loved ones (e.g., hands-on healthcare provider, care manager, friend, companion, surrogate decision-maker, and advocate). Women, on average, are more likely to handle the most challenging caregiving tasks (i.e., bathing, toileting, and dressing), with 36 percent of female caregivers taking on these responsibilities compared with 24 percent of men.

Women caregivers also report spending more time providing care than men (21.9 vs. 17.4 hours per week). ${ }^{33}$ For people at the later stages of dementia, caregivers often report missing work or having to quit their jobs. Female caregivers are 40 percent more likely than male caregivers to quit their jobs. Additionally, as the complexity of care increases the stress in one's life, caregiving is associated with worsened health outcomes and an increase in health-care costs by almost $\$ 5,000$ per year per caregiver.

Moreover, communities of color are likely to be disproportionately impacted by caregiving responsibilities. Because of the increased risk for dementia among African American and Latino communities, coupled with income differences and cultural attitudes toward family caregiving, non-white populations typically provide more dementia care than white populations. Latinos have the highest reported prevalence of caregiving, followed by African Americans, Asian Americans, and non-Hispanic whites. ${ }^{34}$

\section{Cost of Dementia}

Alzheimer's is the most expensive disease in the US and costs more than cancer and heart disease..$^{35}$ According to the Alzheimer's Association, direct costs accounted for $\$ 290$ billion spent in 2019 across Medicare, Medicaid, private insurance, and out-of-pocket costs for individuals living with dementia. By 2050, this number is projected to increase to $\$ 1.1$ trillion. ${ }^{36}$

Dementia drives up overall health costs, as well as outof-pocket expenses for those living with dementia and for their caregivers. In addition to the cost of treatment, direct costs associated with dementia also include paid formal home health care and long-term care services. The annual number of paid home-health visits in the first year 
following a dementia diagnosis averaged 30 compared with 13 among those without a dementia diagnosis. ${ }^{37}$ And four years from the time of diagnosis, the percentage of patients receiving paid home health care increased more than threefold..$^{38}$ The costs for paid home care accounted for 20 percent of the total direct costs associated with dementia. ${ }^{39}$

As the disease progresses, people living with dementia often need round-the-clock care provided in nursing homes and memory care centers. During the late stages of dementia, a person may live in a nursing home for three to four years, depending on the acuity of their symptoms, which can also substantially increase their direct costs or those of the state Medicaid program paying for their care. ${ }^{40}$ Nearly 75 percent of people age 80 or older who are living with dementia live in a nursing home compared with only 4 percent of those without dementia. ${ }^{41}$ Nursing home costs account for a significant portion of the total direct costs associated with dementia. The average cost of a semi-private bed in a nursing home was more than $\$ 85,000$ in $2017 .{ }^{42}$ Some estimates calculate that nursing home care costs accounted for almost half of the total direct costs of dementia. ${ }^{43}$

Family caregivers bear a significant portion of the overall costs of dementia care in the US. Caregiving for people living with dementia is more demanding and requires more intensive care and longer hours than other types of caregiving. The number of caregivers for people living with dementia outnumbers those living with the disease. According to the Milken Institute, there are roughly 9.6 million dementia caregivers compared with 7.2 million people living with dementia (see Tables 1 and 2). The physical and emotional impact on these caregivers resulted in more than $\$ 11$ billion in health costs alone in $2018 .{ }^{44}$ In addition to health-care costs, the time and stress associated with balancing family caregiving with work responsibilities in the workforce can result in absenteeism, presenteeism, and job departure.

According to Milken Institute projections, over the next 20 years, the total number of unpaid caregivers for people living with dementia will increase from 9.6 million to 19.5 million, two-thirds of whom will be women (see Table 2). Dementia caregivers are also more likely to be impacted at work. We project that nearly 60 percent, or 11.6 million, of these caregivers will be employed in 2040 . The
Table 2: Dementia's Projected Impact on Caregivers (Thousands)

\begin{tabular}{|c|c|c|c|}
\hline \multicolumn{3}{|c|}{2012} & \\
\hline Caregivers & $\begin{array}{l}\text { Employed } \\
\text { Caregivers }\end{array}$ & $\begin{array}{l}\text { Caregivers } \\
\text { No Longer } \\
\text { Working }\end{array}$ & \\
\hline $5,749.9$ & $3,162.5$ & 88.9 & Women \\
\hline $3,833.3$ & $2,530.0$ & 56.4 & Men \\
\hline $9,583.2$ & $5,692.4$ & 145.3 & Total \\
\hline
\end{tabular}

\begin{tabular}{|c|c|c|c|}
\hline \multicolumn{3}{|c|}{2040} & \\
\hline Caregivers & $\begin{array}{l}\text { Employed } \\
\text { Caregivers }\end{array}$ & $\begin{array}{l}\text { Caregivers } \\
\text { No Longer } \\
\text { Working }\end{array}$ & \\
\hline $11,671.1$ & $6,419.1$ & 180.4 & Women \\
\hline $7,780.7$ & $5,135.3$ & 114.5 & Men \\
\hline $19,451.8$ & $11,554.4$ & 294.9 & Total \\
\hline
\end{tabular}

Source: Milken Institute, $2019 .{ }^{45}$

Note: Figures are rounded to the nearest tenth, so may not add up to the rounded total.

number of caregivers that will have to leave their jobs due to the strain of caregiving will more than double as well from 145,000 to almost 295,000 . Sixty percent of these caregivers who leave their jobs will be women.

Women experience a more significant financial strain, given that they spend a higher percentage of their average annual income on caregiving expenses ${ }^{46}$ According to the AARP Public Policy Institute, family caregivers age 50 and older who leave the workforce to provide care lose nearly $\$ 304,000$ in wages and benefits over their lifetime. ${ }^{47}$ Women caregivers are also more likely to experience higher levels of stress, impaired mood, depression, and adverse health outcomes than men because they spend more time caregiving, assume more caregiving tasks, and care for those with more cognitive, functional, or behavioral problems. ${ }^{48}$

The economic impact of caregiving impacts racial and ethnic groups differently as well. In 2016, Hispanic and African American caregivers spent a significantly higher 
percentage of their annual income on caregiving than white caregivers did (44 percent and 34 percent versus 14 percent, respectively). ${ }^{49}$ Almost 61 percent of the overall economic impact of dementia on African Americans (\$72 billion) is attributed to unpaid caregiving, which is valued at nearly $\$ 44$ billion.

Hispanic caregivers experience relatively high caregiving costs due, in part, to a more intensive caregiving situation (63 percent in highly complex situations compared with 51 percent of non-Latino caregivers). ${ }^{50}$ On average, they provide care to a recipient for five or more years. Latinos tend to underutilize formal dementia caregiving services, which can increase the economic and other impacts on family caregivers. ${ }^{51}$ Furthermore, a quarter of Hispanics care for a person living with dementia, a costlier population, and relatively few Hispanic caregivers divide their caregiving work up among other unpaid caregivers.

While many states have been promoting home and community-based services as a more cost-effective way to care for people living with dementia, new research raises concerns about how this may further impact caregivers negatively. To calculate the cost of care, researchers typically consider replacement costs and foregone wages. These approaches are limited, however, because they do not capture the value of informal care that goes beyond earnings, including the cost of foregone leisure, future employment opportunities, or the intangible value of fulfilling a person's familial duty. Economists from the University of Pennsylvania have developed a dynamic discrete choice model to estimate and monetize the effect of caregiving on a caregiver's well-being. They found that the costs of informal care are the same as a two-year stay in a semi-private bed in a nursing home. This research method suggests that the median cost to well-being is approximately $\$ 180,000$ over two years - seven times more than the traditional forgone wage estimate (see Table 3)..$^{52,53}$

According to our projections, the economic impact of dementia will reach nearly $\$ 380$ billion by 2040 (see Table 4). This is a cumulative $\$ 520$ billion over a nearly threedecade period. More than 70 percent of these costs would be attributed to the treatment of women, even though women are less likely to be treated for the disease than men are. Because most people living with dementia and caregivers are women, the economic loss associated with women alone will total $\$ 2.1$ trillion, representing over 80 percent of the cumulative costs from 2012 to 2040.

Our analysts believe this economic cost estimate is conservative given that the 2016 Milken Institute study used Medicare Expenditure Panel Survey (MEPS) data from 2012, whereas numbers reported by the Alzheimer's Association rely on the data from the Medicare Current

Table 3: Two-Year Median Cost Estimates of Informal Caregiving by Assets and Education

\begin{tabular}{|c|c|c|c|c|c|c|}
\hline & 1st Ass & Tercile & 2nd Ass & Tercile & 3rd Ass & Tercile \\
\hline & $\begin{array}{c}\text { Forgone Wage } \\
\text { Method }\end{array}$ & Welfare Cost & $\begin{array}{c}\text { Foregone } \\
\text { Wage Method }\end{array}$ & Welfare Cost & $\begin{array}{c}\text { Foregone } \\
\text { Wage Method }\end{array}$ & Welfare Cost \\
\hline $\begin{array}{l}\text { Across All Non-Healthy } \\
\text { States }\end{array}$ & $\$ 18,170$ & $\$ 141,807$ & $\$ 27,060$ & $\$ 215,141$ & $\$ 30,920$ & $\$ 188,805$ \\
\hline
\end{tabular}

Assets are the initial assets with which a person enters the discrete choice model.

\begin{tabular}{|c|c|c|c|c|c|c|}
\hline & Less than & gh School & High Scho & I Graduate & Some Coll & se or More \\
\hline & $\begin{array}{c}\text { Forgone Wage } \\
\text { Method }\end{array}$ & Welfare Cost & $\begin{array}{c}\text { Foregone } \\
\text { Wage Method }\end{array}$ & Welfare Cost & $\begin{array}{c}\text { Foregone } \\
\text { Wage Method }\end{array}$ & Welfare Cost \\
\hline $\begin{array}{l}\text { Across All Non-Healthy } \\
\text { States }\end{array}$ & $\$ 9,310$ & $\$ 74,087$ & $\$ 18,370$ & $\$ 139,178$ & $\$ 39,150$ & $\$ 250,350$ \\
\hline
\end{tabular}

Source: Calculations by Norma Coe with a dynamic discrete choice model as in Skira (2015) ${ }^{54}$ and Coe et al. (2018), which accounts for the current and future labor market and well-being impacts of caregiving from a daughter to a mother, calibrated using data from the Health and Retirement Study. Welfare costs are the dollar amount a daughter who provides informal care to her mother would have to receive to be just as well off as if she never needed to provide that care. 
Table 4: Economic Impact of Dementia (2012 US \$Billions)

\begin{tabular}{|c|c|c|c|c|c|c|c|c|c|}
\hline & & Men & & & Women & & & Total & \\
\hline & Treatment & $\begin{array}{l}\text { Living } \\
\text { Arrange- } \\
\text { ments }\end{array}$ & $\begin{array}{l}\text { Indirect } \\
\text { Impact }\end{array}$ & Treatment & $\begin{array}{l}\text { Living } \\
\text { Arrange- } \\
\text { ments }\end{array}$ & $\begin{array}{l}\text { Indirect } \\
\text { Impact }\end{array}$ & Treatment & $\begin{array}{l}\text { Living } \\
\text { Arrange- } \\
\text { ments }\end{array}$ & $\begin{array}{l}\text { Indirect } \\
\text { Impact }\end{array}$ \\
\hline 2012 & 2.8 & 19.2 & 7.2 & 7.5 & 39.9 & 43.7 & 10.3 & 59.1 & 50.9 \\
\hline 2040 & 9.5 & 64.6 & 25.4 & 25.2 & 133.2 & 122.5 & 34.7 & 197.8 & 147.9 \\
\hline Cumulative & 151.2 & 989.4 & 435.9 & 368.3 & $1,879.0$ & $2,087.7$ & 519.5 & $2,868.4$ & $2,523.7$ \\
\hline
\end{tabular}

Source: Milken Institute, 2019. Note: Figures are rounded to the nearest tenth, so may not add up to the rounded total.

Beneficiary Survey (MCBS) in 2011. The cost estimates from these surveys differ in several important ways. MEPS data sample individuals in health-care institutions such as nursing homes and facilities for the cognitively impaired. In addition, the cost estimates from MEPS data tend to underestimate total spending, especially by highspenders. ${ }^{55}$ On the other hand, Medicare claims-based data such as MCBS tend to overestimate costs, largely due to errors in identifying the medical condition. ${ }^{56}$ Living arrangements were calculated using data from the Centers for Disease Control and Prevention and the National Centers for Health Statistics and include expenditures for nursing home care and adult day center services. Indirect impact costs were calculated as the sum of the economic cost of absenteeism (missing workdays) and presenteeism (reduced productivity due to the condition), based on several national data sources. ${ }^{57}$
We know that the economic impact of dementia disproportionately affects minority populations. While Milken Institute analysis did not predict future costs based on race and ethnicity, research supported by UsAgainstAlzheimer's found that while African Americans make up only 13.6 percent of the US population, they bear a third of the costs of dementia. ${ }^{58}$ This research estimated that the overall economic impact of dementia on African Americans was almost $\$ 72$ billion in $2012 .{ }^{59}$ Based on the prevalence rate, and the growth and aging of the African American population, the costs of dementia for African Americans is expected to more than double by $2050 . .^{60}$ Direct costs for Latinos with dementia were roughly $\$ 7$ billion in 2012 and will likely more than double in 2030 to $\$ 19.6$ billion. In 2060 , these costs will increase more than nine times to $\$ 65.7$ billion. ${ }^{61}$ The most significant expenditures are medical and nursing home care costs. 


\section{Goal \#1}

\section{Promote strategies to maintain and improve brain health for all ages, genders, and across diverse populations}

We will all experience normal changes in thinking, reasoning, and memory as we age (e.g., sometimes forgetting people's names or appointments, or not being able to pay attention for long periods). For some of us, more serious cognitive changes related to diseases like Alzheimer's and other dementias may significantly impair normal functioning and drastically reduce our quality of life. New evidence suggests that we can extend our healthy and productive years, reduce the impact of aging on the brain, and delay the progression of diseases that may lead to dementia.

Many still believe that dementia is inevitable as we age. In actuality, there is emerging evidence that many "commonsense" lifestyle choices can improve the resilience of our brains and decrease our risk of developing dementia.
More awareness of these risk-reduction strategies can help people of all ages maintain and improve their brain health and help to reduce the impact and projected costs associated with dementia. Sarah Lenz Lock, senior vice president for policy at AARP and executive director of the Global Council on Brain Health, believes that focusing on brain health "can improve people's lives and ... save healthcare costs in a really immediate and tangible way as we look for a cure. Even if we can delay the onset of dementia in people by only five years, we can cut the incidence rate in half."62 


\section{Evolution of Brain Health Science}

A focus on brain health should start at an early age and continue throughout our lifetimes. Leading global experts emphasize behavioral and lifestyle modifications that target the essential elements of cognitive functioning, such as memory, perception, and judgment. Several notable experts and partners are leading the research on brain health, including:

- The Global Council on Brain Health, an independent collaborative of scientists, doctors, scholars, and policy experts that provides information on how to maintain and improve brain health. The Global Council on Brain Health helps people apply the latest scientific insights to boost their cognitive health and live their best lives.

- The Brain Health Partnership, launched by UsAgainstAlzheimer's and its corporate and advocacy partner organizations, promotes a lifetime approach to caring for brain health, recognizing that the risk and indications of dementia can be identified well before symptoms appear. The Brain Health Partnership is advancing a comprehensive strategy that includes brain health as an integral element of overall good health and promotes early identification of cognitive decline.

- The Healthy Brain Initiative is a multifaceted approach to cognitive health developed by the Centers for Disease Control and Prevention (CDC), the Alzheimer's Association, and other public- and private-sector partners. Healthy Brain Initiative partners work together to better understand the public health burden of cognitive impairment through surveillance, build a strong evidence base for policies and interventions, and advance effective public health practice in states, American Indian and Native Alaska tribal nations, and communities. The Healthy Brain Initiative provides data, information, and education to promote brain health, including information on Alzheimer's disease and other dementias, and contains several components, including a Public Health Road Map Series, Surveillance, Communications Center, Data Portal, and resources and publications that support public health practice.

These efforts reflect a multi-pronged approach by scientists, health professionals, advocates, public health officials, and policymakers to develop and promote evidence-based strategies to maintain and improve brain health as a way to reduce our risk of dementia and improve overall cognitive functioning and mental fitness. As the body of research grows more substantial, we must ensure that individuals and health professionals in all communities have equal access to reliable information about the importance of brain health. Robert Egge, chief public policy officer at the Alzheimer's Association, emphasizes that "we must work to improve brain health for all communities to reduce dementia risk and, for those already impacted by this devastating disease, to improve care services and supports." ${ }^{33}$

\section{"Focusing on brain health can improve}

\section{people's lives and ... save health-care}

\section{costs in a really immediate and tangible way as we look for a cure. Even if we can delay the onset of dementia in people by only five years, we can cut the incidence rate in half."}

\begin{abstract}
SARAH LENZ LOCK
SENIOR VICE PRESIDENT FOR POLICY AT AARP;

EXECUTIVE DIRECTOR OF THE GLOBAL COUNCIL ON BRAIN HEALTH
\end{abstract}

\section{The Aging Brain: A Window of Opportunity}

We now know that changes in the brain may begin as many as 20 years before dementia symptoms surface. ${ }^{64}$ A lifetime of damaging effects from injuries, trauma, chronic disease, lifestyle, and genetics are cumulative and increase our risk of dementia. The foundation for brain function, memory, and resilience later in life is affected by our behaviors and actions at a younger age. And as we get older, our risk of developing one or more agerelated health chronic conditions increases. Many of these conditions affect the flow of oxygen-rich blood to our brains and contribute to other known causes of dementia.

Researchers agree that focusing on brain health should start at an early age and continue throughout our lifespan. Research also suggests that mid-life is not too late to improve brain health by engaging in healthy behaviors 
that will pay dividends later in life. Interestingly, some studies have shown that the incidence of dementia among older adults may have fallen in recent decades, which may be due, in part, to healthier lifestyles that improve our cardiovascular health and reduce our risk for chronic diseases like diabetes and hypertension. However, increasing mid-life rates of obesity and associated health conditions threaten to reverse these improvements and are projected to lead to a 9 percent increase in dementia in the US. ${ }^{65}$

Effectively prioritizing, promoting, and building awareness of brain health during this critical window of opportunity will equip us with the information and tools to build the resilience of our brains and reduce our risk of impaired cognitive functioning.

\section{Causes of Dementia Can Vary}

Dementia rarely presents as a single disease but often develops alongside other chronic conditions. ${ }^{66,67}$ Dementia occurs most often in people age 65 and older, which is when other age-related chronic diseases also become more common. According to the Alzheimer's Association, 26 percent of Medicare beneficiaries age 65 and older with Alzheimer's or other dementias have five or more chronic conditions, while only 4 percent of those without dementia have five or more chronic conditions. ${ }^{68}$ Chronic conditions that commonly occur with dementia include cardiovascular disease, diabetes, vascular disease, depression, and hypertension. Scientists are studying how these conditions contribute to age-related changes in the brain, including the shrinking of certain parts of the brain, inflammation, vascular damage, cellular damage, and the emergence of toxic free radicals. Some theories suggest that these age-related diseases impact the brain's natural resilience and ability to repair itself, and increase the risk of developing cognitive impairments and dementia.

Evidence is emerging that the adoption of healthy behaviors that lower the risk of heart disease and diabetes may also reduce risk of dementia. ${ }^{69,} 70$ Several studies show that people with diabetes, especially type- 2 diabetes, are at a higher risk for dementia than those individuals without diabetes. The results of the SPRINT MIND study connect cardiovascular and brain health and find that interventions focusing on intensive blood pressure control decrease the risk of developing mild cognitive impairment. ${ }^{71}$ Evidence from the Finnish Geriatric Intervention Study to Prevent Cognitive Impairment and Disability (FINGER) shows that multidomain interventions (e.g., diet, exercise, cognition, and vascular risk) may help prevent cognitive decline.

Scientists, health professionals, scholars, and policy experts are rapidly building the evidence base to understand how we can reduce dementia risk and enhance cognitive function as we age. As science advances, we must increase awareness of the steps that individuals, communities, and health professionals can take that may reduce risk, maintain cognitive function, and preserve brain health for all ages.

To promote strategies to maintain and improve brain health for all ages, genders, and across diverse populations, we recommend the following high potential action steps:

\section{Action Item \#1}

Raise awareness of modifiable risk factors associated with cognitive decline (e.g., hypertension, diabetes, diet, exercise, sleep, obesity, depression, and social engagement) through public awareness campaigns.

The Lancet Commission on dementia identified nine modifiable health and lifestyle factors from different phases of life that, if properly addressed, could potentially prevent one-third of future dementia cases. These include low childhood education, hearing loss, hypertension, obesity, smoking, depression, physical inactivity, social isolation, and diabetes. ${ }^{72}$ Similar findings have come from other organizations studying causes of dementia, including the Alzheimer's Society of Canada, Alzheimer's Association, World Health Organization, and the Cleveland Clinic. The Global Council on Brain Health emphasized the importance of treating these lifestyle issues in tandem rather than separately. According to Sarah Lenz Lock at a roundtable discussion, "It's not just one healthy behavior, but instead a holistic approach to brain health that will make the biggest difference. The more you do, the more likely you are to reduce risk." The Global Council on Brain Health emphasizes additional lifestyle factors, including sleep, social engagement, 
and challenging your brain. AARP echoes these lifestyle factors in its messages to people to help them stay sharp as they age: move, relax, nourish, discover, and connect. AARP has developed a scientifically based program called "Staying Sharp" that assesses people's cognitive health across these dimensions and recommends specific lifestyle improvements.

Raising brain health awareness requires coordination among health-care systems, community-based organizations, and government agencies. Integrating the best available evidence on brain health and cognitive decline risk factors into existing health communications and public health campaigns will reinforce the importance of lifestyle choices at every age. Brain health awareness campaigns and education programs complement and should be incorporated into other public health campaigns and activities, including programs focused on diabetes prevention, heart disease and stroke prevention, smoking cessation, and traumatic brain injury prevention. Those tested messages resonate in communities and can help reduce risk of dementia. For example, CDC's Alzheimer's Disease and Healthy Aging program worked with partners to integrate messages about brain health into a product about heart disease and stroke among older adults, and in a series of health communication materials about the connection between heart health and brain health for American Indian and Alaskan Native communities.

Further action should be taken to understand and address the needs of communities that have unequal access to preventive health information and opportunities. It is difficult to implement many of these recommendations equally across all communities. Targeted, communityspecific messages can more effectively raise awareness of these findings and recommendations and lead to better health outcomes.

\section{Action Item \#2}

Develop tools and resources for physicians and other health professionals to promote healthy brains for patients of all ages before and after symptoms of cognitive impairment present.

Today's health-care system focuses on diagnosing, treating, and managing a variety of age-related health conditions, from diabetes to cardiovascular disease, without prioritizing the brain. As previously discussed, dementia often develops alongside other age-related diseases. A health-care delivery system that emphasizes a "brain first" approach to care will not only enhance efforts to reduce our risk of dementia but will also better equip health-care professionals to treat other age-related conditions more holistically.

The CDC's Healthy Brain Initiative's Accelerating Risk Reduction and Promoting Brain Health Issue Map provides 11 actions based on the Healthy Brain Initiative report "State and Local Public Health Partnerships to Address Dementia: The 2018-2023 Road Map." This Road Map includes 25 actions to help public health professionals promote healthy brains as an integral part of overall physical health. These actions include educating healthcare professionals about sources of reliable brain health information and the importance of treating co-occurring conditions, addressing injury risks, and attending to health needs among people at all stages of dementia.

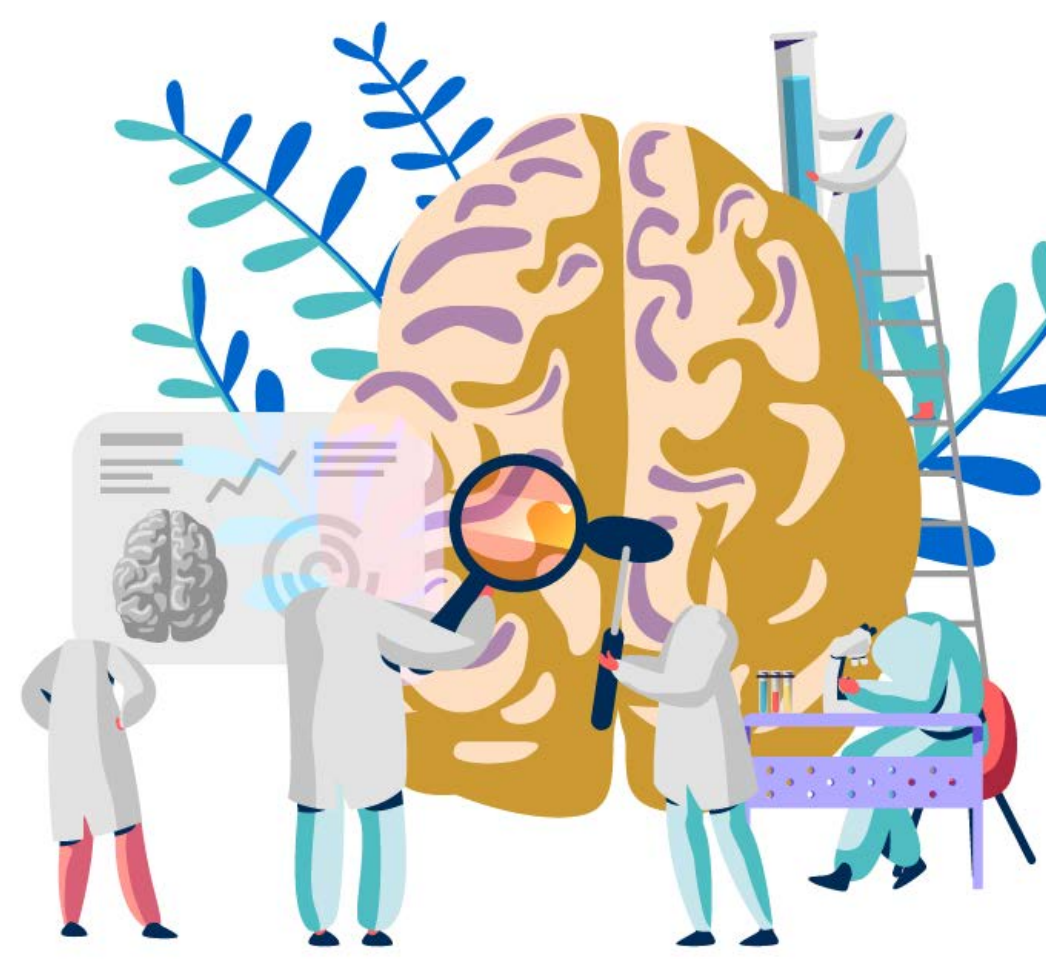

Many states are developing programs to promote brain health that leverage these action steps and build around other age-related disease campaigns. For example, the South Carolina Department of Health and Environmental Control developed an educational campaign called "Take 
Brain Health to Heart." This campaign targets rural and racial/ethnic minority populations that have higher cardiovascular risk factors associated with cognitive decline and dementia. Campaign elements include health education materials, social media messages, and an online pledge in which people commit to keeping their body, heart, and brain healthy.

Developing a robust public health infrastructure is another fundamental approach to help health professionals promote healthy brains for people of all ages. The Building Our Largest Dementia (BOLD) Infrastructure for Alzheimer's Act, which was signed into law in December 2018, aims to establish this infrastructure by helping states make changes in policies, systems, and environments to reduce risk, detect early symptoms, advance care, improve data, and ultimately change the trajectory of Alzheimer's disease. While the funds have not yet been appropriated to implement the BOLD Act, we believe it will be a wise investment to help prevent much more expensive future health-care costs.

On a more individual level, primary care providers are often the first level of care for patients and are in an ideal position to promote the importance of brain health. George Vradenburg, chairman and co-founder of UsAgainstAlzheimer's, advocates for prioritizing a "checkup from the neck up," during which physicians can check patients' brain health or cognitive function as part of their annual wellness exam. This checkup will proactively help clinicians identify brain changes early when interventions are more effective. Evidence-based cognitive screening tools and assessment resources are also available for physicians, including the Alzheimer's Association Cognitive Assessment Toolkit, and are viable for large-scale implementation.

Primary care clinicians are also ideal educators and can provide reliable information, guidelines, and action steps that integrate brain health strategies into their overall discussion of prevention and wellness. These efforts should not be limited to primary care settings but should extend to all settings in which we seek care, including visits with specialists like cardiologists and gynecologists, pharmacies, emergency departments, and community health clinics.
Tools and resources that help physicians and other health professionals facilitate these discussions in the context of other age-related chronic diseases will go a long way to promote the importance of brain health. Currently, these conversations are not routinely happening. More than nine out of 10 surveyed older adults thought their doctor would recommend cognitive testing, and one in seven brought the topic up on their own. ${ }^{73}$ However, primary care physicians are often waiting for patients and their families to report symptoms and ask for an assessment. ${ }^{74}$ The tools can help physicians and other health-care professionals initiate these patient conversations and assessments with more confidence.

\section{Action Item \#3}

Tailor and disseminate culturally sensitive messages with a particular focus on underserved populations, including women and minorities.

Dementia disproportionately impacts women, some minority communities, and people with IDD. ${ }^{75}$ Women, who make up two-thirds of all Americans living with Alzheimer's disease, are further impacted because they also represent 60 percent of all caregivers of people living with dementia.

Latinos and African Americans, in particular, are more likely to have certain chronic diseases, including heart disease and diabetes, which also increases their risk of dementia. African Americans are 40 percent more likely than non-Hispanic whites to have high blood pressure, and the rate of diabetes is 77 percent higher among African Americans and 66 percent higher among Hispanics. ${ }^{76}$

Sharing accurate information through culturally appropriate health communications techniques can elevate the importance of brain health and resolve long-standing reservations in minority communities. Culturally tailored messaging can raise awareness about specific changes in cognition that merit a conversation with a health professional, shift mindsets and normalize discussions about cognitive health in the routine delivery of health care, improve access to care planning and community services, and reduce stigmas and myths surrounding the disease. ${ }^{77}$ 
Recently, the US Department of Health and Human Services added a new objective related to dementia in its "Healthy People 2030" report. This new objective aims to increase the number of people with noticeable changes in their memory performance who discuss these changes with a health-care provider. We are hopeful that this effort will provide new incentives for providers and older adults from diverse communities to discuss their concerns earlier and thereby increase early diagnosis and treatment.

Any approach to develop or promote culturally effective awareness strategies that address brain health must first consider the unique needs of the community. Coordinating with and through trusted community organizations is essential to affect lifestyle and behavioral changes among high-risk individuals in their communities. Strategies utilizing faith-based groups to disseminate health information are effective because of their trusted status in a community. In Mecklenburg County, NC, cardiovascular disease disproportionately impacts the African American community. More than 60 local faithbased organizations were asked to help residents access health resources to reduce cardiovascular risk. As a result, the campaign decreased smoking in the community from 17.4 percent to 13.9 percent and obesity rates from 70 percent to 64.7 percent. $^{78}$

Leveraging communication techniques that health plans, clinicians, and public health agencies already use for conditions like diabetes, hypertension, and cardiovascular disease would also raise awareness of brain health. Packaging and linking information on the value of brain health to these other age-related diseases would elevate the importance of brain health to all body systems. It would also reinforce the interconnected nature of these diseases and emphasize the lifestyle changes that can help delay the onset of cognitive decline and reduce symptoms of dementia.

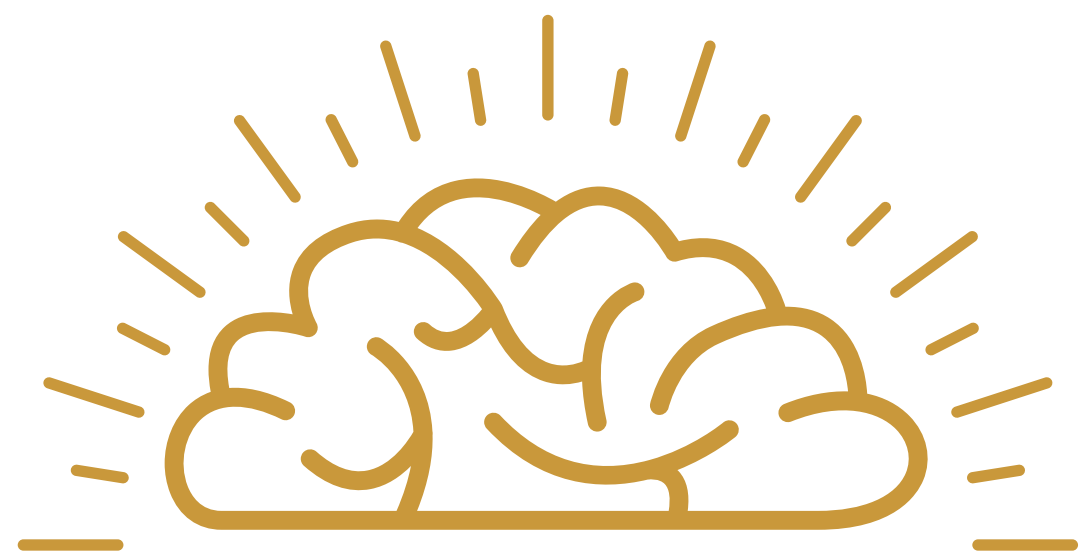

\section{Action Item \#4}

Increase community capacity to promote brain health messages and to support interventions at state and local levels.

Local communities play a significant role in promoting brain health and supporting people with dementia and their caregivers. While the federal government plays a critical role in leading and funding research, programs, and services on dementia, state and local agencies provide training, policies, education, and information and support services at the community level. The CDC and the Alzheimer's Association have developed the third in a series of Healthy Brain Initiative Road Maps that outline 25 specific actions for how state and local public health agencies and their partners can promote brain health.

The Healthy Brain Initiative encourages cross-sector partnerships that leverage shared resources to accomplish state and local goals. It promotes a public health approach, which bridges scientific discovery with communitybased interventions to accelerate action. Additionally, the Healthy Brain Initiative encourages the public health community to embrace brain health as a priority, invest in its promotion, and move scientific discoveries rapidly into public health practice. By embracing a coordinated, multi-sector approach, communities gain additional layers of support for their work in their jurisdictions. This, in turn, allows for increased local-level program reach and improved impact of individual interventions.

A community's ability to serve the variety of needs of people living with dementia and improve brain health at a societal level depends on improving services and resources across all sectors, including:

- Physical: including providing safe and accessible public spaces, and reliable and age-friendly infrastructure

- Financial: including increasing direct funding of programs or discounts for local services

- Social: including promoting resilient networks of people or organizations, community norms, shared understanding, and trust

- Educational: including developing data, skills, knowledge, and competencies of cross-sector community stakeholders $^{79}$ 
Community-led efforts also account for the socioeconomic issues and challenges that minority communities face. Ian Kremer, executive director at Leaders Engaged on Alzheimer's Disease, stresses the importance of distinguishing between behaviors we should and should not do from behaviors many of us can and cannot do. He explains that "there are things people should do like [maintain a] healthy diet that are made very hard by the systems in which many of us live and operate." ${ }^{180}$ For example, adopting a healthy diet is made more difficult in a community without access to fresh produce. Likewise, increasing physical activity is challenging in communities that lack safe and accessible public spaces. Community-focused organizations understand the needs of their residents and can tailor the one-size-fits-all recommendations to account for their unique strengths and weaknesses.

\section{Conclusion}

Developing and promoting strategies to maintain and improve brain health for everyone is important to create better health outcomes as we age. Brain health is intricately tied to other age-related chronic conditions, and identifying ways to improve and maintain brain health will go a long way towards our overall quality of life as we get older. This approach will also help lower costs by reducing preventable hospitalizations and improving overall well-being, which will promote independent living for as long as possible.

\section{Goal \#1 Promote strategies to maintain and improve brain health for all ages, genders, and across diverse populations}




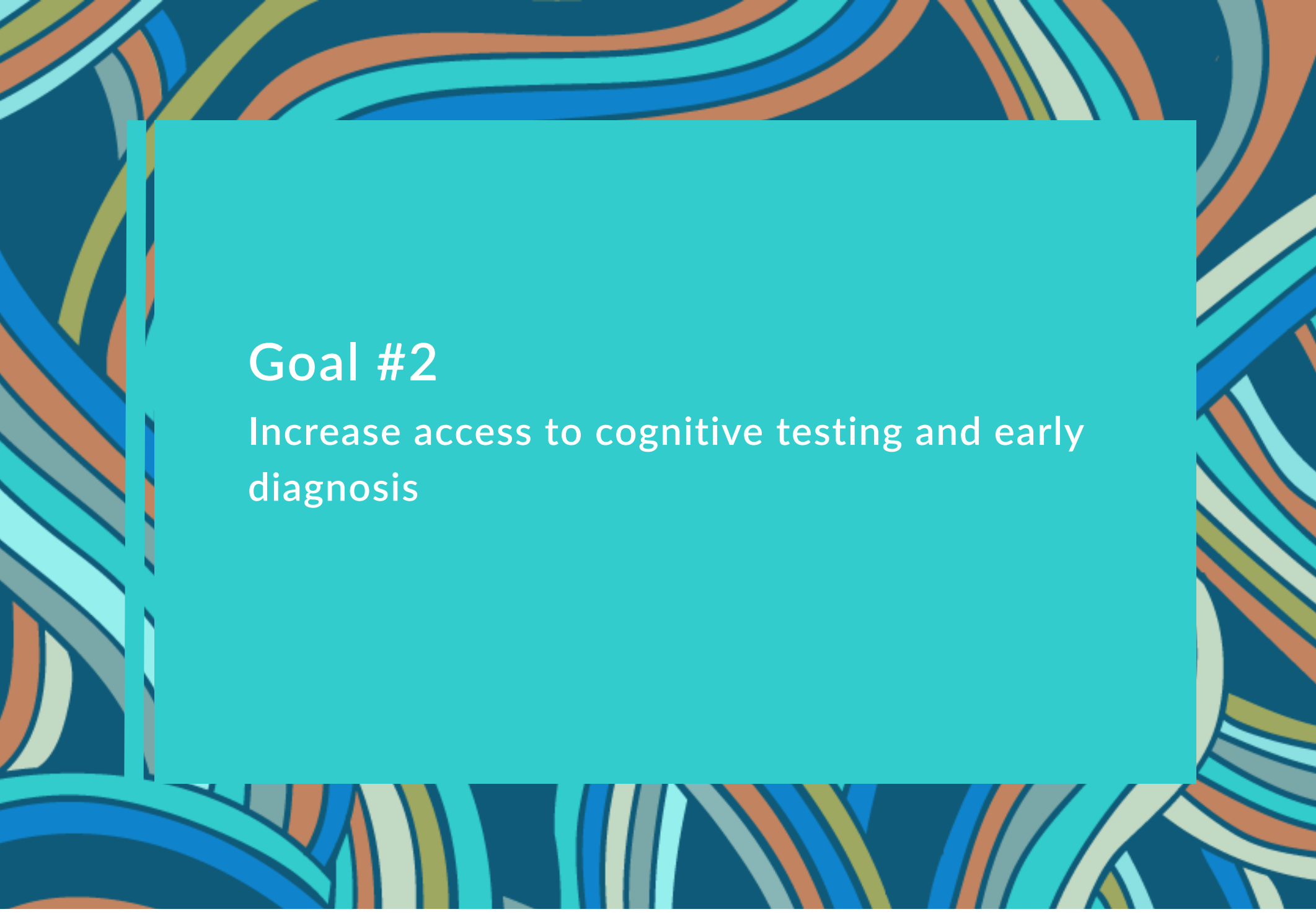

Early and accurate diagnosis of dementia is important to treat or delay cognitive decline and prepare for the future. Early diagnosis of diseases related to dementia, such as Alzheimer's disease, could help to slow the rapidly escalating cost of Alzheimer's disease, which is projected to reach $\$ 1.1$ trillion by $2050 .{ }^{81}$ Estimates show that early diagnosis in the mild cognitive impairment (MCl) stage could create cost savings of as much as $\$ 7.9$ trillion in US health- and long-term care expenditures by enabling better planning, management, and care. ${ }^{82}$ Despite the benefits of early diagnosis, dementia is currently underdiagnosed or diagnosed at a later stage in the disease process. ${ }^{83,}{ }^{84}$ The Alzheimer's Association's Consumer and Physician Cognitive Assessment Surveys found that only half of adults 65 and older received an assessment, and only 16 percent are being assessed regularly. ${ }^{85}$ This percentage is significantly lower than the high percentages of Medicare beneficiaries who routinely receive preventive screenings for health issues such as blood pressure and cholesterol levels. ${ }^{86}$ While the Medicare Annual Wellness Visit includes a required assessment of cognitive functions and a general health risk assessment, dementia may not be detected or patients are not told of their diagnosis. For individuals who show signs of cognitive impairment, Medicare also includes a cognitive assessment and care planning service to help establish or confirm a diagnosis.

Regular cognitive assessments are important to determine baselines, highlight changes in cognition, and connect high-risk people to appropriate treatments, interventions, and services and supports. 


\section{Cognitive Testing Can Enable Early Diagnosis}

Individuals with memory problems should see a physician. It is important to identify memory issues that may require medical attention before they become more acute and harder to treat. Memory problems are one of the earliest noticeable symptoms of cognitive impairment, which can progress to more serious brain conditions like mild cognitive impairment or Alzheimer's disease. Individuals with memory concerns or other signs of Alzheimer's disease should receive screenings and evaluations to get diagnosed early, identify other treatable conditions and diagnoses that may be impacting cognition, and determine the best interventions and treatments. It can take as many as nine years from the first self-reported memory change to a diagnosis of mild cognitive impairment, whereas the progression to dementia may take up to 12 years. ${ }^{87} \mathrm{By}$ reporting memory problems early, we can take advantage of a window of opportunity for interventions that may reduce risk, maintain cognitive function, and preserve our brain health.

Mild cognitive impairment progresses to Alzheimer's disease or another dementia in 15 to 38 percent of people. ${ }^{88}$ Therefore, evidence-based cognitive screening tools should be easily accessible and made a part of routine annual wellness exams as early as possible. Although no cure for Alzheimer's disease currently exists, health-care professionals can effectively manage dementia. Regular cognitive testing can lead to early diagnoses and put health-care professionals in a better position to:

- Treat conditions that may be causing cognitive issues (e.g., depression or sleep apnea)

- Optimize medications

- Inform treatment decisions for other conditions

- Connect to services, supports, and education

- Identify patients interested in participating in clinical trials and other research

- Address any safety issues

- Engage people with dementia and caregivers in planning for the future (e.g., goals for treatment or long-term care financing)

Scientists believe that future drugs that effectively treat or delay the progression of the disease may be most effective early in the disease process. As such, early detection and diagnosis also enables participation in clinical studies needed to find effective treatments. This makes early detection even more of a priority.

\section{Overcoming Barriers to Cognitive Testing}

While the majority of health professionals and older adults think cognitive screenings are beneficial, both groups have reported challenges that inhibit cognitive testing. Some older adults have reported facing stigma and cultural barriers, and may have misperceptions about the value of assessments and early detection. Some people may not have memory complaints or other symptoms, or may not be aware that they should be getting routine screenings. Similarly, primary care physicians report that they have limited time during annual and regular doctor's visits to conduct cognitive assessments or are unsure how to help a patient once a cognitive impairment is detected.

To increase access to cognitive testing and early diagnosis, we propose the following series of high-potential action items:

\section{Action Item \#5}

Identify and address the stigma surrounding dementia and cultural barriers that inhibit screenings and early diagnosis among diverse populations.

The stigma surrounding dementia often prevents people from seeking help when symptoms arise. Surveys have found that people are more frightened of developing dementia in old age than any other condition, including cancer. ${ }^{89}$ Moreover, many believe that there is nothing we can do to improve brain health. Overcoming this stigma will require a multi-pronged effort, including educational and awareness campaigns, dissemination of reliable information, positive media coverage, and tools that make it easier to assess individuals.

Cultural attitudes and practices can also present barriers to seeking help, especially within minority communities. ${ }^{90}$, ${ }^{91}$ These barriers may include a lack of understanding that dementia is an illness rather than a consequence of normal aging, negative experiences with care facilities, and beliefs that caring for a person living with dementia is a 


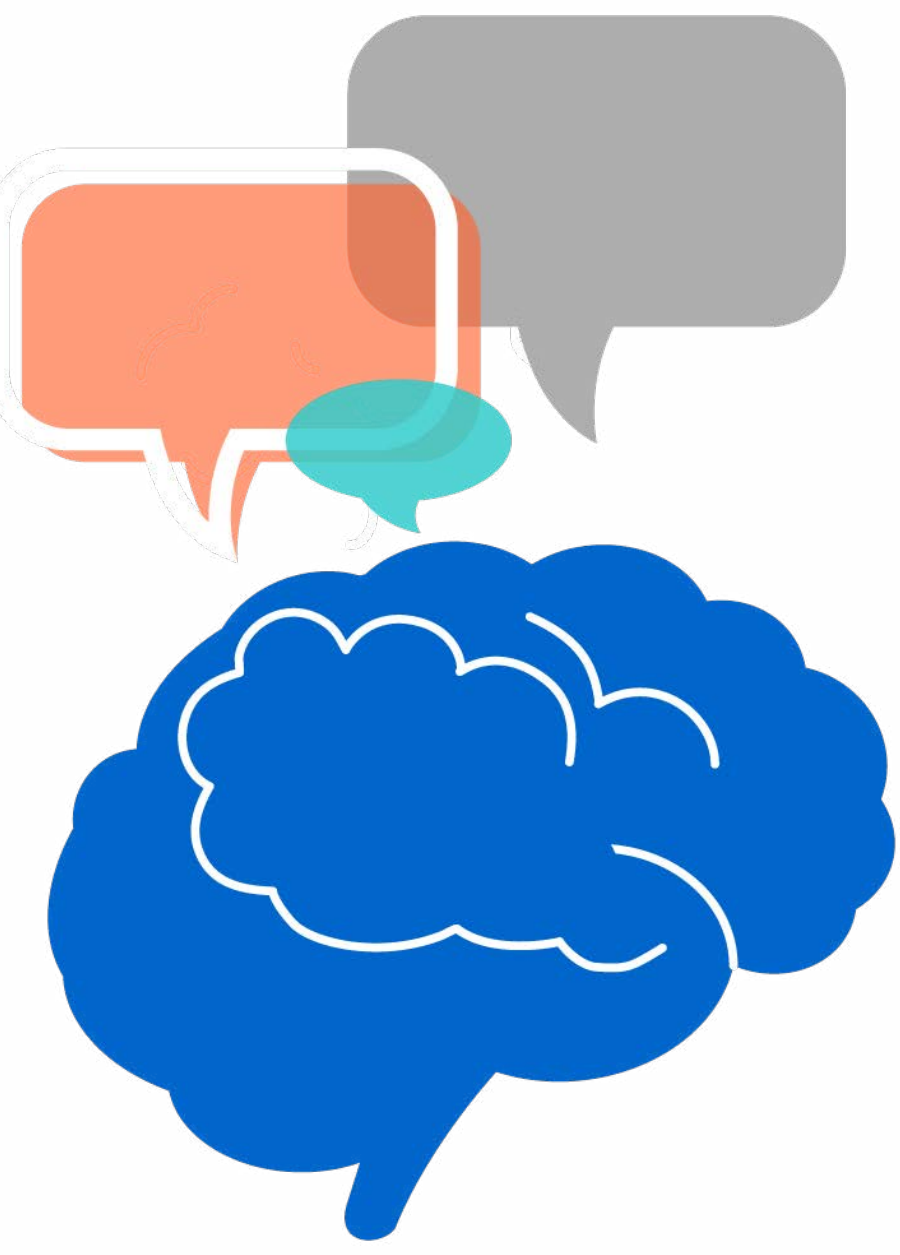

private, family responsibility. ${ }^{92}$ Marginalized groups who have been historically discriminated against or attacked for non-conforming behaviors and activities may also be more unwilling to admit if they are having trouble with thinking skills. Providing more information about how we can improve our brain health and the differences between normal aging and dementia, as well as the different ways that dementia symptoms may present based on gender, race, ethnicity, and disability can help encourage these communities to seek early cognitive screenings.

\section{Action Item \#6}

Develop a national Medicare dementia prevention and detection strategy to spread awareness of risk reduction strategies, increase regular cognitive assessments, and improve early detection rates.

The National Alzheimer's Project Act, enacted in 2011, established a public-private Advisory Council on
Alzheimer's Research, Care, and Services to work with the US Secretary of Health and Human Services to create and maintain a National Plan to overcome Alzheimer's disease and related dementias. The National Plan has been updated on an annual basis since 2012 and seeks to prevent and effectively treat Alzheimer's disease and related dementias by 2025 .

As part of the Affordable Care Act enacted in 2010, Medicare established an Annual Wellness Visit that includes an assessment of cognitive function. This annual visit is free to Medicare beneficiaries as long as their doctor accepts Medicare. While more Medicare beneficiaries have taken advantage of the Annual Wellness Visit, its use is generally low. A recent study found that more than half of physician practices did not provide Annual Wellness Visits, and less than 20 percent of all eligible beneficiaries received an Annual Wellness Visit. ${ }^{93}$ Medicare Annual Wellness Visit rates were lower for underserved populations, such as racial minorities, which could potentially worsen dementia diagnosis disparities. Centers for Medicare \& Medicaid Services (CMS) recommends that to detect any cognitive impairment the Medicare beneficiary may have during the Annual Wellness Visit, clinicians use a brief validated structured cognitive assessment tool. The National Institute on Aging's Alzheimer's and Dementia resources for professionals includes a list of tools for assessment, diagnoses, treatment, and management.

To assist primary care physicians and other providers, researchers could develop decision support tools using electronic health records and cognitive screening templates that support wellness exams. These screening tools should seamlessly integrate into established workflows that clinicians already use during these exams.

The National Institute on Aging and several other professional organizations (such as the Alzheimer's Association, the Gerontological Society of America, and the American Academy of Family Physicians) provide useful information to help primary care physicians perform brief cognitive assessments. Because the vast majority of people with dementia are covered by Medicare, and their numbers are expected to grow exponentially, the Medicare program has a key role in encouraging clinicians to diagnose cognitive impairment proactively. 
The Brain Health Partnership, an initiative convened by UsAgainstAlzheimer's, calls for a National

Medicare Dementia Prevention Strategy, among other recommendations to align business incentives for payers and health systems to better promote brain health. We wholeheartedly agree. The Brain Health Partnership advocates for developing this national Medicare strategy as a means to "encourage providers and payers to proactively address brain health among non-symptomatic, healthy older adults and to strengthen early detection and interventions that delay disease progression." ${ }^{.94}$ They recommend strategies that include a review of payment systems, demonstration programs, measure development, risk-adjustment methodology changes, benefit flexibility, bonus payments for individual enrollee retention, and lifetime risk reduction activities.

As part of the Health Outcomes, Planning, and Education (HOPE) Act, a new Current Procedural Terminology (CPT) code was created to reimburse for services aimed at improving detection, diagnosis, and care planning for patients with Alzheimer's disease and related dementias. The "Cognitive Assessment and Care Planning Service" CPT code (CPT 99483) is for clinicians to assess patients with cognitive impairment, including dementia, and then create a care plan. This code requires a functional assessment and use of standardized instruments for determining the severity of dementia that incorporate cognitive evaluation to arrive at a specific diagnosis. In addition, CMS is increasing reimbursement opportunities to Medicare Advantage plans to account for the increased risk and cost of treating beneficiaries living with dementia. CMS bases payments on the Hierarchical Condition Category ( $\mathrm{HCC}$ ) risk adjustor, which calculates a risk score for each beneficiary based on his or her diagnosis and characteristics. CMS is creating new HCCs for dementia (HCC 51 and HCC 52).

George Vradenburg from UsAgainstAlzheimer's believes these types of changes will dramatically improve the detection and diagnosis of people with dementia. Vradenburg predicts that "Medicare Advantage plans are going to get greater reimbursement from CMS for enrollees that have dementia. That's going to drive, over the next two to three years, a huge amount of resources and incentives in the private industry to increase detection and diagnosis." ${ }^{15}$ It would be helpful to evaluate the impact of Medicare payment incentives across all types of payment models to ensure equitable access to these services no matter the payment source.

\section{Action Item \#7}

Optimize cognitive screening tools, referral pathways, and workflows for health-care providers (e.g., cardiologists, OB/ GYNs, and community health workers) making sure to focus on those who serve women and minorities.

The primary care setting is well positioned to identify memory impairment and other early signs of cognitive impairment. However, these early symptoms are not always apparent during a routine office visit, and patients or caregivers may not voice their concerns.

To address disparities and improve early detection, cognitive screenings should be made available in multiple settings where individuals receive their health care. For example, developing a workflow that promotes cognitive testing in the emergency department may improve early detection and facilitate referrals to community-based care and other providers. ${ }^{96}$ Prioritizing cognitive screenings for older adults in the emergency department may also improve their overall care while in the emergency department and impact clinical outcomes for other co-occurring diseases. Other specialties and settings of care may also benefit from implementing cognitive screening protocols. The American Diabetes Association, for example, recommends cognitive screening for adults age 65 and older at their initial clinic visit and annually, recognizing the impact that cognitive impairment can have on diabetes management, co-occurring diseases, and activities of daily living.

Unique screening issues exist for people with IDD due to wide variability in cognitive functioning of individuals with IDD. Many experts have voiced concern over the ineffectiveness of standardized neuropsychological tests that are used to assess decline in function with this population. Specialized types of dementia screening instruments for people with IDD do exist, including observer-rated scales, direct neuropsychological tests, and adaptive behavior measures. ${ }^{97}$ Some instruments are easily administered and can be used by family members or staff. Other tools are more complicated and may require a health-care provider to have specialized training to administer them. Ensuring that reliable tools are available, and that providers are trained to use them, will increase access to early screenings for people with IDD and others. Increasing access to cognitive screenings can also be 
accomplished through a population-based approach. Cognitive testing in a clinician's office may be effective but may not reach broad and diverse patient populations. Telephonic or web-based cognitive tests may increase early detection of dementia. Some Medicare Advantage plans have conducted telephonic-based cognitive tests as a means to reach a wider population of enrollees. In 2019, Medicare Advantage plans represent 22 million people or one-third of all Medicare beneficiaries..$^{98}$ If more Medicare Advantage enrollees are assessed on a population basis, high-risk individuals could be identified earlier and referred to additional services and resources as appropriate. Additional research on testing methods outside of a medical setting is warranted.

\section{Action Item \#8}

Conduct more research on screening and treatment for mild cognitive impairment. Develop an evidence base to demonstrate links between cognitive screenings, early diagnosis, and improved outcomes for people diagnosed with dementia early.

Despite Medicare benefits for cognitive assessment and care, some clinicians may be reluctant to perform screenings for their patients because they have not been endorsed by the US Preventive Services Task Force (USPSTF). The USPSTF makes recommendations about the "effectiveness of specific preventive care services for patients without related signs or symptoms." 99 In its 2014 Final Recommendation Statement and 2019 Draft Recommendation Summary on screening for cognitive impairment for older adults, the USPSTF concluded "that the evidence of screening for cognitive impairment is lacking and the balance of benefits and harms cannot be determined." Moreover, the USPSTF found "no published evidence on the effect of screening on decision making or planning by patients, clinicians, or caregivers." Importantly, however, it did find adequate evidence that some screening tools can be helpful in assisting clinicians in identifying dementia.

The American Academy of Neurology recently published recommendations that people $65+$ be screened yearly for memory problems. "Physicians fail to recognize about 50 percent of patients in their practice with significant cognitive deficits, missing an opportunity to offer appropriate evaluation and treatment. Depending solely on a complaint is insufficient because patients may not recognize or report worsening memory problems to their physicians. Although there is conflicting evidence on the benefits of screening for dementia in older adults, there is growing support for the benefits of assessment of cognitive health in patients over the age of $65 .{ }^{100}$

Howard Fillit, MD, founding executive director and chief science officer of Alzheimer's Drug Discovery Foundation, believes that improving the system of care through better case management is necessary to increase routine cognitive screenings. According to Fillit, it is important to determine "who to screen, when to screen, what kind of instruments to use, and then define good quality of care." ${ }^{101}$ The type of screening instrument used depends on several factors based on the patients' needs, including where the screening takes place (e.g., physician's office or community-based setting), who is administering the screening, the context of its use, and clinician preferences.

As health care moves toward a more team-based approach, studies should be conducted to assess different types of screenings, conducted by a variety of professionals (e.g., pharmacists, social workers, and physicians) to determine the effect of screenings on decision-making or planning by patients, clinicians, or caregivers.

\section{"Improving the system of care through}

better case management is necessary to increase routine cognitive screenings. It's important to determine who to screen, when to screen, what kind of instruments to use, and then define good quality of care." 


\section{Action Item \#9}

Develop more reliable, affordable, and minimally invasive diagnostic tests to improve rates of early diagnosis and more accurately monitor responses to services, supports, and treatments.

As we advocate for more access to cognitive screenings, the next question invariably is "then what?" Once any cognitive impairment is detected, it can be complex and challenging for physicians to diagnose dementia accurately. Keith Fargo, MD, director of scientific programs and outreach for the Alzheimer's Association, explains that "because of that complexity, all brief assessment tools for cognitive impairment are imperfect." ${ }^{102}$

In addition to cognitive and neuropsychological tests, clinicians may use blood tests and psychiatric tests to rule out other possible reasons for cognitive symptoms. Brain scans can identify changes in the brain's structure and function. However, these tests are expensive and often only covered for limited populations (e.g., those participating in clinical trials). In the future, diagnostic tools like brain-imaging diagnostic scans and tests that examine cerebrospinal fluid may improve early detection. Currently, such devices are too invasive and expensive and are used for later stages in the disease process when symptoms are more acute. Moreover, Medicare currently does not cover these diagnostic tests outside approved research studies, which limits their availability and accessibility.
Scientists have been working to develop a blood test to determine Alzheimer's risk. New results seem quite promising and may soon be used to recruit and monitor people in federally funded and other studies. ${ }^{103}$ However, most experts predict it will take longer before they can be used during routine medical exams.

Recognizing the importance of developing easier and more accurate ways to diagnose dementia, Bill Gates and the Alzheimer's Drug Discovery Foundation cofounder Leonard Lauder have launched the Diagnostics Accelerator program with financial commitments totaling more than $\$ 50$ million. This call-to-action "challenges the research community to develop cutting-edge biomarkers and explore novel diagnostic technologies to reduce the impact of this devastating disease." ${ }^{104}$

To find treatments for Alzheimer's disease and related dementias, scientists and clinicians must first identify those at greatest risk to understand how the disease progresses. Increasing access to cognitive screening and early diagnosis is a critical step in this process.

\section{Conclusion}

Early and accurate diagnosis of dementia is important to treat or delay cognitive decline and prepare for the future. Efforts to increase regular cognitive assessments are important to determine baselines, identify changes in cognition, and guide people at risk or showing signs of dementia to appropriate treatments, interventions, services, and supports. Early diagnosis could create cost savings by enabling better planning, management, and care.

\section{Goal \#2 Increase access to cognitive testing and early diagnosis}




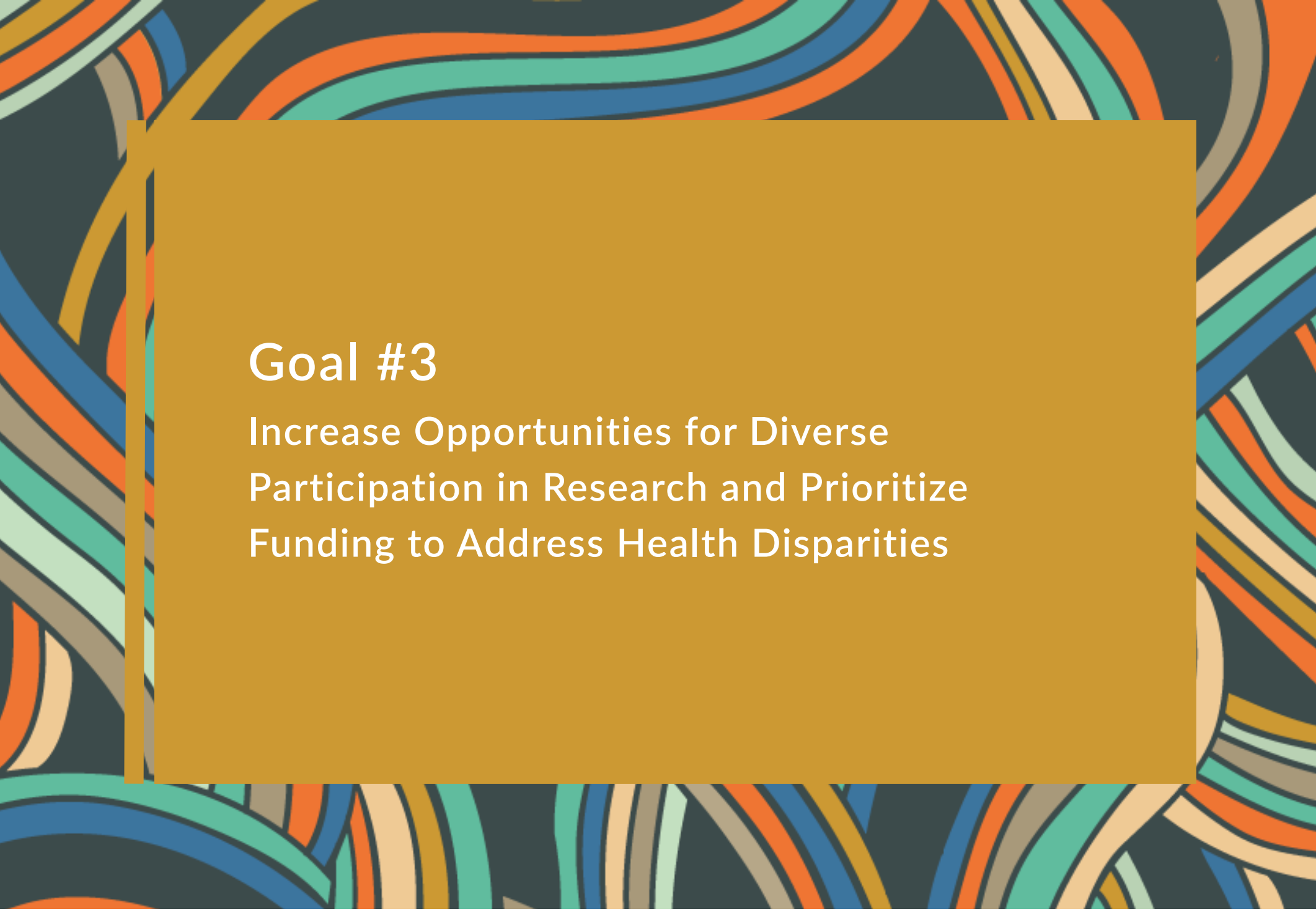

Although we are making progress in understanding the pathology of dementia, including its causes, symptoms, and risk factors, applying these findings to the entire population is still challenging. Diverse research participants are needed to build an inclusive, evidencebased dementia care model. Additionally, given there are currently no cures for Alzheimer's disease or related dementias, we should increase research funding to study risk reduction, prevention, and the underlying factors that create health disparities between women and men, white and non-white populations, and other populations at higher risk for dementia.

New research reveals important biological clues as to why women may be more likely than men to develop Alzheimer's disease, but more study is needed. Until recently, many of the major clinical trials only included white, male subjects. In 1993, the NIH Revitalization Act was signed into law and, for the first time, required $\mathrm{NIH}$ funded investigators to include women in human subject research. However, progress has been slow. A 2000 US Government Accountability Office report found that, although significant progress was made to increase the representation of women in clinical trials, studies were still not routinely being designed to enable analyses by sex. As recently as 2005 , there were 22,000 men and zero women included in a clinical trial of aspirin for cardiovascular disease prevention. ${ }^{105}$

Today, women in the US represent almost 50 percent of all clinical trial participants in NIH-funded research. ${ }^{106}$ Women represent 57 percent of clinical trial participants in NIH-funded Alzheimer's disease research (including 
Alzheimer's disease-related dementias). ${ }^{107}$ There is a lot of catch-up work that we still need to do given that almost two-thirds of Americans with Alzheimer's are women. We need to be much more sophisticated about how we collect necessary data regarding sex- and gender-based differences across diseases and situations. We also need to take into account the social construct of gender as issues around lifestyle become more important in understanding risk factors and prevention research.

There is a significant need for diverse participants in dementia clinical research. Evidence indicates that minority populations are grossly underrepresented in clinical trials. For instance, only 2 percent of people in clinical studies assessing the efficacy of anti-amyloid drugs were African American, even though 20 percent of Alzheimer's patients are African American.

Additionally, Latino communities have higher reported rates of dementia but represent only 6 percent of all clinical trial participants in NIH-funded Alzheimer's disease research (including Alzheimer's disease-related dementias). ${ }^{108,}{ }^{109}$ Unfortunately, these high-risk populations are less likely to be recruited to participate in Alzheimer's disease and other clinical trials. Similarly, there is little research that intersects both aging and intellectual and developmental disabilities, leaving a significant gap in understanding the interaction of disability and age-related illnesses. ${ }^{110}$

Today in the US, almost 200 Alzheimer's disease clinical trials still need more than 270,000 participants. ${ }^{111}$ Because of strict eligibility requirements and participant availability, researchers often have to screen 10 people to identify one eligible participant. ${ }^{112}$ Today, unfortunately, most clinical trials rely on findings based on studies of primarily white, well-educated populations. And until recently, many Alzheimer's disease trials included participants who did not suffer from the disease, making their conclusions questionable.

Diverse trial participants help ensure that a clinical trial represents the patients who might benefit from the treatment and that the results are generalizable. ${ }^{113}$ Diversity can also help researchers develop safer and more effective clinical interventions. If we can better understand the differences in how dementia manifests itself across different genders, races, and intellectual abilities, researchers and clinicians can develop treatments that are uniquely tailored to account for these differences. Reducing gender, racial, and other disparities in clinical trials could also save costs through disease prevention and improved treatment. ${ }^{114}$

To reduce disparities, we propose the following action items to engage a broader and more diverse number of participants in Alzheimer's and dementia research:

\section{Action Item \#10}

Ensure that gender- and sex-based differences are integrated into the design, analysis, and reporting of biomedical research and more emphasis is placed on understanding why women are more likely than men to develop dementia.

While we've seen a dramatic shift toward inclusion of women in clinical trials recently, there is still a great deal we do not know about the reasons why women are more prone to develop dementia than men. Despite strides in understanding the nature of the disease, we still do not have answers to some of the most fundamental questions about Alzheimer's disease like who develops the disease, why two-thirds of those who do are women, and, most importantly, how to cure it. ${ }^{115}$

The rapid increase in research dollars committed to studying Alzheimer's disease, as seen in Figure 2, has yielded important discoveries. Marie Bernard, MD, deputy director of the National Institute on Aging, explained that "...the hope is in the acceleration that has occurred in the last many years. In 2013 , we had $\$ 500$ million that was devoted to Alzheimer's research. It's $\$ 2.4$ billion now... and we've had an explosion in discovery." 116

Moreover, due to the increase in the number of women in trials, researchers have a better understanding of the potential biological and social reasons why more women than men have Alzheimer's or other dementias. The prevailing view has been that this discrepancy is due to women having longer life expectancies than men do on average, and that older age is the greatest risk factor for Alzheimer's. However, researchers are now questioning whether these sex-based disparities are due to biological or genetic variations or differences in life experiences. 
Leading neuroscientist Roberta Brinton asserts that "women are not getting the disease more often because they live longer than men, but because they undergo perimenopause beginning in their 40s, causing a shift in brain chemistry." ${ }^{118}$

\section{Figure 2: Alzheimer's and Related Dementia Research} Funding at the NIH

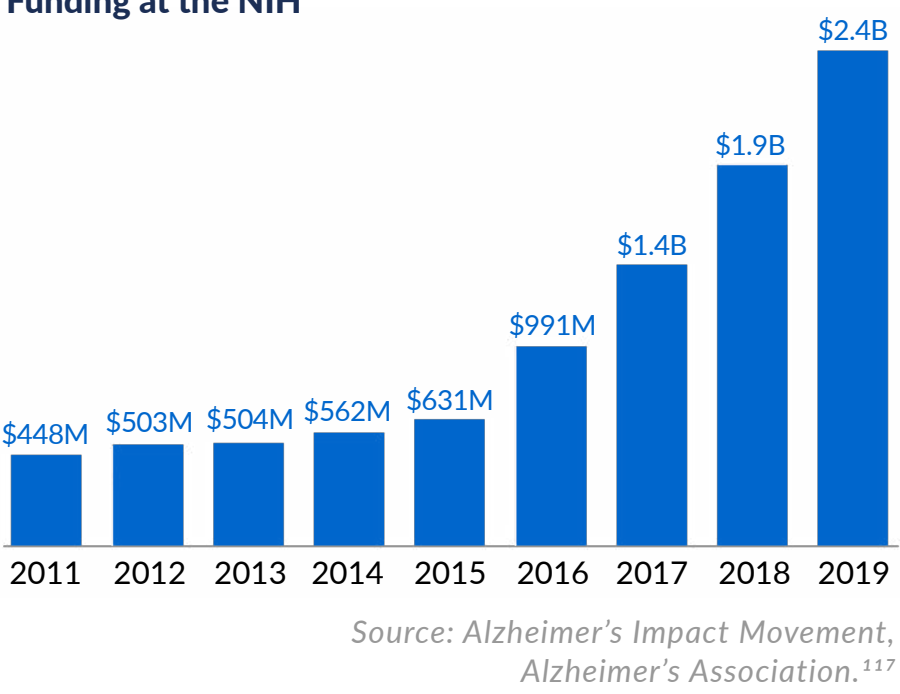

Her insights into the transition states of the aging female brain provide therapeutic opportunities to prevent, delay, and treat neurodegenerative diseases.

Most recently, at the 2019 Alzheimer's Association International Conference, scientists presented evidence that the disease spreads differently in the brains of women than in men. Other researchers showed that several newly identified genes seem related to the disease risk by sex.

The scientific understanding of differences in dementia between men and women on a neurological level is growing. According to research at Vanderbilt University, brain scans of 161 individuals with mild cognitive impairment and 301 of those without revealed that tau proteins (the source of tangles that can destroy neurons and disrupt networks of nerves in the brain) distributed differently between men and women. In particular, tau networks were more diffuse in women with mild impairment, a sign that more brain areas are at risk for Alzheimer's disease compared with men. ${ }^{119}$

Even though women have a greater distribution of tau proteins and thus increased risk, traditional tests for cognitive impairment may not be as reliable for women as they are for men. For example, Erin Sundermann and colleagues at the University of California, San Diego compared men and women with various levels of damage to their hippocampus, the portion of the brain that manages memory. Despite having similar levels of impairment or dementia, women performed significantly better than men. ${ }^{120}$ This suggests that different forms of screening may be required to determine the early stages of cognitive impairment.

These new findings offer new avenues to explore effective treatments. Medical specialties like cardiology and addiction medicine have analyzed and made significant progress on the effects of gender on health outcomes. ${ }^{121}$ By adopting an approach that fully integrates sex- and gender-based differences in dementia research from the outset, we can create a body of data to understand and narrow these differences.

\section{Action Item \#11}

Increase culturally sensitive recruitment and retention efforts of women, communities of color, and people with IDD in clinical trial research through tailored awareness and engagement strategies. Explore strategies to bring clinical trials into underrepresented communities, including the utilization of mobile technologies.

Many believe that racial and ethnic minorities are less willing than non-minority populations to participate in health research. However, studies have found that African Americans and Hispanics, especially in the US, are just as willing to participate in health research as those in nonminority communities. ${ }^{122}$ These findings have led some to suggest that efforts to increase minority participation in clinical trials should focus more on increasing access to these trials, rather than trying to change minority attitudes toward research.

Nonetheless, others have pointed to institutional barriers and cultural differences that deter minority populations from participating in clinical trials and other patientoriented research. These barriers include not having information about dementia, not understanding the risk for dementia, and historical skepticism toward clinical trials and research. ${ }^{123}$ 
We need to build awareness for dementia clinical trials and increase engagement within currently underrepresented communities. The NIH developed a National Strategy for Recruitment and Participation in Alzheimer's and Related Dementias Clinical Research (the "National Recruitment Strategy") that addresses the challenges of recruiting and retaining participants. To encourage people from diverse communities to participate in clinical research, the National Recruitment Strategy calls for more direct education about the causes, symptoms, and treatment. ${ }^{124}$ Increasing awareness of clinical trial opportunities, as well as the importance of these studies to finding a cure, should also improve recruitment efforts.

As part of a larger effort to improve clinical research, $\mathrm{NIH}$ also developed the All of Us program, which utilizes strategies that target underrepresented communities and prioritizes trust and transparency in clinical research methods. This program will significantly oversample African American, Latino, rural, and lower socioeconomic status participants to improve diversity. NIH hopes to recruit more than 1 million new participants for research trials conducted by their institutes and partners, including some focused on dementia. ${ }^{125}$ To improve participant access and awareness, $\mathrm{NIH}$ provides grants for community engagement campaigns and targeted outreach initiatives. For example, NIH and the National Library of Medicine have partnered with local public libraries to spread information about the program and train staff to identify potential participants and supply them with information about engagement.

We need to understand the needs of underrepresented communities. To build awareness for these clinical trials, first, we must understand the beliefs, attitudes, and social norms in diverse communities. These insights will help us appreciate the motivations of each community and their barriers to participation. We need to build research studies that respond to these needs and norms.

Furthermore, it is critical to broaden the eligibility criteria of Alzheimer's clinical trials to increase diversity and retention in studies. The often strict eligibility criteria of Alzheimer's trials can lead to limited representation of minorities in clinical research given the multiple chronic conditions that African Americans and Hispanic Americans often face. For example, research suggests that nonHispanic blacks and Hispanic Americans have more than twice the prevalence of diabetes alone and diabetes and cardiovascular disease (CVD) as non-Hispanic whites. ${ }^{126}$ Individuals living with these conditions are often excluded from Alzheimer's research. ${ }^{127}$ In fact, a 2019 study that included individuals with prior stroke and CVD risk factors found that Hispanic Americans and African Americans were more likely to have mixed pathologies, that is, a combination of Alzheimer's disease and CVD, than non-Hispanic whites, demonstrating the importance of examining inclusion and exclusion factors to broaden our understanding of Alzheimer's. ${ }^{128}$ Addressing the inclusion and exclusion criteria of Alzheimer's trials is critical to promoting diversity.

We need to communicate the benefits of participating in dementia clinical trials more clearly. Current messaging generally focuses on the benefits to researchers and the field of science. But according to Holly Massett, $M D$, senior advisor on clinical research recruitment and engagement at the National Institute on Aging, says these messages do not "resonate with people when you're asking them to give so much to participate in a study." Instead, she found, "one message [that works] over and over, is hope ... [They say] 'if I participate in this, there's some nugget that's going to come out that's either going to help myself or going to help my family or help my community.' And that's the sense of hope that is needed when it comes to clinical study messaging." ${ }^{129}$

We also need to bring dementia clinical trials and studies to potential participants where they live. Many communities are not located near research centers or lack the resources to support large-scale clinical trials. For these historically inaccessible communities, clinical trial sponsors and investigators should identify alternative approaches to recruit, enroll, and retain participants. For example, more effort should be made to integrate primary care providers into research teams, increasing the understanding of clinical trial opportunities among minority-serving health providers, including registered nurses and nurse practitioners.

Academic medical centers lead the majority of trial programs. ${ }^{130}$ And while they play a crucial role in dementia clinical research, most people living with dementia receive their care in community settings. These community settings are often not connected to clinical research and study sites. Leveraging best practice recruitment approaches from other disease-specific campaigns, while respecting the unique challenges this population must 
navigate, can help researchers increase recruitment for dementia clinical trials. Expanding clinical research beyond the academic setting facilitates access to a more extensive and more diverse patient population across a variety of health-care delivery settings. ${ }^{131}$

\section{"It is important to improve current}

\section{communication messages and focus on}

\section{the benefits of participating in dementia}

\section{clinical trials more clearly. One message}

[that works] over and over, is hope...

\section{[Participants say] 'if I participate in}

\section{this, there's some nugget that's going} to come out that's either going to help myself or going to help my family or help my community.' And that's the sense of hope that is needed when it comes to clinical study messaging."

\author{
HOLLY MASSETT \\ SENIOR ADVISOR ON CLINICAL RESEARCH \\ RECRUITMENT AND ENGAGEMENT, \\ NATIONAL INSTITUTE ON AGING
}

For example, the National Cancer Institute's Community Oncology Research Program (NCORP) is a national network of cancer researchers and other stakeholders that provide care to diverse populations. This program brings cancer clinical trials and studies to individuals in their communities to reduce health disparities. NCORP employs a "hub and spoke" recruitment model that relies on NCORP community sites to recruit participants into national-level clinical trials and research studies. NCORP has been successful, with approximately 30-35 percent of the patients enrolled in NCl's National Clinical Trials Network coming from NCORP community sites. ${ }^{132}$ This hub and spoke model could apply to recruit diverse representation in dementia clinical trials. By working directly in the community, physicians providing care to a person with dementia can make a referral to a clinical trial. According to Massett at the National Institute on Aging, this recommendation is valuable to achieve recruitment goals. "We know that [up to] 80 percent of the time when a doctor recommends a clinical study, the person goes into it." ${ }^{133}$

Several new technologies also have the potential to support study recruitment in communities. As medical technology becomes smaller, more mobile, and reliable, researchers can leverage those digital tools to access communities not easily connected to clinical studies. Mobile clinical trial methods make it easier to identify, match, and accelerate enrollment of participants from isolated, rural communities in clinical trials. Dementia researchers can adapt these mobile tools to their needs to connect with underrepresented populations and provide access to resources for those who may not receive them otherwise. Tools like mobile clinical and research trial units can standardize the recruitment process in smaller communities, improve the experience of people participating in clinical trials, and increase retention. Jennifer Ann Zimmer, MD, senior medical advisor at Eli Lilly, understands that designing recruitment tools for smaller communities may create variability that conflicts with experienced study sites. "As we develop cognitive assessment tools [for smaller communities] ... a high amount of variability can affect the likelihood that a clinical trial is positive. We must consider how to keep that standardization and high quality of data. Innovations such as mobile trial centers may be one way to address that."134

Currently, several startup companies focus on developing clinical trial patient recruitment solutions, some of which include mobile-friendly, search-engine-optimized landing pages and embeddable forms that make it simple for patients to move through the application process and match them with clinical trials. These new tools can be leveraged to help meet recruitment goals for dementia clinical trials, augmenting and informing community outreach and education efforts. 
Action Item \#12

Build research capacity and a recruitment infrastructure in study sites that are conducting clinical trials on dementia, including workforce development.

Increasing enrollment of participants from underrepresented communities requires improving recruitment infrastructure and study site capacity. The National Recruitment Strategy recommends utilizing robust and connected patient registries, information technology, and incentives to reward retention and recruitment. Study sites can also build capacity by engaging with more potential volunteers, collaborating with peers at the local, regional, and national levels, and sharing successful recruitment strategies.

Information technology will help identify potential dementia trial participants. Electronic health records can be used to identify potential participants across various clinical settings while consumer mobile applications can gather data to identify volunteers outside of clinical settings. Online communities are an essential distribution channel for making potential participants aware of new research. The NIA is in the process of developing an online tool to help clinical sites create outreach materials to better engage potential trial participants in their communities. By answering a series of questions about the audience of interest, the tool will pull from a database of well-tested materials and package them into a social marketing campaign that can be tailored locally. As Massett from the National Institute on Aging notes, this tool can assist "at a push of a button, with figuring out where people are on trials and where people are not on trials and where the gaps are so they will be in the infrastructure." ${ }^{135}$ It is, of course, important that these tools be employed in ways that address privacy concerns and respect consumer choice. Respecting boundaries and establishing trust can also encourage participation.

Research infrastructure requires developing a diverse and capable workforce. A staffing strategy that aligns with a project's diverse recruitment goals ensures that researchers and study site personnel are representative of the people they are trying to recruit. Cultural training and community outreach help build trust with potential participants from underrepresented communities, so they feel more comfortable participating in a clinical trial.
Robyn Stone, $\mathrm{PhD}$, senior vice president of research and co-director at the LeadingAge LTSS Center, believes that a culturally competent workforce is necessary to build trust in participants. "In many of our projects, we have at least five languages that are being spoken, [but] it's way beyond just the language. It's also the competence around the culture and behavior. I'm not sure I would be comfortable funding a team that had no experience doing work in some of these communities." ${ }^{136}$

Positive participant experience is essential for retaining participants in clinical research. Participants withdrawing from clinical research can adversely impact the study's conclusions. The average dropout rate across all clinical trials is about 30 percent. ${ }^{137}$ Negative experiences are amplified today as more participants share stories online. Clinical trials are already time-consuming and burdensome, and participants with dementia may need more assistance to navigate these trials. Karen Love, executive director at Dementia Action Alliance (DAA), wants researchers to focus on creating a positive experience for study volunteers. "People 70 and younger are involved in a huge vibrant online community where they talk, share information, network, and engage together. When somebody has a bad experience, it gets personified. [You] have to try to go through all the different floors and alleys and back ways to get to where you're supposed to be, and then you get a clipboard with 15 pages of information. Being sensitive to the condition itself is important because that can get distributed virally, and people get completely turned off to want[ing] to participate." ${ }^{138}$

\section{Action Item \#13}

Ensure data collection and sharing across subgroups of racial and ethnic minorities, as well as people with IDD, and stratify by gender to promote a more precise understanding of Alzheimer's pathologies among high-risk populations.

Clinical trial data are often inaccessible to the broader research community and are held securely by the academic researcher or pharmaceutical company that conducted the research. Sharing de-identified clinical trial data is beneficial because it allows researchers to build upon each other's work, deters inaccurate result reporting, and quickens potential findings and treatments. Creating open-access databases may help to 
reduce health disparities. Data generated from diverse volunteers may lead to tailored findings that increase the safety and effectiveness of medical products for specific communities.

Volunteers in clinical trials believe the benefits of data sharing outweigh the potential consequences. According to a new study by Michelle Mello et al. published in the New England Journal of Medicine, 93 percent of clinical trial participants report that they would be comfortable with data sharing and would allow universities and other nonprofit organizations to access their information to accelerate discoveries. ${ }^{139}$ Appropriate safeguards ensuring proper use and storage of data will protect consumers and may make them more comfortable sharing data. Sarah Lenz Lock, AARP, echoes this need to "encourage data sharing and data harmonization as a fundamental element of building research infrastructure in diverse communities and ensure those diverse datasets are accessible on a data-sharing platform while ensuring consumer's concerns regarding security and privacy are addressed." ${ }^{140}$

Several data-sharing platforms have been developed to mitigate researchers' concerns and facilitate sharing. The Yale University Open Data Access (YODA) project and Duke University's Supporting Open Access for Researchers (SOAR) initiative create standardized approaches that promote transparency, ensure data privacy, protect researchers' intellectual property, and facilitate data accessibility. Programs funded by the NIA also support initiatives for data-sharing practices. These data-sharing platforms are promising tools to increase access to data, even after clinical trials have ended, and help to inform future research.
Action Item \#14

Increase investment in prevention and risk reduction research.

The importance of finding a cure should not overshadow research efforts to prevent and reduce the risk of dementia. For fiscal year 2019, the US Congress passed a \$425 million increase for Alzheimer's research funding, marking the sixth consecutive year that Congress has voted to increase Alzheimer's funding. The failure rate is extremely high; there are no disease-modifying drugs currently approved for Alzheimer's disease and no preventive treatments approved since 2003. ${ }^{141}$ With recent high-profile biomedical failures of Phase II/III drug trials for Alzheimer's prevention, increased funding for prevention and risk reduction research promises to have the most substantial immediate impact on reducing the burden of dementia.

Prevention may help delay the onset, slow the progression, or improve the symptoms of dementia, decreasing the cost burden of dementia on people living with dementia, their caregivers, and the overall health system. The BOLD Act, established in 2019, creates a public health infrastructure for the prevention, treatment, and care of Alzheimer's disease and related dementias. To ensure this new infrastructure is successful in promoting effective dementia and caregiving interventions, we must increase the study of lifestyle factors that can reduce the risk of cognitive decline. These investments will promote prevention and improve the quality of life for those living with dementia, including the experiences of their caregivers.

\section{Conclusion}

Now is the time to fully integrate sex, gender, race, ethnicity, developmental ability, and age into clinical research. To accomplish this, we must first improve our efforts to increase access to these studies for underrepresented populations. By increasing our understanding of how dementia manifests in different populations, we can develop interventions and treatments for the benefit of all.

\section{Goal \#3 Increase Opportunities for Diverse Participation in Research and Prioritize Funding to Address Health Disparities}




\section{Goal \#4}

\section{Build a Dementia-Capable Workforce Across}

the Care Continuum

Dementia care requires contributions from multiple providers across the care continuum. These include primary care physicians, specialists such as neurologists, geriatricians, psychiatrists, nurse practitioners, community health workers, social workers, psychologists, pharmacists, allied health long-term care professionals, and direct care workers. Too often, people with dementia and their caregivers are left to navigate this complex system by themselves.

People living with dementia typically have multiple cooccurring diseases and conditions (see Figure 3). However, primary care providers and specialists may not fully understand how dementia can complicate clinical care and undermine a person's ability to manage other chronic conditions. Moreover, the presence of dementia may even be a key factor in higher use of emergency services and nursing homes.

To serve people with dementia and their caregivers, we must build a dementia-capable workforce that is highly coordinated, trained, and equipped with the necessary tools and resources. This dementia-capable workforce must be culturally competent to meet the needs of diverse communities. Unpaid caregivers must be given better tools and resources to help provide care. And finally, new dementia-specific payment and delivery models must be developed and tested to lower the direct and indirect costs of dementia and improve the overall care experience. 


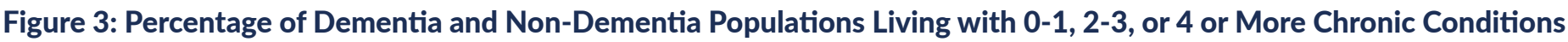

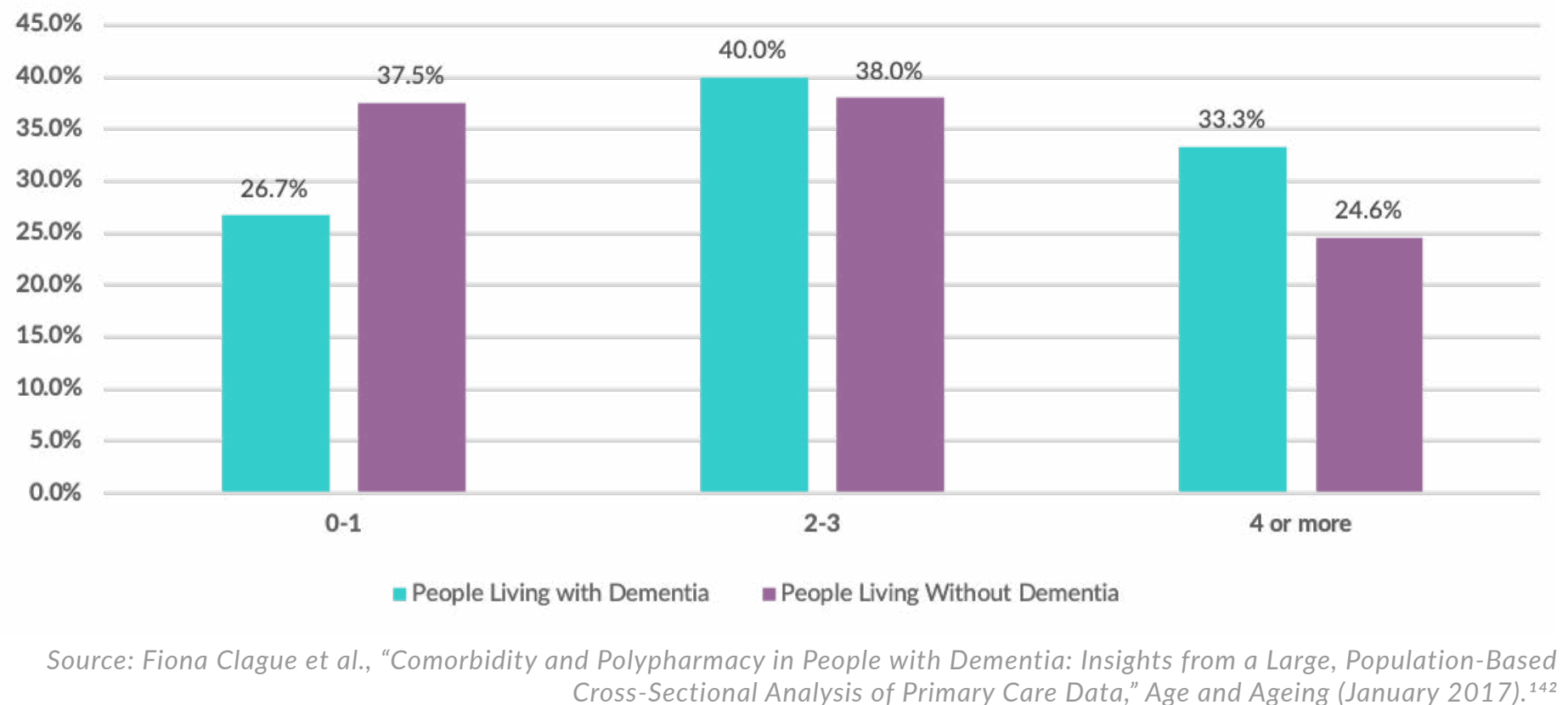

\section{Preparing Health and Long-Term Care Professionals for Older Populations}

Even though the number of people with Alzheimer's disease is projected to triple by 2050 , there is an impending shortage of physicians, nurses, and social workers with specialized training in geriatrics and dementia care. ${ }^{143}$ By 2030 , we will require a five-fold increase in the number of geriatricians in the US. ${ }^{144}$, ${ }^{145}$ According to the Health Resources and Services Administration (HRSA), which tracks data on the workforce we need as we age, the supply of geriatricians is projected to increase only modestly from 2013 to 2025. Demand will far outpace supply.

To recognize this growing shortage, as part of the 2015 White House Conference on Aging, HRSA announced \$35 million in awards to health profession training programs to better prepare the health-care workforce to respond to the needs associated with advancing age. ${ }^{146}$ The Geriatric Workforce Enhancement Program (GWEP) was established in 2015 to "[develop] a health care workforce that maximizes person and family engagement and improves health outcomes for older adults [by] integrating geriatrics and primary care." The Geriatrics Academic Career Award (GACA) program focuses on developing clinical educators to train the next generation of geriatrics health-care professionals. In 2019, HRSA funded 48
GWEPs in 35 states and two territories and 26 GACAs in 16 states.

To promote strategies to build a dementia-capable workforce, we recommend the following high potential action steps:

\section{Action Item \#15}

Reauthorize and increase funding for GWEPs to improve health outcomes for older adults by developing a health-care workforce that maximizes patient and family engagement and integrates geriatrics with primary care. Prioritize communities that have growing populations of older Americans and a particular shortage of geriatric specialists.

The 2019 HRSA GWEP integrates geriatrics-focused training across the educational continuum. GWEP educates and trains patients, families, caregivers, direct care workers, health professions students, faculty, and practitioners. Goals of this education and training include:

- Developing reciprocal partnerships throughout academia, primary care delivery sites or systems, and community-based organizations to educate and train a workforce to provide value-based care that improves 
health outcomes for older adults

- Training geriatrics specialists, primary care providers, health professions students, residents, fellows, and faculty to assess and address the primary care needs of older adults

- Transforming clinical training environments into integrated geriatrics and primary care systems to become age-friendly health systems that incorporate the principles of value-based care and alternative payment models

- Delivering community-based programs that provide patients, families, caregivers, and direct care workers with the knowledge and skills to improve health outcomes for older adults

- Providing education and training to patients, families, caregivers, direct care workers, health-care providers, and health professions students, residents, fellows, and faculty on Alzheimer's disease and related dementias and how cognitive and behavioral impairments impact medical care throughout the course of illness. ${ }^{147}$

"People with dementia, and their families and caregivers, are at the center of the [GWEP] model," according to Joan Weiss, senior advisor, division of medicine and dentistry, HRSA. ${ }^{148}$ The GWEP has produced impressive results throughout the country. For example, the University of North Texas Health Science Center's GWEP partnered with the local Area Agency on Aging, the county hospital, and a private university to train current and future healthcare professionals in interdisciplinary geriatrics. The partnership gave medical, nursing, social work, pharmacy, physical therapy, physician assistant, and dietetics students the opportunity to go on team-based home visits as well as to be trained in evidence-based geriatric care. Of the 718 students in the GWEP program, "81 percent improved their understanding of team collaboration to improve patient care and safety, 95 percent improved confidence in conducting cognitive assessments, and 93 percent improved confidence in completing fall risk screenings." ${ }^{149}$

The John A. Hartford Foundation funds the GWEP Coordinating Center, which serves as a strategic operation to provide support to the sites, as well as aggregates data for analysis and implementation of changes to the program. The GWEP Coordinating Center provides opportunities for collaborative learning among HRSA GWEP grant recipients, content and resources for professional and public education to improve quality of care for older adults, mentoring and consultation with geriatrics experts, engagement in advocacy for Title VII and Title VIII funding, and evaluation of HRSA GWEP programs.

The GWEP is a highly effective model for incorporating best practices for geriatric and dementia care training. As such, we support its reauthorization. Introduced by Senators Susan Collins (R-ME) and Bob Casey (D-PA), the Geriatric Workforce Improvement Act would reauthorize the GWEP for an additional five years and increase funding to $\$ 45$ million per year. The bill would also reauthorize the GACA program.

"Maine has an aging population of more than a quartermillion residents over the age of 65 and only 40 geriatricians. As the oldest state in the nation by median age, Maine is a prime example of the acute need to quickly train more geriatric health professionals and direct service workers to meet the growing demand," said Senator Collins, the chairman of the Aging Committee. "Expanding GWEP would promote geriatric education for our current workforce, while optimizing resources to bolster academic careers in geriatrics, helping to attract the best and the brightest into the field. This bipartisan bill is necessary to develop a high-quality geriatric workforce ready to provide care for Americans as we grow older." ${ }^{150}$

In addition, in 2018, HRSA developed two training curricula on Alzheimer's disease and related dementias. The first curriculum educates the primary care workforce about dementia care. In 2019, these modules were converted to continuing education training materials for physicians, nurses, allied health professionals, and health educators. The second curriculum focuses on caregiving. It assists providers in understanding and addressing the needs of caregivers of persons living with dementia and helps family and other caregivers functioning as members of the inter-professional team take care of their health, and understand and cope with the challenges of caregiving. 


\section{Action Item \#16}

Spread Age-Friendly Health Systems for older adults with dementia.

Our current health-care system does not give optimal care to older adults with Alzheimer's and related dementias or enough support to their caregivers. ${ }^{151}$ Yet we pay significantly more for care provided to people living with dementia than for those without the condition (see Figure 4). In 2019, Medicare will spend, on average, nearly $\$ 25,000$ per older adult living with dementia, which is more than three times higher than what Medicare will spend on older adults without dementia. Under Medicaid, per-person spending is on average 23 times higher for individuals with dementia, in part because Medicaid is the nation's primary public payer for the long-term services and supports many people with dementia need.

A large portion of these costs can be attributed to avoidable or preventable hospitalizations, poor coordination and communication across care teams, and ineffective care transitions. ${ }^{153}$ Older adults with dementia have a 30 percent greater risk of having a preventable hospitalization than those without and a higher risk of re-hospitalization within 30 days of discharge. ${ }^{154,155}$ Their care is often more complex and difficult for unpaid caregivers, in part, because of a higher prevalence of cooccurring chronic conditions. ${ }^{156}$ Often the professional care team does not know about or offer evidence-based caregiver support and training to assist these caregivers. ${ }^{157}$

To prepare for an aging population, in 2017, the John A. Hartford Foundation and the Institute for Healthcare Improvement, in partnership with the American Hospital Association and the Catholic Health Association of the United States, launched the Age-Friendly Healthy Systems (AFHS) initiative. An AFHS is a "health care system that aims to provide older adults with the best care possible, to reduce health care-related harms to older adults, and to optimize the value of all, including patients, families, caregivers, health care providers, and health systems." ${ }^{158}$ To date, there are 500 AFHS (which represent 8 percent of all active hospitals in the US), with the goal of spreading to 20 percent of US hospitals and medical practices by 2020 . AFHS offers measurable ways to care for older adults with dementia and optimize value for health systems,
Figure 4: Comparison of Annual Medicare and Medicaid Spending for People with and Without Dementia

Average Annual per Person Medicare Spending

$\$ 7,561$

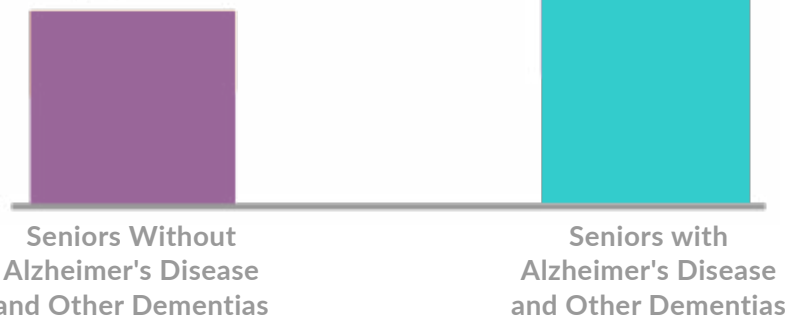

Average Annual per Person Medicaid Spending

$\$ 8,565$

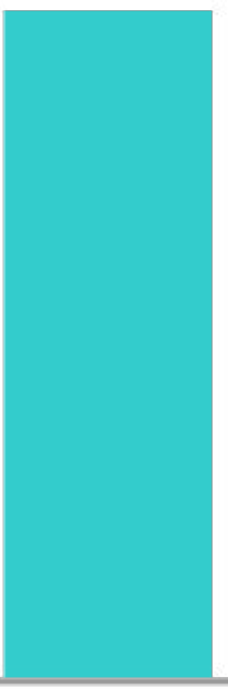

Seniors Without

Alzheimer's Disease

and Other Dementias
Seniors with Alzheimer's Disease and Other Dementias
Source: "Costs of Alzheimer's to Medicare and Medicaid Fact Sheet," Alzheimer's Impact Movement (March 2019). ${ }^{152}$

\section{"An age-friendly health system starts and}

\section{ends at your kitchen table, and creates}

continuity across care settings." 159 
employing a systematic approach to information sharing and coordination across care settings to reduce unnecessary costs and inefficient care. AFHS models train interdisciplinary teams to work with and support caregivers to best meet the needs of older adults with dementia. The goal is to provide evidence-based, coordinated, person- and family-centered care.

\section{Action Item \#17}

Develop and train workers to provide high-quality care to people living with dementia.

A majority of individuals living with dementia reside in their homes and communities. In 2017, approximately 81 percent of these individuals lived alone or with another individual, such as a spouse or family member, while only 6 percent lived in residential care and 13 percent lived in a nursing home. ${ }^{160}$ As the disease progresses, people living with dementia typically require extensive care-either from unpaid caregivers or direct care workers. These direct care workers (including home health aides and personal care aides) provide the majority of paid, hands-on home care. ${ }^{161}$

By 2030, the US will need an estimated 3.4 million direct care workers to provide long-term services and supports (LTSS), a 1.1 million increase over the 2.3 million who filled these jobs in 2015. ${ }^{162}$ Immigrants account for about a quarter of the home care workforce, a number that could change depending on US immigration policies. ${ }^{163}$

Direct care workers, including personal care aides, home care aides, and certified nursing aides, often do not have access to dementia-specific training. ${ }^{164}$ While 23 states require dementia training for staff of nursing home and long-term care facilities, there are few dementia-related training requirements for home care workers. Proposed adjustments to the Affordable Care Act include mandatory ongoing trainings on dementia care and abuse prevention; however, these requirements have not yet been fully implemented. ${ }^{165}$ Research shows that proper training can improve the quality of life for people living with dementia. It can also help stabilize the home care workforce by providing them tools to cope with challenging caregiving situations. ${ }^{166}$
With more women working full-time and family size decreasing over time, the availability of family caregivers is also declining. We will need to rely even more on the direct care workforce to provide supports and services for people living with dementia. To attract and retain this workforce, we need to ensure these are high quality, high paying jobs. In 2018, the average income of home health and personal care aides was $\$ 24,060$, the lowest of all health-care occupations. ${ }^{167}$ Workers could earn more in fast-food restaurants, the US Government Accountability Office noted in a 2018 report on Medicaidsupported, home-care programs. ${ }^{168}$ One in five home-care workers lives in poverty, compared to 7 percent of all US workers. ${ }^{169}$ Elevating and professionalizing caregiving must be a national priority if we are to meet the growing demand.

As our aging populations, like the rest of society, become more diverse, we must ensure that the health and LTSS workforce is trained to accommodate the cultural aspects of care. Between 2018 and 2060, the share of the older population that is non-Hispanic white is projected to drop from 77 percent to 55 percent. ${ }^{170}$ As noted previously, Latinos and African Americans are significantly more likely to have dementia, as are individuals living at or near poverty. ${ }^{171,172}$ These groups tend to have multigenerational households and to be active in faith-based communities. ${ }^{173}$ The population of individuals living with IDD will also continue to age, developing dementia at an increased rate. As the number of individuals living with dementia in these communities continues to grow, we must develop innovative approaches to identify and address unique needs and promote culturally sensitive communication strategies.

\section{Action Item \#18}

Increase the cultural competency of the existing dementia workforce to ensure culturally sensitive care, services, and research opportunities are provided to high-risk populations.

Several programs have been developed to train health and LTSS professionals and direct care workers for cultural competency in the dementia care setting. The HRSA Bureau of Health Workforce (BHW) includes a training module that covers how prevalence, risk factors, and education about dementia varies across diverse 
populations. The training module addresses the sex-based disparities in dementia, unique risk factors for diverse populations, and how to discuss screenings and diagnosis when words for dementia may not exist in a particular language. ${ }^{174}$ Similarly, the Administration for Community Living (ACL) offers resources in diversity and cultural competency as part of its program initiative to strengthen aging networks, including the US Administration on Aging's toolkit for serving diverse communities and cultural competence resources for health-care providers. ${ }^{175}$

Erin Long with the Office of Supportive and Caregiver Services, US ACL, noted a particularly innovative program that trains community health workers in Minnesota. These workers are being taught dementia-specific training as part of an English as a Second Language class. She remarked, "They were really amazed at the number of young people who really were interested and committed to learning that education. They had a captive audience. They were teaching them English, and they were teaching them about dementia." ${ }^{176}$

Cultural competency in health-care settings has been shown to improve health outcomes for people with dementia. ${ }^{177}$ While geriatric and dementia-focused training across interdisciplinary teams should be ubiquitous, training for cultural sensitivity will require regional specificity, based on the racial, ethnic, and cultural characteristics of each community. Unique risks and challenges of dementia for the intellectual and developmental disability community should be respected in the same way. Existing research on the efficacy of cultural sensitivity training for dementia care staff is limited and will require further work within respective communities to understand their needs. ${ }^{178,}{ }^{179}$ This will create opportunities to engage those communities and recruit diverse individuals into health and LTSS professions. The synergy of these strategies provides a basis to address health disparities for coming generations.

ACL also has numerous resources to expand access to dementia training. ACL funds state and community-level programs that improve home and community-based services for people living with dementia and for their caregivers. This includes educating workers on the symptoms of dementia and how to assist caregivers in accessing resources in their community. ${ }^{180}$

\section{Training and Equipping Caregivers}

A recent report from the Home Alone Alliance-a coalition that includes AARP, the United Hospital Fund, the Family Caregiver Alliance, and the Betty Irene Moore School of Nursing at the University of California at Davis-found that 20 million US residents perform complex medical and nursing tasks for individuals with challenges to physical, cognitive, and behavioral health. ${ }^{181}$ The study found that many family caregivers are largely on their own when it comes to managing these tasks. Caregivers often have to learn tasks such as managing incontinence and special diets through trial and error.

According to the Alzheimer's Association, there are approximately 16 million unpaid caregivers caring for someone with dementia. Dementia caregivers have reported higher levels of stress than other caregivers, largely due to the progressive nature of the disease, which can be all-consuming.

\section{Action Item \#19}

Provide paid and unpaid caregivers with the tools, information resource centers, and training to meet the unique challenges of caring for people living with dementia.

In addition to the Alzheimer's disease and related dementia curriculum for health professionals, HRSA $\mathrm{BHW}$ created a separate curriculum on caregiving. For caregivers, the training includes seven specific learning modules to help family and other caregivers of people with dementia take care of their health and better understand and cope with the unique challenges of caring for a person with dementia. Topics range from what to consider when choosing an assisted living facility to caregiver self-care. For health-care professionals, training focuses on the importance of engaging the caregiver as a member of the inter-professional team in the care management process and assisting the caregiver with their self-care. Increasing access to training opportunities for both groups will help caregivers take care of their health and understand and cope with the challenges of caring for people living with dementia.

Another example comes from the private sector. Home Instead Senior Care, a global home care organization, 
offers a number of resources and programs to family caregivers to help empower them on their caregiving journey. These tools can be found at Home Instead's Help for Alzheimer's Families website and include information on educational resources, community forums to share experiences, and grants to alleviate home care costs. ${ }^{182}$ The aggregated resources are distributed to families caring for people living with dementia, helping to better support unpaid caregivers. Similarly, both the Alzheimer's Association and AARP offer toolkits for a variety of caregiver needs, including information about support groups, financial planning, and self-care.

Finally, new technologies are emerging that can provide helpful assistance to both paid and unpaid caregivers, as well as those living with dementia. While these solutions can be expensive early in their implementation, we are hopeful that the positive return-on-investment will be substantial. The National Science and Technology Council has identified six key areas for technology to effectively support aging: key activities of independent living, cognition, communication and social connectivity, personal mobility, transportation, and access to health care. ${ }^{183}$

The spectrum of tools available for individuals living with dementia is expansive-from sensors and software that monitor vital signs to robotic caregiving assistants that can carry on conversations, assist with mobility, and give reminders about medications. ${ }^{184,}{ }^{185}$ Despite the variety of functions and designs, the new technologies promise to provide needed assistance to individuals who require help with activities of daily living and their caregivers. Technology can also allow people living with dementia to be more independent, while caregivers can monitor their needs less invasively. ${ }^{186}$

Issues such as privacy, functionality, and cost need to be addressed to make caregiver technology fully viable. ${ }^{187}$ The data generated by monitoring sensors, connected devices, and the network of information as a whole require security and consent from the individuals being monitored. ${ }^{188}$ Knowledge about the variety of tools is also an issue; research suggests that a significant number of caregivers are not aware of the technology that is available to them, and thus don't use it. ${ }^{189}$ Increasing access to such technology, as well as addressing concerns about data and utility, can open up opportunities for wide-scale implementation.

\section{Testing New Models for Providing Dementia Care}

Ultimately, to attract more health professionals to dementia care, we must change the way Medicare and Medicaid pay to encourage more team-based and collaborative approaches. Promising new models are being tested but can better serve those living with dementia.

\section{Action Item \#20}

Pilot new payment and delivery models to improve comprehensive, coordinated, and person-centered care for people living with dementia and provide services in the home and out of more costly settings of care, where possible.

The Affordable Care Act created the CMS Center for Medicare and Medicaid Innovation (CMMI) to develop and test new payment and delivery models for providing value-based care to Medicare and Medicaid beneficiaries. Robust development and testing of models began as part of the Affordable Care Act and continues in the Trump Administration. While several new models of care are being designed to improve care for a host of chronic conditions, new models specific to dementia care do not exist. ${ }^{190}$ This gap could and should be filled, for example, by a demonstration aimed at Medicare beneficiaries diagnosed with dementia who need progressive interventions, to avert or delay institutional care and enrollment into Medicaid.

In San Francisco, one promising approach supported by the Ray and Dagmar Dolby Family Fund seeks to address two fundamental questions: 1) when is the emergency department (ED) the appropriate place for people with dementia and how do we help ensure that the experience is as safe and effective as possible; and 2) when the ED is not the appropriate setting, how do we reduce ED use for people with dementia? ${ }^{191}$

To address the first question, the project looks to build on the model of the Geriatric Emergency Department (GED), a concept developed by the John A. Hartford Foundation and Gary and Mary West Health Foundation and administered by the American College of Emergency Physicians. ${ }^{192}$ The San Francisco-based project will focus on dementia care in the GED, by preparing ED staff with 
evidence-based, dementia-specific protocols, the inclusion of caregivers, and effective care coordination. ${ }^{193}$ To address the second question, the project seeks to provide alternatives to ED visits. CMS is testing one promising approach.

Figure 5: Annual Reported Instances of Adults Age 60 and Older Using EDs in San Francisco, with Proportions Reporting Cognitive Impairment and Determined Not Having Medical Reason for Visit

ADULTS 60+ HAVE

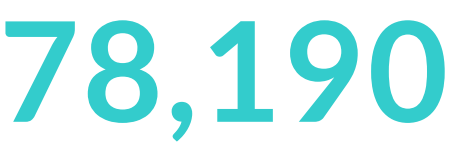

ENCOUNTERS ANNUALLY IN SAN FRANCISCO EDS

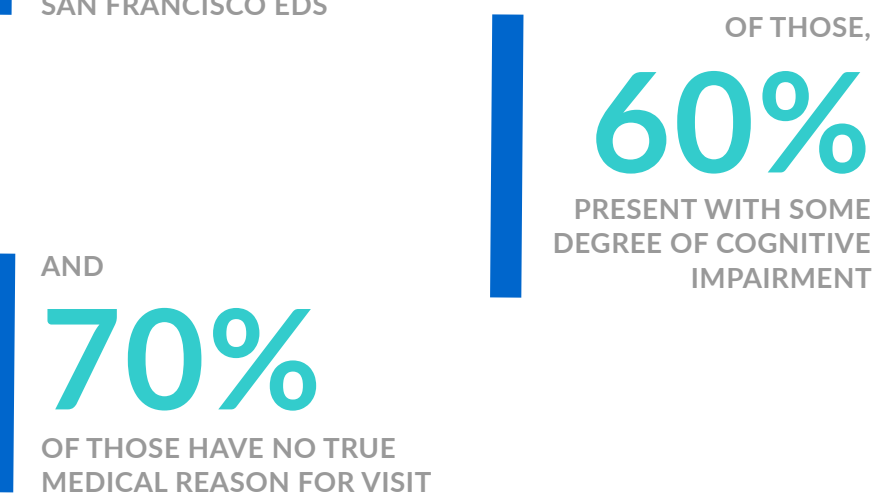

Source: "Transforming Emergency Care for Persons with Dementia," The Ray and Dagmar Dolby Fund, (September 2018). ${ }^{194}$

In 2019, CMS announced a new model that could fundamentally change the way Medicare beneficiaries receive emergency care, which may be helpful for those living with dementia. "This model will create a new set of incentives for emergency transport and care, ensuring patients get convenient, appropriate treatment in whatever setting makes sense for them," said HHS Secretary Alex Azar in announcing the new model. Under the current payment system, ambulance providers can only be reimbursed for transporting patients to the hospital. Under the new model-the Emergency Triage, Treat and Transport model-participating ambulance suppliers and providers will partner with qualified healthcare practitioners to deliver treatment in place (either on-the-scene or through telehealth) and with alternative destination sites (such as primary care doctors' offices or urgent-care clinics) to provide care for Medicare beneficiaries following a medical emergency for which they have accessed 911 services. ${ }^{195}$ By empowering paramedics to stabilize beneficiaries at home or in less stressful and expensive settings, the model could improve the experience of people living with dementia while simultaneously reducing costs and improving the time that EDs are overcrowded or on diversion.

Prominent brain science and dementia researchers Malaz Boustani et al. recently analyzed several evidencebased collaborative dementia care models to support the complex needs of people with dementia and their caregivers. According to the researchers, the ultimate goal of this model "is to improve the experience of care, health, and well-being of patients and their unpaid caregivers as a result of management of the cognitive, functional, behavioral, and psychological needs of people living with Alzheimer's disease; prevention and management of caregiver burden; coordination of care transitions and services among providers and community resources, including home and community-based services; and advance care planning and shared decision making."196

Another promising approach in Texas partners health plans and community-based organizations to build a network of support and resources for individuals living with dementia and their caregivers. Based on the California MediConnect program, the "Texas Takes on Dementia" initiative connects the local chapters of the Alzheimer's Association and United Way to community developers and plans such as UnitedHealthcare and Amerigroup through grants from the Administration on Aging. ${ }^{197}$ These organizations provide education and training on the needs of the dementia population for health plans and create a referral network for direct care services. While funded by a federal grant, the initiative has been largely self-sustaining, requiring minimal involvement from regulatory agencies.

Another innovative model comes from the University of California, Los Angeles (UCLA) Alzheimer's and Dementia Care (ADC) program. The program supports primary care practices by providing access to nurse practitioners who receive additional specialized training in Alzheimer's and dementia care. ${ }^{198}$ The ADC model has demonstrated reductions in patients' behavioral and depressive symptoms; family caregivers' depressive symptoms, distress, and strain, nursing home placements; and Medicare costs. It is now being tested in four states with funding from the Patient-Centered Outcomes Research Institute and National Institute on Aging. According to the 
dissemination team, the model can only be sustainable at scale if adequate reimbursement is provided to "cover the cost of care and pathways for incentivizing and recognizing nurse practitioners who have specialized training and skills in dementia care management." ${ }^{199}$

Implementing new dementia care models across settings requires swift action. Coupled with new billing codes in traditional Medicare and increased opportunities for Medicare Advantage plans treating people with dementia (as detailed in section 2), we must jumpstart innovation to deliver new cost-effective, high-quality models as soon as possible.

\section{Conclusion}

Building a dementia-capable workforce will entail identifying people with signs of dementia, communicating with those affected and their families and caregivers, training at all levels, tailoring of services, and directing people across the continuum of care. Components of effective dementia care interventions should include effective care coordination, safety evaluation and strategies, management of coexisting conditions, connection to community resources including home and community-based services, caregiver support, and education and training of the workforce, advance care planning, and interventions that are flexible and tailored to changing needs.

New policies should help identify and promote highquality and culturally sensitive dementia care guidelines and measures across care settings. These guidelines and measures should be tailored to the stages of the disease and address the physical, cognitive, emotional, and behavioral symptoms of dementia. These guidelines should also take into account how care might be modified for diverse populations and in the context of co-occurring chronic conditions in people with dementia.

With no cure or substantive treatment to delay or improve the course of the disease in sight and rates of dementia projected to double every $10-15$ years, we must invest in new models of team-based approaches to value-based care.

\section{Care Continuum}




\section{Goal \#5}

\section{Establish Services and Policies that Promote Supportive Communities and Workplaces for People with Dementia and Their Caregivers}

Communities and workplaces are critical sources of support for the growing population of people living with dementia and their caregivers. According to the Alzheimer's Association, an estimated 70 percent of people living with Alzheimer's and other dementias live in their homes and community, with an estimated onequarter or more living alone. ${ }^{200}$ Further, research suggests that people of color are 40 percent less likely than nonHispanic whites to enter a long-term care facility. ${ }^{201}$

Although we often focus on their medical needs, people living with dementia and their caregivers report feeling isolated and stigmatized in their communities. Studies indicate that communities that are informed and supportive can help reduce social isolation. ${ }^{202}$ Reducing social isolation can improve health outcomes, reduce emergency department visits, and enhance quality of life for all. ${ }^{203}$

Between 28 and 34 percent of individuals living with dementia in the US are socially isolated and living alone, leading to potential risks of greater cognitive and functional decline. ${ }^{204}$ Because of the stigma associated with a dementia diagnosis, many people living with dementia and their caregivers report growing further apart from relatives and friends. Unpaid dementia caregivers report that they spend significantly more time per week providing care than other caregivers. ${ }^{205}$ Caregiving also impacts their work more than other caregivers. 


\section{Reducing Stigma}

After receiving a diagnosis, a person living with dementia lives, on average, four to eight years, but some people live as long as 20 years. ${ }^{206}$ Nevertheless, far too many individuals diagnosed with dementia are treated like their lives are already over by the health-care system and their communities. Many people living with dementia live active, engaged lives filled with love and appreciation. Research shows that a positive and purposeful attitude towards aging-and even dementia-results in better health outcomes and quality of life, such as an increased lifespan and reduced risk of heart disease and stroke. ${ }^{207,} 208$ People with dementia want to pursue goals and engage in meaningful activities, just like those without the disease. ${ }^{209}$

People living with dementia deserve the same rights and dignity and are mobilizing across the world to demand respect for their essential humanity. The Dementia Alliance International (DAI) is a global organization comprised exclusively of people diagnosed with dementia. They strive to "provide a unified voice of strength, advocacy, and support" for their rights, autonomy, and quality of life. Adopting the disability rights mantra "nothing about us without us," Dementia Action Alliance (DAA) advocates for inclusion and accommodating people living with dementia with strategies for changing abilities. In recognition of this growing movement, the DAI and DAA made joint statements to the United Nations in 2016 calling for the protection of their rights under the Convention for the Rights of People with Disabilities. These advocacy organizations-as well as many others, such as UsAgainstAlzheimer's, AARP, and the Alzheimer's Association-help to integrate people with dementia into communities through education about stigma and misperceptions.

To endorse strategies to establish services and policies that promote supportive communities and workplaces for people with dementia and their caregivers, we recommend the following high potential action steps:

\section{Action Item \#21}

Reduce the stigma associated with dementia through increased community engagement between people living with dementia and those who are less familiar with the condition. Include people with dementia in discussions about how to improve their lives and increase funding for community-based services to support them.

Despite the pervasiveness of dementia through the older adult population, many people have a difficult time interacting with individuals who have the condition. The impact of dementia stigma, combined with existing ageist attitudes, can contribute to feelings of shame, dehumanization, and social isolation. ${ }^{210}$ Moreover, stigma can prevent people from seeking medical treatment, participating in clinical trials, making plans for the future, and living their best quality of life. ${ }^{211}$

A recent survey confirms that stigma exists and can lead people to react negatively by "patronizing, isolating, and discriminating against a person living with the disease."212 We can reduce stigma by creating opportunities for people in the community to interact with individuals with dementia. As people learn more about the condition and personalize the experience through meeting people who live with dementia, the anxieties and misconceptions that lead to stigma will lessen. In turn, people living with dementia will feel more understood and less isolated.

Numerous community-based programs aim to provide support for people living with dementia and their caregivers. ${ }^{213}$ Such community-based programs can deliver services and support for those living with dementia (e.g., home-delivered meals, housekeeping, and transportation) as well as caregiver support such as respite care. One of the significant challenges of these programs is sustainability. Service providers often operate with limited funding and, consequently, cannot meet the increasing demands for these services from their communities. Area agencies on aging and other community-based organizations have typically relied on traditional funding sources such as the Older Americans Act. However, these funds have remained flat or declined, despite upward growth in the number of people who could benefit from community-based organizations' support. Until funding for these critical programs increases, either through public or private sector investments, communities must step up to 
address the needs of people living with dementia and their caregivers.

\section{Financial Wellness}

The first area that older adults show signs of cognitive decline and dementia is often money management. ${ }^{214}$ Some of the earliest signs can include difficulty balancing a checkbook, forgetting to pay bills, unusual charges on a credit card, and increased susceptibility to scams. ${ }^{215} \mathrm{~A}$ recent study by the Rush Alzheimer's Disease Center in Chicago found that "decreased scam awareness in old age is in part due to accumulating Alzheimer's changes in the brain and may occur well before cognitive symptoms can be detected." 216

\section{Action Item \#22}

Educate individuals, family members, and financial services professionals about early warning signs of dementia and implement safeguards to protect against financial exploitation.

Recognizing this risk, leading financial institutions have supported research and created consumer-friendly materials to help individuals, family members, and financial advisers be more aware of warning signs that an individual may be a victim of fraud or financial exploitation. For example, Florida State University researchers, supported by Bank of America/Merrill Lynch, identified the top indicators of financial fraud against older adults to raise concern and highlight situations that may require further investigation:

- 43 percent: New influencers/decision-makers

- 22 percent: Large financial transfers or gifts

- 21 percent: Change in investment style or behavior

Financial advisers can help to protect older adults' independence and ability to live in the community through dementia-friendly practices. For example, financial service providers can alert family members or caregivers about unusual financial transactions that may suggest cognitive decline and therefore might help individuals with care and financial planning. AARP developed the BankSafe Initiative to help train bank employees to spot potential fraud being perpetrated on older customers, especially those with dementia.
If not prevented, financial abuse can be devastating to someone living with dementia, causing them to lose their savings, often resulting in depression, increased cognitive impairment, and even mortality. ${ }^{217}$ According to the Consumer Financial Protection Bureau (CFPB), the average financial loss due to financial exploitation is $\$ 41,800$ among adults age 70 and older. ${ }^{218}$ CFPB has urged financial institutions to report suspected financial exploitation of an older adult to the appropriate authorities to better understand the problem and identify ways to improve prevention and response practices. ${ }^{219}$ Private companies like Eversafe are using technology to analyze financial behavior across accounts, identify erratic activity, and alert "trusted advocates" like family or caregivers. ${ }^{220}$

\section{Creating Dementia Friendly Communities}

As the number of people living with dementia continues to increase exponentially, the concept of "dementiafriendly communities" has been growing across the globe with more than 30 countries working toward making their communities more dementia-friendly. While there is not a single model or template for what constitutes a dementia-friendly community, in general, these communities focus on stigma reduction and the inclusion of people living with dementia. Different sectors of the economy such as financial institutions, first responders, public transportation, retailers, health-care providers, and employers are all beginning to recognize challenges inherent to an increased incidence of cognitive decline and dementia. But they are also starting to realize there are economic and social benefits when people living with dementia and their caregivers continue to participate in their communities and maintain customer loyalty, retain employees, reduce fraud and exploitation of their customers, and reduce emergency expenditures.

In the US, dementia-friendly communities were first implemented by Act on Alzheimer's in Minnesota-a statewide, multi-dimensional collaboration to help drive Minnesota's response to Alzheimer's disease. Building on Minnesota's success, Dementia Friendly America (DFA) was launched as part of the 2015 White House Conference on Aging and has grown from a pilot of eight communities in 2015 to approximately 300 dementia friendly communities across 39 states. The remaining eleven states each have communities that are planning to join Dementia Friendly America or inquiring about 
the process."221 Today, DFA is a nation-wide grass-roots collaboration administratively supported by the National Area Agencies on Aging.

A dementia-friendly community is a town, village, city, or county where multiple community sectors work together to reduce stigma and make sure residents living with dementia are safe and able to access community support. ${ }^{222}$ The goal is to give people with dementia and their caregivers better community support and more opportunities to stay actively engaged and remain at home as long as possible. ${ }^{223}$

\section{Action Item \#23}

Expand DFA's national network of communities, organizations, and individuals to foster the ability of people living with dementia to remain in communities and engage and thrive in day-to-day living.

DFA requires participation from multiple community stakeholders. These stakeholders come from many sectors, including banking, transportation, housing, businesses, legal services, faith-based organizations, emergency responders, and much more. Together, these stakeholders create partnerships, develop action plans, and build support systems for people with dementia and their care partners.

To address the critical issue of potential financial abuse, for example, DFA has specific guidelines to help banks and other financial institutions communicate with people with dementia and their caregivers to address financial challenges. Best practices include asking the client to identify a trusted family member or care partner to assist in making important financial decisions, increasing fraud prevention efforts, planning for declining abilities, speaking slowly and calmly, and treating the person with dignity and respect.
On a broader level, becoming a dementia-friendly community means establishing goals and evaluating successful integration of individuals with dementia:

- Increasing awareness: Recognize early warning signs of dementia, reduce the stigma, and understand how best to support people with dementia and their caregivers.

- Developing and utilizing a friendly environment: Implement clearly marked signage, quiet public spaces during events, and supportive transportation.

- Tailoring government and emergency services: Serve and protect people with dementia and remove barriers that may isolate people affected by dementia.

Nearly all dementia-friendly community plans include public health recommendations and strategies for public awareness, early detection, education about brain health, and assistance for those with dementia and their caregivers. These community-based efforts promote and provide evidence-based strategies to meet the needs of individuals living with dementia and their caregivers in the community.

Due to their higher risk for diseases that cause dementia, communities of color should be a focus during the expansion of the DFA network. The education and awareness that DFA brings to a community are vital to help with early diagnosis, understanding, and prevention. Faith-based efforts have proven valuable in reaching out and connecting with communities of color.

Dementia Friendly Denver is working on eight projects to make the Greater Denver area more dementia-friendly. These projects include community and government education events, lunch and learns for area businesses where they can earn a Dementia-Friendly Business designation, training for clergy of all faiths for dementia-friendly worship services, video education segments for advance care planning topics to address caregiver needs, and pocket English and Spanish guides listing services available in the greater Denver area. ${ }^{224}$ 
Memory cafes offer welcoming places for people living with dementia and their family and friends to gather. Some invite guest artists to lead exercises, some offer education about memory changes, and some are set up for relaxing and chatting-designed to decrease social isolation for people with dementia and their care partners. Massachusetts-which now boasts over 60 memory cafes across the Commonwealth-put together a toolkit to help other communities launch memory cafes.

Dementia Friendly Kansas City has put together a coalition of partners interested in creating a dementia-friendly city. The Plaza branch of the Kansas City Missouri Public Library hosts two monthly programs, as well as dementia-friendly events. The Movies \& Memories program offers popcorn, live music, and short films paired with themed activities. KC Memory Cafe features speakers from area arts, cultural, and educational organizations, such as the Nelson-Atkins Museum of Art, the Kansas City Symphony, and the Kansas City Zoo. Both programs are free and specifically designed for people who are living with dementia, their care partners, family, and friends. During the past year, these programs have attracted more than 700 attendees. Dementia Friendly Kansas City is also offering free educational programs, initially targeting neighborhoods, faith communities, libraries, and the airport.

As the movement grows, questions have arisen about the best way to measure the effectiveness of dementiafriendly communities. As they move to the next stage of maturation, increased funding is needed to measure their effectiveness and develop metrics so that promising innovations can be scaled. AARP, the Health and Global Policy Institute, and the Alzheimer's Society including the World Dementia Council with the help of the World Health Organization (WHO) recently agreed to conduct a review to identify essential components of dementiafriendly communities and identify measures to evaluate their impact. The "Meaningful Dementia Friendly Initiatives Review," which is conducting a global survey of dementia-friendly communities to better understand the current state and quality of the existing evidence, and how that relates to the similar concept of Age-Friendly Initiatives, is scheduled to be delivered to the World Dementia Council at the beginning of 2020.

We look forward to the recommendations of this review so that we can ensure that dementia-friendly communities have an impact on those living with dementia.

\section{Implement Policies to Support Caregivers}

Family members, friends, and other unpaid caregivers provide 83 percent of care to older adults in the United States. Forty-eight percent of those caregivers are caring for someone with Alzheimer's or related dementias. ${ }^{225}$ The majority of caregivers for people with dementia are middle-aged women, ages 35 to 64, caring for a parent or parent-in-law. ${ }^{226}$ According to UsAgainstAlzheimer's, less than half (49 percent) of employed dementia caregivers reported having access to paid and flexible medical and family leave options. ${ }^{227}$ Among those with the benefits, just over half (51 percent) reported taking advantage of them, which resulted in caregivers being able to provide better care for their loved ones and improved emotional well-being. ${ }^{228}$

Caregiving affects the health, finances, and quality of life of those providing care. In 2018, caregivers for people living with dementia provided 18.5 billion hours of unpaid care, averaging almost 22 hours per week valued at almost $\$ 234$ billion annually. ${ }^{229}$ We need to provide caregivers with a network of support that includes assistance with care as well as opportunities to manage their own lives, such as time for respite, paid work, and tending to their children. Jisella Dolan, global chief advocacy officer for Home Instead Senior Care, notes that based on their surveys of family caregivers, "...people want flexibility from their employer, they want compassion, they want to know they're not alone." ${ }^{230}$

Caregivers of people living with dementia are impacted more severely by challenges than non-dementia caregivers and seek out resources more frequently for assistance. ${ }^{231}$ Without support systems, dementia caregivers are more likely to experience psychological and physical health issues and experience financial setbacks. Caregiving can lead to lost benefits and promotions if work interruptions occur. 
Grace Whiting, president and CEO of the National Alliance for Caregiving, notes that "as the disease progresses, there are people who will exit the workforce, and the real issue here is what is the re-entry point, particularly for women in their fifties, to come back into the workforce?"232

\section{"People want flexibility from their}

\section{employer; they want compassion; they}

\section{want to know they're not alone."}

JISELLA DOLAN

GLOBAL CHIEF ADVOCACY OFFICER, HOME INSTEAD SENIOR CARE

Meryl Comer, author of "Slow Dancing with a Stranger" and founding board member of UsAgainstAlzheimer's, knows this from experience. "I was 48 when I had no option, but to leave my career to care for my husband with early-onset Alzheimer's. Twenty-two years later, I'm still caring for him at home as well as my 95-yearold mother. When I look back, nothing has changed: no disease-modifying therapy, no better care options for the next generation of young women forced to leave the workplace. There is no plan B in this country if millions of informal family caregivers get sick or give up."233 In addition to negative impacts on their physical and mental health, caregivers spend, on average, $\$ 7,000$ on caregiving per year, which goes toward paying for personal, medical, and household needs. ${ }^{234}$ Many are contributing far more. Caregivers for people living with Alzheimer's and other dementias spend, on average, 54 percent more than the average caregiver. Caregivers for a spouse spend 68 percent more than the average, and those who are caregiving from a distance spend 71 percent more than the national average.

As Lorna Sabbia, head of retirement and personal wealth solutions for Bank of America, says concisely, "In our study on Women and Financial Wellness, we learned that women on average live five years longer than men, by age 85 they outnumber men two-to-one, and the majority (81 percent) of centenarians are women. This means that women are more likely to be alone and financially selfreliant in their later years. Given that women also have a higher prevalence of dementia, their need to factor in longevity and the potential impact of this disease later in life is critically important."235

\section{Action Item \#24}

Support and promote bipartisan federal and state policy efforts to expand paid family and medical leave for elder care.

To date, four states have state-paid family and medical leave laws: California, New Jersey, Rhode Island, and New York. Four more states (Washington, Massachusetts, Connecticut, and Oregon) and the District of Columbia have enacted state paid family and medical leave insurance laws, but they are not in effect yet. ${ }^{236}$ While we are making progress, most people caring for someone living dementia must take leave without pay or withdraw from the workforce altogether. Given the projections of those who will need care in the future, we must develop more protections and benefits for these essential caregivers.

\section{"In our study, 'Women and Financial} Wellness,' we learned that women on average live five years longer than men, by age 85 they outnumber men twoto-one, and the majority (81 percent) of centenarians are women. This means that women are more likely to be alone and financially self-reliant in their later years. Given that women also have a higher prevalence of dementia, their need to factor in longevity and the potential impact of this disease later in life is critically important."

\author{
LORNA SABBIA \\ HEAD OF RETIREMENT AND \\ PERSONAL WEALTH SOLUTIONS, \\ BANK OF AMERICA
}


More than 34 million Americans provide care to someone over the age of 50 , and 61 percent of them juggle work and caregiving. Further, dementia care is becoming an acute challenge for younger generations of caregivers. In fact, of the 10 million millennial family caregivers in the US, 15 percent are caring for someone living with dementia. ${ }^{237}$ According to UsAgainstAlzheimer's, four in 10 employed millennial caregivers reported that either themselves or someone in their household has had to borrow money or go into debt to provide care for their loved one. ${ }^{238}$

The US is one of the few developed countries without guaranteed paid leave to care for children or older relatives. This forces far too many family caregivers to choose between their work and caring for their loved ones-often putting themselves in financial jeopardy to do so. We must also recognize that employed caregivers need time to care for aging relatives. Across the world, time off to care for children is more common and more generous than for other relatives such as aging parents. ${ }^{239}$

A study by the AARP Public Policy Institute finds that of the roughly 100 major US firms that have adopted or expanded paid family leave over the past three years, only about 20 percent made the benefit available to family caregivers. The rest limit it only to new parents. ${ }^{240}$

\section{Action Item \#25}

Create a National Employer Task Force on Eldercare to explore innovative caregiver support strategies. Encourage employers to provide benefits such as flexible work schedules, respite care, and paid family and medical leave.

As suggested by UsAgainstAlzheimer's, we recommend creating a National Employer Taskforce on Eldercare to create a network of best-practice approaches for supporting their employee caregivers. ${ }^{241}$ Many companies have already enacted initiatives and can share the impacts of such programs on employee well-being, develop strategies for funding, and discuss innovative ways to meet the needs of their employees. Existing programs for employees have already shown positive impacts on flexibility for medical appointments, providing care, and emotional and physical well-being. ${ }^{242}$ These programs could be instrumental in helping caregiver employees navigate existing paid family and medical leave benefits given the barriers to utilization that exist, particularly for caregivers of color.

The US Department of Veterans Affairs (VA) created the Veterans' Family, Caregiver, and Survivor Advisory Committee to advise the secretary of the VA on matters related to veterans' families, caregivers, and survivors. They hope to increase awareness, gain a better understanding of the needs of caregivers, and identify ways the VA can support them. ${ }^{243}$

Beyond that, several experts we consulted discussed needing to address stigma in the workplace. "We have to look at what drives stigma to address stigma. And fear, I think, is a big part of this equation, including the fear of workforce retribution and workforce insecurity that often come with utilizing benefits like paid family leave," remarks Jason Resendez, executive director, LatinosAgainstAlzheimer's, a network of UsAgainstAlzehimer's. ${ }^{244}$ A national survey of employed caregivers found that of those who had access to paid leave, just over 50 percent used the benefit because of fear of workforce retribution and because they did not know how to apply for their benefits. ${ }^{245}$

Access to employer-sponsored benefits for workers can help caregivers meet the needs of the people they care for without having to leave their jobs. Unfortunately, these programs are not available to all workers. Those who do have access generally are higher-paid workers, leaving lower-income employees more vulnerable. ${ }^{246}$ Sixty-one percent of employee caregivers report having to make a workplace accommodation such as going in late, leaving early, taking a leave of absence, turning down a promotion, or retiring early, because of their caregiving responsibilities. ${ }^{247}$ More than half of employed caregivers report negative impacts on their productivity, time, personal health, and opportunities at work because they do not have the flexibility and support they need. We need to spread awareness among employers about the value of these benefits for recruitment, retention, and reduced stress among their employees.

Nationwide, AARP estimates that about 40 million people are caring for family members. The ratio of potential family caregivers will decrease from $7: 1$ to $3: 1$ by $2050,{ }^{248}$ which will put even more stress on those who take on this critical role on behalf of loved ones. 
Only 13 percent of private-sector workers had access to paid family leave through their employer in 2017.249 However, research shows that the benefits of paid family leave extend far beyond the caregiver; the value reaches employers and the economy at large as well. ${ }^{250}$ According to a 2016 study by AARP and ReACT, for every dollar invested in flexible work arrangements, businesses can expect a return ranging from $\$ 1.70$ to $\$ 4.34$.

\section{Conclusion}

The evidence is clear why policymakers and employers should strive to assist employed caregivers, especially for those caring for people living with dementia. Reducing the stigma of living with dementia improves the long-term outcome of health and well-being for these individuals and increases use of the resources within communities that are most in need. Dementia Friendly America provides a packaged, best-practices model for organizations and city governments to implement and adapt. Further growth of their network will continue to build the evidence base for supporting the dementia community.
Companies who already provide resources to employee caregivers are setting the standard for how their policies are creating value for all stakeholders. Not only are paid family leave and flexible work arrangements the right thing to do, but they have also demonstrated improvement in retention and recruitment efforts. Establishing a network of employers will set a standard for business practice.

Once it is standard to offer paid leave, caregivers will have more opportunities for a stable income and the ability to utilize health benefits.

For those without access to employer-provided benefits, the government needs to step up to provide protections for these employed caregivers. As the number of people living with dementia continues to grow, and the number of family caregivers continues to decline, we must provide better support for these caregivers.

\section{Goal \#5 Establish Services and Policies that Promote Supportive Communities and Workplaces for People with Dementia}




\section{ENDNOTES}

1. "2019 Alzheimer's Disease Facts and Figures," Alzheimer's Association, Alzheimer's \& Dementia, vol. 15, no. 3 (2019): 17, https://alz.org/media/Documents/ alzheimers-facts-and-figures-2019-r.pdf.

2. "Lifestyle Interventions Provide Maximum Memory Benefit When Combined, May Offset Elevated Alzheimer's Risk Due to Genetics, Pollution," Alzheimer's Association, July 14, 2019, https://alz.org/aaic/releases_2019/ sunLIFESTYLE-jul14.asp.

3. John F. Hodes et al., "Alzheimer's 'Prevention' vs. 'Risk Reduction:' Transcending Semantics for Clinical Practice," Frontiers in Neurology (January 2019), https://doi. org/10.3389/fneur.2018.01179.

4. Ibid.

5. "Lifestyle Interventions Provide Maximum Memory Benefit When Combined, May Offset Elevated Alzheimer's Risk Due to Genetics, Pollution," Alzheimer's Association, July 14, 2019, https://alz.org/aaic/releases_2019/ sunLIFESTYLE-jul14.asp.

6. Ibid.

7. "New Clues on Why Women's Alzheimer's Risk Differs from Men's," Associated Press, July 16, 2019, https:// www.statnews.com/2019/07/16/new-clues-womenalzheimers-risk-differs-from-men/.

8. "Women and Alzheimer's," What is Alzheimer's, Alzheimer's Association, accessed September 11, 2019, https://www.alz.org/alzheimers-dementia/what-isalzheimers/women-and-alzheimer-s.

9. "Caregiver Statistics: Work and Caregiving," Family Caregiver Alliance, National Center on Caregiving, https:// www.caregiver.org/caregiver-statistics-work-andcaregiving.

10. Sheung-Tak Cheng, "Dementia Caregiver Burden: A Research Update and Critical Analysis," Current Psychiatry Reports, vol. 19, no. 9 (2017): 64, https://doi.org/10.1007/ s11920-017-0818-2
11. Kent Allen, "Dementia Cases to Grow Substantially Among African Americans, Hispanics," AARP, September 27, 2018, https://www.aarp.org/health/dementia/info2018/dementia-alzheimer-cases-grow-nonwhites.html.

12. Darrell J. Gaskin, Thomas A. LaVeist, and Patrick Richard, "The Costs of Alzheimer's and Other Dementia for African Americans,"

AfricanAmericanNetworkAgainstAlzheimer's (September 2013), 13, https://www.usagainstalzheimers.org/sites/ default/files/USA2_AAN_CostsReport.pdf.

13. M. McCarron et al., "A Prospective 14-Year Longitudinal Follow-Up of Dementia in Persons with Down Syndrome," Journal of Intellectual Disability Research, vol. 58, no. 1 (January 2014): 65-66, https://doi. org/10.1111/jir.12074.

14. Phillip McCallion, Molly Knowles, and Elizabeth Gould, "2019 NADRC: Intellectual and Developmental Disabilities and Dementia: Practical Strategies for Professionals," Administration for Community Living, National Alzheimer's and Dementia Resource Center, RTI International (July 2019), https://nadrc.acl.gov/node/169.

15. "What is Dementia? Symptoms, Types, and Diagnosis," Health Information, National Institute on Aging at $\mathrm{NIH}$, December 31, 2017, https://www.nia.nih.gov/health/ what-dementia-symptoms-types-and-diagnosis.

16. "Alzheimer's Disease: A Giving Smarter Guide," Milken Institute (October 2015): 3, https://www.fastercures.org/ assets/Uploads/AD-GSG-2.0.Final.pdf.

17. "The Price Women Pay for Dementia: An Update to Projected Prevalence and Costs of Dementia," Milken Institute (2019).

18. "Risk Factors for Dementia," Alzheimer's Society (April 2016): 4, https://www.alzheimers.org.uk/sites/default/ files/pdf/factsheet_risk_factors_for_dementia.pdf.

19. Elizabeth Arias and Jiaquan $\mathrm{Xu}$, "United States Life Tables, 2017," National Vital Statistics Reports, vol. 68, no. 7 (June 24, 2019), https://www.cdc.gov/nchs/data/nvsr/ nvsr68/nvsr68_07-508.pdf.

20. "2019 Alzheimer's Disease Facts and Figures," Alzheimer's Association, Alzheimer's \& Dementia, vol. 
15, no. 3 (2019): 17, https://alz.org/media/Documents/ alzheimers-facts-and-figures-2019-r.pdf.

21. Ibid, 23.

22. Ken Sagynbekov, "The Price Women Pay for Dementia: An Update to Projected Prevalence and Costs of Dementia," Milken Institute, (2019).

23. Kevin A. Matthews et al., "Racial and Ethnic Estimates of Alzheimer's Disease and Related Dementias in the United States (2015-2060) in Adults Aged $\geq 65$ Years," Alzheimer's \& Dementia, vol. 15 (2019): 20, https:// doi.org/10.1016/j.jalz.2018.06.3063.

24. "Facts and Figures," Alzheimer's Association, accessed August 24, 2019, https://www.alz.org/alzheimersdementia/facts-figures.

25. Esther M. Friedman et al., "US Prevalence and Predictors of Informal Caregiving for Dementia," Health Affairs, vol. 32, no. 10 (October 2015), https://doi. org/10.1377/hlthaff.2015.0510.

26. "Facts and Figures," Alzheimer's Association, accessed August 24, 2019, https://www.alz.org/alzheimersdementia/facts-figures.

27. Regina A. Shih et al., "Improving Dementia Long-Term Care: A Policy Blueprint," RAND Corporation, (2014), xii, https://www.rand.org/content/dam/rand/pubs/research_ reports/RR500/RR597/RAND_RR597.pdf.

28. "Dementia Caregiving in the US Research Report," National Alliance for Caregiving (February 2017): 8, https://www.caregiving.org/wp-content/ uploads/2014/01/Dementia-Caregiving-in-the-US_ February-2017.pdf.

29. Ibid, 25.

30. Ibid, 35.

31. "Caregiving in the US 2015," AARP Public Policy Institute and National Alliance for Caregiving (June 2015): 52-53, https://www.aarp.org/content/dam/aarp/ ppi/2015/caregiving-in-the-united-states-2015-reportrevised.pdf.
32. "Dementia Caregiving in the US Research Report," National Alliance for Caregiving (February 2017): 8, https://www.caregiving.org/wp-content/ uploads/2014/01/Dementia-Caregiving-in-the-US February-2017.pdf.

33. "Caregiver Statistics: Demographics," Family Caregiver Alliance, National Center on Caregiving, (updated April 17, 2019), https://www.caregiver.org/caregiver-statisticsdemographics.

34. "Caregiving in the U.S. 2015," AARP Public Policy Institute and National Alliance for Caregiving (June 2015), 15, https://www.aarp.org/content/dam/aarp/ppi/2015/ caregiving-in-the-united-states-2015-report-revised.pdf.

35. "Costs of Alzheimer's to Medicare and Medicaid Fact Sheet," Alzheimer's Impact Movement, Alzheimer's Association (March 2019), accessed September 6, 2019, https://act.alz.org/site/DocServer/2012_Costs_Fact_ Sheet_version_2.pdf?docID=7161.

36. "Facts and Figures," Alzheimer's Association, accessed August 24, 2019, https://www.alz.org/alzheimersdementia/facts-figures.

37. Arijita Deb et al., "Direct and Indirect Cost of Managing Alzheimer's Disease and Related Dementias in the Unites States," Expert Review of Pharmacoeconomics \& Outcomes Research, author manuscript, vol. 17, no. 2 (April 2017): 7, https://dx.doi.org/10.1080\% 2F14737167.2017.1313118.

38. Ibid.

39. Ibid.

40. Ibid.

41. Ibid, 7-8.

42. "How to Pay for Nursing Home Care/Convalescent Care," Paying for Senior Care, (updated June 2019), https:// www.payingforseniorcare.com/longtermcare/paying-fornursing-homes.html.

43. Arijita Deb et al., "Direct and Indirect Cost of Managing Alzheimer's Disease and Related Dementias in the Unites States," Expert Review of Pharmacoeconomics 
\& Outcomes Research, author manuscript, vol. 17, no. 2 (April 2017): 8 https://dx.doi.org/10.1080\% 2F14737167.2017.1313118.

44. "2019 Alzheimer's Disease Facts and Figures," Alzheimer's Association, Alzheimer's \& Dementia, vol. 15, no. 3 (2019): 38, https://alz.org/media/Documents/ alzheimers-facts-and-figures-2019-r.pdf.

45. Ken Sagynbekov, "The Price Women Pay for Dementia: An Update to Projected Prevalence and Costs of Dementia," Milken Institute (2019).

46. Chuck Rainville, Laura Skufca, and Laura Mehegan, "Family Caregiving and Out-of-Pocket Costs: 2016 Report," AARP Research (November 2016): 11, https://doi. org/10.26419/res.00138.001.

47. Lynn Feinberg and Rita Choula, "Understanding the Impact of Family Caregiving on Work," AARP Public Policy Institute (October 2012): 2, https://www.aarp. org/content/dam/aarp/research/public_policy_institute/ Itc/2012/understanding-impact-family-caregiving-workAARP-ppi-Itc.pdf.

48. "2019 Alzheimer's Disease Facts and Figures," Alzheimer's Association, Alzheimer's \& Dementia, vol. 15, no. 3 (2019): 32, https://alz.org/media/Documents/ alzheimers-facts-and-figures-2019-r.pdf.

49. "Family Caregivers Spend 20 Percent of Annual Income on Caregiving Expenses," AARP, accessed August 24, 2019, https://press.aarp.org/2016-11-14-FamilyCaregivers-Spend-20-Percent-of-Annual-Income-onCaregiving-Expenses.

50. Shinyi Wu et al., "Latinos \& Alzheimer's Disease: New Numbers Behind the Crisis," USC Edward R. Roybal Institute on Aging and the LatinosAgainstAlzheimer's Network (2016): 12, https://health.ucdavis.edu/ latinoaging/news/pdf/Latinos_and_AD_USC_UsA2Impact-Report.pdf.

51. Ibid.

52. Norma Coe, Meghan Skira, and Eric Larson, "A Comprehensive Measure of the Costs of Caring for a Parent: Differences According to Functional Status," Journal of the American Geriatrics Society, vol. 66
(October 2018): 2005, https://doi.org/10.1111/jgs.15552.

53. Meghan Skira, "Dynamic Wage and Employment Effects of Elder Parent Care," International Economic Review, vol. 56, no. 1 (January 23, 2015): 89, https://doi. org/10.1111/iere.12095.

54. Ibid.

55. Samuel Zuvekas and Gary Olin, "Accuracy of Medicare Expenditures in the Medical Expenditure Panel Survey," Inquiry, vol. 46 (Spring 2009): 93, https://doi. org/10.5034\%2Finquiryjrnl_46.01.92.

56. D. H. Taylor, Jr. et al., "The Accuracy of Medicare Claims as an Epidemiological Tool: The Case of Dementia Revisited," Journal of Alzheimer's Disease, author manuscript, vol. 17, no. 4 (2009): 7, https://doi. org/10.3233/JAD-2009-1099.

57. Ken Sagynbekov, "The Price Women Pay for Dementia: An Update to Projected Prevalence and Costs of Dementia," Milken Institute (2019).

58. Darrell J. Gaskin, Thomas A. LaVeist, and Patrick Richard, "The Costs of Alzheimer's and Other Dementia for African Americans,"

AfricanAmericanNetworkAgainstAlzheimer's (September 2013): 1, https://www.usagainstalzheimers.org/sites/ default/files/USA2_AAN_CostsReport.pdf.

59. Ibid, 2.

60. Ibid.

61. Shinyi Wu et al., "Latinos \& Alzheimer's Disease: New Numbers Behind the Crisis," USC Edward R. Roybal Institute on Aging and the LatinosAgainstAlzheimer's Network (2016): 7, https://www.usagainstalzheimers.org/ sites/default/files/Latinos-and-AD_USC_UsA2-ImpactReport.pdf.

62. Sarah Lenz Lock, "Milken Institute and AARP Roundtable Discussion," July 22, 2019, used with permission.

63. Robert Egge, Interview with Nora Super, (September 11, 2019). Used with permission. 
64. Randall J. Bateman et al., "Clinical and Biomarker Changes in Dominantly Inherited Alzheimer's Disease," New England Journal of Medicine, author manuscript, vol. 367, no. 9 (August 30, 2012): 7, https://www.ncbi.nlm.nih. gov/pmc/articles/PMC3474597/pdf/nihms405217.pdf.

65. Martin Loef and Harald Walach, "Midlife Obesity and Dementia: Meta-Analysis and Adjusted Forecast of Dementia Prevalence in the United States and China," Obesity, vol. 21, no. 1 (January 2013): E54. https://doi. org/10.1002/oby.20037.

66. "A Call for Action: Creating an Optimal System of Brain Health Care in the United States," Anne Tumlinson Innovations, Brain Health Partnership, 4, https://www. usagainstalzheimers.org/sites/default/files/2019-04/ BrainHealthOptimalSystemFINAL.pdf.

67. Gill Livingston et al., "Dementia Prevention, Intervention, and Care," The Lancet Commissions, vol. 390, no. 10113 (December 16, 2017): 2674, https://doi. org/10.1016/S0140-6736(17)31363-6.

68. "2019 Alzheimer's Disease Facts and Figures," Alzheimer's Association, Alzheimer's \& Dementia, vol. 15, no. 3 (2019): 47, https://alz.org/media/Documents/ alzheimers-facts-and-figures-2019-r.pdf.

69. Iliana Lourida et al., "Association of Lifestyle and Genetic Risk with Incidence of Dementia," Journal of the American Medical Association, vol. 322, no. 5 (2019): 434, https://doi.org/10.1001/jama.2019.9879.

70. Silvan Licher et al., "Genetic Predisposition, Modifiable-Risk-Factor Profile and Long-Term Dementia Risk in the General Population," Nature Medicine Letters, vol. 25 (August 26, 2019): 1365, https://doi.org/10.1038/ s41591-019-0547-7.

71. "Effect of Intensive vs. Standard Blood Pressure Control on Probable Dementia: A Randomized Clinical Trial," the SPRINT MIND Investigators for the SPRINT Research Group, JAMA, vol. 321, no. 6 (2019): 559, https://jamanetwork.com/journals/jama/ fullarticle/2723256.
72. Gill Livingston et al., "Dementia Prevention, Intervention, and Care," The Lancet, vol. 390 (December 16, 2017): 2677, https://www.thelancet.com/pdfs/ journals/lancet/PIIS0140-6736(17)31363-6.pdf.

73. "2019 Alzheimer's Disease Facts and Figures," Alzheimer's Association, Alzheimer's \& Dementia, vol. 15, no. 3 (2019): 62-64, https://alz.org/media/Documents/ alzheimers-facts-and-figures-2019-r.pdf.

74. Ibid.

75. Kevin A. Matthews et al., "Racial and Ethnic Estimates of Alzheimer's Disease and Related Dementias in the United States (2015-2060) in Adults Aged $\geq 65$ Years," Alzheimer's \& Dementia, vol. 15 (2019): 20, https:// doi.org/10.1016/j.jalz.2018.06.3063.

76. "Racial and Ethnic Approaches to Community Health (REACH)," National Center for Chronic Disease Prevention and Health Promotion, Centers for Disease Control and Prevention, accessed August 9, 2019, https://www.cdc. gov/chronicdisease/resources/publications/aag/reach. htm.

77. "Healthy Brain Initiative, State and Local Public Health Partnerships to Address Dementia: The 2018-2023 Road Map," Alzheimer's Association and Centers for Disease Control and Prevention, (2018): 16, https://www.cdc.gov/ aging/pdf/2018-2023-Road-Map-508.pdf.

78. "Aetna Foundation, American Public Health Association and the National Association of Counties Unveil Winners of National Health Challenge," Aetna, (February 12, 2019), https://news.aetna.com/newsreleases/2019/02/aetna-foundation-american-publichealth-association-and-the-national-association-ofcounties-unveil-winners-of-national-health-challenge/.

79. "Healthy Brain Initiative, State and Local Public Health Partnerships to Address Dementia: The 2018-2023 Road Map" Alzheimer's Association and Centers for Disease Control and Prevention, (2018): 12, https://www.cdc.gov/ aging/pdf/2018-2023-Road-Map-508.pdf.

80. Ian Kremer, "Milken Institute and AARP Roundtable Discussion," July 22, 2019, used with permission.

81. "2019 Alzheimer's Disease Facts and Figures," Alzheimer's Association, Alzheimer's \& Dementia, vol. 
15, no. 3 (2019): 61, https://alz.org/media/Documents/ alzheimers-facts-and-figures-2019-r.pdf.

82. Ibid, 57.

83. Linda Lang et al., "Prevalence and Determinants of Undetected Dementia in the Community: A Systematic Literature Review and a Meta-Analysis," BMJ Open, vol. 7, no. 2 (2017): 3-4, https://bmjopen.bmj.com/content/ bmjopen/7/2/e011146.full.pdf.

84. Andrea Bradford et al., "Missed and Delayed Diagnosis of Dementia in Primary Care: Prevalence and Contributing Factors," Alzheimer's Disease \& Associated Disorders, author manuscript, vol. 23, no. 4 (October-December 2009): 6, https://www.ncbi.nlm.nih.gov/pmc/articles/ PMC2787842/pdf/nihms127304.pdf.

\section{Alzheimer's Association, "2019 Alzheimer's Disease} Facts and Figures," Alzheimer's Association, Alzheimer's \& Dementia, vol. 15, no. 3 (2019): 61, https://alz.org/media/ Documents/alzheimers-facts-and-figures-2019-r.pdf.

86. Ibid.

87. Richard J. Kryscio et al., "Self-Reported Memory Complaints: Implications from a Longitudinal Cohort with Autopsies," Neurology, vol. 83 (2014): 1361-63, https:// doi.org/10.1212/WNL.0000000000000856.

88. "2019 Alzheimer's Disease Facts and Figures," Alzheimer's Association, Alzheimer's \& Dementia, vol. 15, no. 3 (2019): 6, https://alz.org/media/Documents/ alzheimers-facts-and-figures-2019-r.pdf.

89. Weizhou Tang et al., "Concern About Developing Alzheimer's Disease or Dementia and Intention to be Screened: An Analysis of National Survey Data," Archives of Gerontology and Geriatrics, vol. 71 (July 2017): 2, https://doi.org/10.1016/j.archger.2017.02.013.

90. Claudia Cooper et al., "A Systematic Review and Meta-Analysis of Ethnic Differences in Use of Dementia Treatment, Care, and Research," The American Journal of Geriatric Psychiatry, vol. 18, no. 3 (March 2010): 197-98, https://doi.org/10.1097/JGP.0b013e3181bf9caf.

91. Miriam Goudsmit et al., "One Size Does Not Fit All: Comparative Diagnostic Accuracy of the Rowland
Universal Dementia Assessment Scale and the MiniMental State Examination in a Memory Clinic Population with Very Low Education," Dementia and Geriatric Cognitive Disorders Extra, vol. 8, no. 2 (May-August 2018): 301-302, https://doi.org/10.1159/000490174. 92. Ibid, 291.

93. Ishali Ganguli et al., "Practices Caring for the Underserved Are Less Likely to Adopt Medicare's Annual Wellness Visit," Health Affairs, author manuscript, vol. 37, no. 2 (February 2018): 5-6, https://doi.org/10.1377/ hlthaff.2017.1130.

94. "Creating an Optimal System of Brain Health Care in the United States," Anne Tumlinson Innovations, Brain Health Partnership, 12, https://annetumlinsoninnovations. com/wp-content/uploads/2019/05/ BrainHealthOptimalSystemFINAL.pdf.

95. George Vradenburg, "Milken Institute and AARP Roundtable Discussion," (July 22, 2019), used with permission.

96. William Perry et al., "Population Health Solutions for Assessing Cognitive Impairment in Geriatric Patients," Innovations in Aging, vol. 2, no. 2 (2018): 3, https://doi.org /10.1080/13854046.2018.1517503.

97. Kate Gordon et al., "IDD and Dementia: Report," (Washington, D.C.: RTI International, July 2015): 9, http:// resource.nlm.nih.gov/101673149.

98. Gretchen Jacobson et al., "A Dozen Facts About Medicare Advantage in 2019," accessed August 13, 2019 , https://www.kff.org/medicare/issue-brief/a-dozen-factsabout-medicare-advantage-in-2019/.

99. "Cognitive Impairment in Older Adults: Screening," Final Recommendation Statement, US Preventive Task Force, accessed August, 16, 2019, https://www. uspreventiveservicestaskforce.org/Page/Document/ RecommendationStatementFinal/cognitive-impairment-inolder-adults-screening.

100. Norman L. Foster et al., "Quality Improvement in Neurology: Mild Cognitive Impairment Quality Measurement Set,"Neurology, special article (September 18, 2019): 3-4, https://doi.org/10.1212/ WNL.0000000000008259. 
101. Howard Fillit, "Milken Institute and AARP Roundtable Discussion," (July 22, 2019), used with permission.

102. Judy George, "Primary Care Tests Flunk for Classifying Dementia," MedPage Today, accessed August 16, 2019, https://www.medpagetoday.com/neurology/ dementia/76629.

103. "Scientists Close in on Blood Test for Alzheimer's," Associated Press, (July 15, 2019), https://statnews. com/2019/07/15/scientists-close-in-on-blood-testalzheimers/.

104. "Diagnostics Accelerator Fast-Tracking Better Tests for Alzheimer's," accessed September 26, 2019, https:// www.alzdiscovery.org/research-and-grants/diagnosticsaccelerator.

105. Elysium Health, "Do Clinical Trials Have a Sex Problem?" Endpoints, (May 18, 2018), https://endpoints. elysiumhealth.com/why-women-are-underrepresented-inclinical-trials-398c9e0735a.

106. "RCDC Inclusion Statistics Report," NIH, accessed August 22, 2019, https://report.nih.gov/risr/\#/.

107. Ibid.

108. Irving E. Vega et al., "Alzheimer's Disease in the Latino Community: Intersection of Genetics and Social Determinants of Health," Journal of Alzheimer's Disease, author manuscript, vol. 58, no. 4 (2017): 2, https://doi.org/10.3233/JAD-161261.

109. "WomenAgainstAlzheimer's: Overview," UsAgainstAlzheimer's, accessed August 16, 2019, https://www.usagainstalzheimers.org/sites/default/ files/2018-02/WA2_Fact_Sheet.PDF.

110. Tamar Heller et al., "Caregiving and Intellectual and Developmental Disabilities and Dementia: Report of the Pre-Summit Workgroup on Caregiving and Intellectual and Developmental Disabilities," Research Summit on Dementia Care, (August 2017): 7, https://aspe.hhs.gov/ system/files/pdf/257461/IDD\%20PreSummit.pdf.
111. "Together We Make the Difference: National Strategy for Recruitment and Participation in Alzheimer's and Related Dementias Clinical Research," NIH (October 2018): 4, https://www.nia.nih.gov/sites/default/ files/2018-10/alzheimers-disease-recruitment-strategyfinal.pdf.

112. Jennifer L. Watson et al., "Obstacles and Opportunities in Alzheimer's Clinical Trial Recruitment," Health Affairs, vol. 33, no. 4 (April 2014): 574, https://www.healthaffairs.org/doi/pdf/10.1377/ hlthaff.2013.1314.

113. Luther T. Clark et al., "Increasing Diversity in Clinical Trials: Overcoming Critical Barriers," Current Problems in Cardiology, vol. 44, no. 5 (May 2019): 149, https://doi. org/10.1016/j.cpcardiol.2018.11.002.

114. Caroline Chen and Riley Wong, "Black Patients Miss Out On Promising Cancer Drugs," Pro Publica, September 19, 2018, https://www.propublica.org/article/blackpatients-miss-out-on-promising-cancer-drugs.

\section{Susan Pascal, "WAM and AARP Convene Top} Alzheimer's Experts for an Unprecedented Event," (July 31, 2019), https://thewomensalzheimersmovement.org/wamaarp-convene-top-alheimers-experts-for-unprecendentedevent/.

116. Ibid.

117. "Alzheimer's and Dementia Research," Alzheimer's Impact Movement, accessed August 13, 2019, https:// alzimpact.org/issues/research.

118. Susan Pascal, "WAM and AARP Convene Top Alzheimer's Experts for an Unprecedented Event," (July 31, 2019), https://thewomensalzheimersmovement.org/wamaarp-convene-top-alheimers-experts-for-unprecendentedevent/.

119. Kelsey Herbers, "How Proteins Spread Linked to Alzheimer's Disease Sex Differences," Vandervilt University Medical Center Reporter, (July 18, 2019), http://news.vumc. org/2019/07/18/alzheimers-disease-sex-differences/.

120. Erin E. Sundermann et al., "Better Verbal Memory in Women than Men in $\mathrm{MCl}$ Despite Similar Levels of Hippocampal Atrophy," Neuorology, vol. 86, no. 
15 (April 12, 2016): 1371, https://doi.org/10.1212/ WNL.0000000000002570.

121. Carolyn M. Mazure and Daniel P. Jones, "Twenty Years and Still Counting: Including Women as Participants and Studying Sex and Gender in Biomedical Research," BMC Women's Health, vol. 15, no. 94 (2015): 6, https:// doi.org/10.1186/s12905-015-0251-9.

122. David Wendler et al., "Are Racial and Ethnic Minorities Less Willing to Participate in Health Research?" PLoS Medicine, vol. 3, no. 2 (February 2006): 205, https:// dx.doi.org/10.1371\%2Fjournal.pmed.0030019.

123. Joshua D. Grill and James E. Galvin, "Facilitating Alzheimer's Disease Research Recruitment," Alzheimer's Disease and Associated Disorders, author manuscript, vol. 28, no. 1 (January-March 2014): 5, https://dx.doi. org/10.1097\%2FWAD.0000000000000016.

124. "Together We Make the Difference: National Strategy for Recruitment and Participation in Alzheimer's and Related Dementias Clinical Research," NIH (October 2018): 6, https://www.nia.nih.gov/sites/default/ files/2018-10/alzheimers-disease-recruitment-strategyfinal.pdf.

125. "About the All of Us Research Program," NIH, accessed August 16, 2019, https://allofus.nih.gov/about/ about-all-us-research-program.

126. James Davis et al., "Prevalence of Single and Multiple Leading Causes of Death by Race/Ethnicity Among People Aged 60 to 70 Years," Preventing Chronic Disease, vol. 14, no. 101 (October 2017): 3, http://dx.doi.org/10.5888/ pcd14.160241.

127. Teresa Jenica Filshtein et al., "Neuropathological Diagnoses of Demented Hispanic, Black, and NonHispanic White Decedents Seen at an Alzheimer's Disease Center," Journal of Alzheimer's Disease, vol. 68, no. 1 (2019): 146, https://doi.org/10.3233/JAD-180992.

128. Ibid.

129. Holly Massett, "Milken Institute and AARP Roundtable Discussion," (July 22, 2019), used with permission.
130. Robert M. Califf et al., "Discussion Paper: The Clinical Trials Enterprise in the United States: A Call for Disruptive Innovation," Envisioning a Transformed Clinical Trials Enterprise in the United States: Establishing An Agenda for 2020: Workshop Summary, 135, https://www.ncbi.nlm. nih.gov/books/NBK114657/.

131. "About NCORP," National Cancer Institute Community Oncology Research Program (NCORP), accessed August 16, 2019, https://ncorp.cancer.gov/ about/.

132. "About NCORP," National Cancer Institute Community Oncology Research Program (NCORP), accessed August 16, 2019, https://ncorp.cancer.gov/ about/.

133. Holly Massett, "Milken Institute and AARP Roundtable Discussion," (July 22, 2019), used with permission.

134. Jennifer Ann Zimmer, "Milken Institute and AARP Roundtable Discussion," (July 22, 2019), used with permission.

135. Holly Massett, "Milken Institute and AARP Roundtable Discussion," (July 22, 2019), used with permission.

136. Robyn Stone, "Milken Institute and AARP Roundtable Discussion," (July 22, 2019), used with permission.

137. Ashley Tointon, "The Issue of Patient Retention in Clinical Trials," CenterWatch News Online, (June 27, 2016), https://www.centerwatch.com/news-online/2016/06/27/ issue-patient-retention-clinical-trials/.

138. Karen Love, "Milken Institute and AARP Roundtable Discussion," (July 22, 2019), used with permission.

139. Michelle M. Mello, B.S. Can Lieou, and Steven N. Goodman, "Clinical Trial Participants' Views of the Risks and Benefits of Data Sharing," New England Journal of Medicine, vol. 378, no. 23 (June 7, 2018): 2205, https:// www.nejm.org/doi/full/10.1056/NEJMsa1713258\#. WxhZTCw1iVU.

140. Sarah Lenz Lock, email exchange with Nora Super on September 23, 2019, used with permission. 
141. Jeffrey Cummings et al., "Alzheimer's Disease Drug Development Pipeline: 2019," Alzheimer's \& Dementia: Translational Research \& Clinical Interventions, vol. 5 (2019): 272, https://doi.org/10.1016/j.trci.2019.05.008.

142. Fiona Clague et al., "Comorbidity and Polypharmacy in People with Dementia: Insights from a Large, Population-Based Cross-Sectional Analysis of Primary Care Data," Age and Ageing, vol. 46, no. 1 (January 2017): 34, https://doi.org/10.1093/ageing/afw176.

143. Gregg A. Warshaw and Elizabeth J. Bragg, "Preparing The Health Care Workforce to Care For Adults With Alzheimer's Disease And Related Dementias," Health Affairs, vol. 33, no. 4 (2014): 635-637, https://www. healthaffairs.org/doi/full/10.1377/hlthaff.2013.1232.

144. "Projected Future Need for Geriatricians," The American Geriatrics Society, (updated February 2017), https://www.americangeriatrics.org/sites/default/files/ inline-files/Projected-Future-Need-for-Geriatricians_1.pdf.

145. "Current Geriatrician Shortfall," The American Geriatrics Society, (updated February 2017), https://www. americangeriatrics.org/sites/default/files/inline-files/ Current-Geriatrician-Shortfall_0.pdf.

146. "2015 White House Conference on Aging Final Report," The White House, (2015): 7, https:// whitehouseconferenceonaging.gov/2015-whcoa-finalreport.pdf.

147. "Geriatrics Workforce Enhancement Program," US Department of Health and Human Services, Health Resources and Services Administration, accessed September 13, 2019, https://bhw.hrsa.gov/ fundingopportunities/default.aspx?id=4c8ee9ff-617a495e-ae78-917847db86a9.

148. Joan Weiss, "Milken Institute and AARP Roundtable Discussion," (July 22, 2019), used with permission.

149. Jennifer Jurado Severance and Janie Knebl, "Developing the Workforce the Country Needs Through Geriatric Workforce Enhancement Programs," Health Affairs Blog, (August 30, 2019), https://www.healthaffairs. org/do/10.1377/hblog20190827.453632/full/.

150. Senator Susan Collins, interview via email by Nora
Super, (September 13, 2019), used with permission.

151. Terry Fulmer and Nanxing Li, "Age-Friendly Health Systems for Older Adults With Dementia," The Journal for Nurse Practitioners, vol. 14, no. 3 (March 2018): 161, https://doi.org/10.1016/j.nurpra.2017.09.001.

152. "Costs of Alzheimer's to Medicare and Medicaid Fact Sheet," Alzheimer's Impact Movement, Alzheimer's Association (March 2019), accessed September 6, 2019, https://act.alz.org/site/DocServer/2012_Costs_Fact_ Sheet_version_2.pdf?doclD=7161.

153. Pei-Jung Lin et al., "Potentially Avoidable Hospitalizations Among Medicare Beneficiaries with Alzheimer's Disease and Related Disorders," Alzheimer's and Dementia, vol. 9 (2013): 36, https://doi.org/10.1016/j. jalz.2012.11.002.

154. "2019 Alzheimer's Disease Facts and Figures," Alzheimer's Association, Alzheimer's \& Dementia, vol. 15, no. 3 (2019): 55, https://alz.org/media/Documents/ alzheimers-facts-and-figures-2019-r.pdf.

155. Marya Zilberberg and Jennifer Tjia, "Growth in Dementia-Associated Hospitalizations Among the Oldest Old in the United States: Implications for Ethical Health Services Planning," Archive of Internal Medicine, published letter, vol. 171, no. 20 (November 14, 2011): 1850, https://doi.org/10.1001/archinternmed.2011.503.

156. Terry Fulmer and Nanxing Li, "Age-Friendly Health Systems for Older Adults With Dementia," The Journal for Nurse Practitioners, vol. 14, no. 3 (March 2018): 161, https://doi.org/10.1016/j.nurpra.2017.09.001.

157. Terry Fulmer, "Making Dementia Caregiving Support More Available To Those Who Need It," HuffPost, (March 23, 2017), https://www.huffpost.com/entry/ making-dementia-caregiving-support-more-availableto_b_58d166f7e4b0e0d348b34857.

158. Terry Fulmer and Nanxing Li, "Age-Friendly Health Systems for Older Adults with Dementia," The Journal for Nurse Practitioners, vol. 14, no. 3 (March 2018): 163, https://doi.org/10.1016/j.nurpra.2017.09.001.

159. Terry Fulmer, "Milken Institute and AARP Roundtable Discussion," (July 22, 2019), used with permission. 
160. Michael Lepore, Abby Ferrell, and Joshua M. Wiener, "Living Arrangements of People with Alzheimer's Disease and Related Dementias: Implications for Services and Supports," (October 2017): 1, https://aspe.hhs.gov/system/ files/pdf/257966/LivingArran.pdf.

161. Allison Cook, "Home Care Worker Training and People with Alzheimer's Disease and Related Dementias: Ideas for State Policymakers," PHI National, (November 2017), 2, https://phinational.org/wp-content/ uploads/2017/11/Home-Care-Workers-and-AlzheimersPHI-Nov-2017.pdf.

162. "Long-Term Services and Supports: Direct Care Worker Demand Projections, 2015-2030," US Department of Health and Human Services, Health Resources and Services Administration, National Center for Health Workforce Analysis (March 2018): 4, https://bhw.hrsa. gov/sites/default/files/bhw/nchwa/projections/hrsa-lttsdirect-care-worker-report.pdf.

163. Yash M. Patel et al., "Proportion of Non-US-Born and Noncitizen Health Care Professionals in the United States in 2016," Journal of the American Medical Association, vol. 320, no. 21 (December 4, 2018): 2266, https://doi. org/10.1001/jama.2018.14270.

164. Gregg A. Warshaw and Elizabeth J. Bragg, "Preparing the Health Care Workforce to Care for Adults With Alzheimer's Disease and Related Dementias," Health Affairs, vol. 33, no. 4 (2014), https://www.healthaffairs. org/doi/full/10.1377/hlthaff.2013.1232.

165. "Medicare and Medicaid Programs: Reform of Requirements for Long-Term Care Facilities," CMS, Federal Register, (October 4, 2016), 68819, https://www.govinfo. gov/content/pkg/FR-2016-10-04/pdf/2016-23503.pdf.

166. Allison Cook, "Home Care Worker Training and People with Alzheimer's Disease and Related Dementias: Ideas for State Policymakers," PHI National (November 2017): 4, https://phinational.org/wp-content/ uploads/2017/11/Home-Care-Workers-and-AlzheimersPHI-Nov-2017.pdf.

167. "Occupational Outlook Handbook," Healthcare Occupations, Bureau of Labor Statistics, (updated April 12, 2019), https://www.bls.gov/ooh/healthcare/.
168. "Medicaid Home and Community-Based Services: Selected States' Program Structures and Challenges Providing Services," Government Accountability Office Report to the Ranking Member, Committee on Finance, US Senate, (August 2018), https://www.gao.gov/ assets/700/694174.pdf.

169. Stephen Campbell, "US Home Care Workers: Key Facts (2018)," PHI National, (August 31, 2018), 6, https:// phinational.org/resource/u-s-home-care-workers-keyfacts-2018/.

170. "2017 National Population Projections Tables," US Census Bureau, (updated September 6, 2018), https:// census.gov/data/tables/2017/demo/popproj/2017summary-tables.html.

171. Kevin A. Matthews et al., "Racial and Ethnic Estimates of Alzheimer's Disease and Related Dementias in the United States (2015-2060) in Adults Aged $\geq 65$ years," Alzheimer's \& Dementia, vol. 15, no. 1 (January 2019): 20, https://www.alzheimersanddementia.com/article/S15525260(18)33252-7/fulltext.

172. Rachel L. Peterson et al., "State Inequality, Socioeconomic Position and Subjective Cognitive Decline in the United States," SSM - Population Health, vol. 7 (April 2019): 5, https://doi.org/10.1016/j. ssmph.2019.100357.

173. Jane Tilly, Joshua Wiener, and Elizabeth Gold, "Dementia-Capable States and Communities: the Basics," Administration for Community Living (2014): 10, https:// acl.gov/sites/default/files/triage/BH-Brief-DementiaCapable-Basics.pdf.

174. "Recognizing the Role of Diversity in Dementia Care," Bureau of Health Workforce, PowerPoint Presentation, (updated July 2019), https://bhw.hrsa.gov/sites/default/ files/bhw/grants/geriatrics/module-3-role-of-diversity-indementia-care.pptx.

175. "Diversity and Cultural Competency," Strengthening the Aging and Disability Networks, Administration for Community Living, (updated April 8, 2019), https://acl.gov/ programs/strengthening-aging-and-disability-networks/ diversity-and-cultural-competency.

176. Erin Long, "Milken Institute and AARP Roundtable 
Discussion," (July 22, 2019), used with permission.

177. "Achieving High-Quality Multicultural Geriatric Care," American Geriatrics Society Ethnogeriatrics Committee, Journal of the American Geriatrics Society, special article, vol. 64, no. 2 (February 2016): 256-57, https:// onlinelibrary.wiley.com/doi/full/10.1111/jgs.13924.

178. Anna M. Nápoles et al., "Reviews: Developing Culturally Sensitive Dementia Caregiver Interventions: Are We There Yet?" American Journal of Alzheimer's Disease $\&$ Other Dementias, author manuscript, vol. 25 , no. 5 (August 2010): 6-7, https://journals.sagepub.com/doi/ abs/10.1177/1533317510370957.

179. Christopher Shanley et al., "A Qualitative Study into the Use of Formal Services for Dementia by Carers from Culturally and Linguistically Diverse (CALD) Communities," BMC Health Services Research, vol. 12, no. 354 (2012): 8, https://doi.org/10.1186/1472-6963-12-354.

180. "Alzheimer's Disease Programs Initiative - Grants to States and Communities," Administration for Community Living, (modified August 28, 2019), https://acl.gov/grants/ alzheimers-disease-programs-initiative-grants-states-andcommunities-0.

181. Susan C. Reinhard et al., "Home Alone Revisited: Family Caregivers Providing Complex Care," AARP Foundation and the John A. Hartford Foundation, (April 2019): 27, https://www.aarp.org/content/dam/aarp/ ppi/2019/04/home-alone-revisited-family-caregiversproviding-complex-care.pdf.

182. "Help for Alzheimer's Families," Home Instead Senior Care, accessed August 20, 2019, https://www. helpforalzheimersfamilies.com/.

183. "Emerging Technologies to Support an Aging Population," Task Force on Research and Development for Technology to Support Aging Adults, National Science and Technology Council (March 2019): 2, https://www. whitehouse.gov/wp-content/uploads/2019/03/EmergingTech-to-Support-Aging-2019.pdf.
184. Suryatapa Bhattacharya, "In Fast-Aging Japan, Elder Care Is a High-Tech Pursuit," The Wall Street Journal, (January 12, 2019), https://www.wsj.com/ articles/in-fast-aging-japan-elder-care-is-a-high-techpursuit-11547298000.

185. Laura Petrecca, "Technology is Transforming Caregiving," AARP, (October 15, 2018), https://www. aarp.org/caregiving/home-care/info-2018/new-wave-ofcaregiving-technology.html.

186. Joseph Coughlin, "Caregiver Crunch? No Problem, This Is How Tech-Savvy Millennials Will Care for Aging Baby Boomers," Forbes, (May 21, 2018), https://www. forbes.com/sites/josephcoughlin/2018/05/21/caregivercrunch-no-problem-this-is-how-tech-savvy-millennialswill-care-for-aging-baby-boomers/.

187. Malcolm Foster, "Aging Japan: Robots May Have Role in Future of Elder Care," Reuters, (March 27, 2018), https://www.reuters.com/article/us-japan-ageing-robotswiderimage/aging-japan-robots-may-have-role-in-futureof-elder-care-idUSKBN1H33AB.

188. Chris Farrell, "Danger Ahead: Privacy Concerns with High-Tech Caregiving Devices," Next Avenue, (May 30, 2019), https://www.nextavenue.org/privacy-concernshigh-tech-caregiving-devices/.

189. Arielle Burstein et al., "Dementia Caregivers and Technology Acceptance: Interest Outstrips Awareness," Gerontechnology, vol. 14, no. 1 (2015): 54, https://doi. org/10.4017/gt.2015.14.1.005.00.

190. R. John Sawyer, "Value-Based Care Must Strengthen Focus on Chronic Illnesses," NEJM Catalyst, (November 6, 2018): 1, https://catalyst.nejm.org/value-basedstrengthen-dementia-care/.

191. Jennie Chin Hansen and Joanne Handy, "Transforming Emergency Care for Persons with Dementia," The Ray and Dagmar Dolby Fund (September 2018): 2.

192. "ACEP Geriatric Emergency Department Accreditation," American College of Emergency Physicians, accessed August 20, 2019, https://www.acep.org/geda/. 
193. Jennie Chin Hansen and Joanne Handy,

"Transforming Emergency Care for Persons with

Dementia," The Ray and Dagmar Dolby Fund (September 2018): 4-5.

194. Ibid, 11.

195. "HHS Launches Innovative Payment Model with New Treatment and Transport Options to More Appropriately and Effectively Meet Beneficiaries' Emergency Needs," CMS.gov, (February 14, 2019), https://www.cms.gov/ newsroom/press-releases/hhs-launches-innovativepayment-model-new-treatment-and-transport-optionsmore-appropriately-and.

196. Malaz Boustani et al., "An Alternative Payment Model to Support Widespread Use of Collaborative Dementia Care Models," Health Affairs, vol. 38, no. 1 (January 2019): 56, https://doi.org/10.1377/hlthaff.2018.05154.

197. Debra Cherry, Lora Connolly, and Katie Scott, "Improving Health Care for People Living with Dementia," PowerPoint presentation, accessed August 30, 2019, https://nadrc.acl.gov/sites/default/files/uploads/docs/ ImprovingHealthcareforPLWD_508.pdf.

198. Kristin Lees Haggerty et al., "Primary Care Innovations Can Improve Alzheimer's and Dementia Care for Patients, Family Caregivers, and Providers," Health Affairs Blog, March 29, 2019, https://www.healthaffairs. org/do/10.1377/hblog20190327.432411/full/.

199. Ibid.

200. "2019 Alzheimer's Disease Facts and Figures," Alzheimer's Association, 47, https://www.alz.org/media/ Documents/alzheimers-facts-and-figures-2019-r.pdf.

201. Lisa M. Lines, Noha A. Sherif, and Joshua M. Wiener, "Racial and Ethnic Disparities Among Individuals with Alzheimer's Disease in the United States: A Literature Review," RTI Press (December 2014): 7, http://dx.doi. org/10.3768/rtipress.2014.RR.0024.1412.

202. Elizabeth H. Bradley, "Variation In Health Outcomes: The Role Of Spending On Social Services, Public Health, And Health Care, 2000-09," Health Affairs, vol. 35, no. 5 (May 2016), https://doi.org/10.1377/hlthaff.2015.0814.
203. Julianne Holt-Lunstad, "Loneliness and Social Isolation as Risk Factors for Mortality: A Meta-Analytic Review," Perspectives on Psychological Science, (March 2015), https://doi.org/10.1177/1745691614568352.

204. "NADRC Webinar: Addressing Social Isolation and Loneliness Among People Living with Dementia," Administration for Community Living, updated June 6, 2019, https://acl.gov/news-and-events/announcements/ nadrc-webinar-addressing-social-isolation-and-lonelinessamong-people.

205. 'Caring for People with Dementia: Caregivers' Experiences," AARP, accessed August 29, 2019: 6-14, https://doi.org/10.26419/res.00262.001.

206. "Stages of Alzheimer's," Alzheimer's Association, accessed August 30, 2019: 1, https://alz.org/alzheimersdementia/stages.

207. Becca R. Levy et al., "Longevity Increased by Positive Self-Perceptions of Aging," Attitudes and Social Cognition, (2002): 268, https://psycnet.apa.org/doi/10.1037/00223514.83.2.261.

208. "Have a Sense of Purpose in Life? It May Protect Your Heart," Mount Sinai Medical Center, ScienceDaily, (March 6, 2015), http://www.sciencedaily.com/ releases/2015/03/150306132538.htm.

209. Wingyun Mak, "Self-Reported Goal Pursuit and Purpose in Life Among People with Dementia," Journals of Gerontology, vol. 66B, no. 2 (March 2011): 181-182, https://doi.org/10.1093/geronb/gbq092.

210. Simon Chester Evans, "Ageism and Dementia," International International Perspectives on Aging, vol. 19 (May 2018), https://link.springer.com/chapter/10.1007/978-3-319-73820-8_16.

211. "Overcoming Stigma," Alzheimer's Association, accessed on August 30, 2019: 1, https://alz.org/helpsupport/i-have-alz/overcoming-stigma. 
212. Shana Stites, Jonathan Rubright, and Jason Karlawish, "What Features of Stigma Do the Public Most Commonly Attribute to Alzheimer's Disease Dementia? Results of a Survey of the US General Public," Alzheimer's \& Dementia, author manuscript, vol. 14, no. 7 (July 2018): 1, https://doi. org/10.1016/j.jalz.2018.01.006.

213. "Living Well with Dementia in the Community: Resources and Support," Eldercare Locator, National Association of Area Agencies on Aging (2017), https:// eldercare.acl.gov/Public/Resources/Brochures/docs/ Living\%20Well\%20with\%20Dementia\%20in\%20the\%20 Community.pdf.

214. Patricia A. Boyle et al., "Scam Awareness Related to Incident Alzheimer Dementia and Mild Cognitive Impairment: A Prospective Cohort Study," Rush Alzheimer's Disease Center at Rush University, vol. 170, no. 10 (May 2019): 707, https://doi.org/10.7326/M182711.

215. "Managing Money Problems in Alzheimer's Disease," National Institute on Aging, accessed September 6, 2019, https://www.nia.nih.gov/health/managing-moneyproblems-alzheimers-disease.

216. Judy George, "Alzheimer's Dementia Predicted by Low 'Scam Awareness'," MedPage Today, (April 15, 2019), https://www.medpagetoday.com/neurology/ alzheimersdisease/79248.

217. Mark S. Lachs and Karl Pillemer, "Elder Abuse," The Lancet (October 2004), https://doi.org/10.1016/S01406736(04)17144-4.

218. "Consumer Financial Protection Bureau Recommends Financial Institutions Report Suspected Financial Exploitation of Older Adults," Consumer Financial Protection Bureau, (July 17, 2019), https://www. consumerfinance.gov/about-us/newsroom/bureaurecommends-financial-institutions-report-suspectedfinancial-exploitation-older-adults/.

219. Ibid.

220. "What We Do," EverSafe, accessed September 6, 2019, https://www.eversafe.com/.
221. Sue Sveum, "Dementia-Friendly Cities Prepare for an Aging Populace," CityLab, (May 3, 2019), https://www. citylab.com/life/2019/05/aging-dementia-friendly-babyboomer-denver/588406/.

222. "What is DFA," Dementia Friendly America, accessed August 29, 2019, https://www.dfamerica.org/what-is-dfa.

223. "Public Health Spotlight: Dementia-Friendly Communities," Alzheimer's Association, (September 2016), https://www.alz.org/media/Documents/spotlightdementia-friendly-communities.pdf.

224. "DFA Communities," Dementia Friendly America, accessed August 29, 2019, https://www.dfamerica.org/ dfa-communities.

225. "2019 Alzheimer's Disease Facts and Figures," Alzheimer's Association: 31, https://www.alz.org/media/ Documents/alzheimers-facts-and-figures-2019-r.pdf.

226. Ibid

227. Stephanie Monroe, Mary Bissell, and Tiffany Allen, "A New Frontier in Paid Leave: Supporting Family Caregivers Providing Alzheimer's and Dementia Care," USAgainstAlzheimer's (September 2018): 5, https://www. usagainstalzheimers.org/sites/default/files/2018-09/A_ New_Frontier_In_Paid_Leave.pdf.

228. Ibid, 4.

229. "2019 Alzheimer's Disease Facts and Figures," Alzheimer's Association: 31, https://www.alz.org/media/ Documents/alzheimers-facts-and-figures-2019-r.pdf.

230. Jisella Dolan, "Milken Institute and AARP Roundtable Discussion," (July 22, 2019), used with permission.

231. "Caring for People with Dementia: Caregivers' Experiences," AARP, accessed August 29, 2019, 3, https:// doi.org/10.26419/res.00262.001.

232. Grace Whiting, "Milken Institute and AARP Roundtable Discussion," (July 22, 2019), used with permission.

233. Meryl Comer, "Milken Institute and AARP Roundtable Discussion," (July 22, 2019), used with permission. 
234. "The Journey of Caregiving: Honor, Responsibility and Financial Complexity," Merrill Lynch and Age Wave (October 2017): 23, https://www.ml.com/financial-goalsand-priorities/caregiver-benefits-challenges.html.

235. Lorna Sabbia, interview via email by Nora Super, (September 7, 2019), used with permission.

236. "State Paid Family and Medical Leave Insurance Laws," National Partnership for Women and Families (August 2019), http://www.nationalpartnership.org/ourwork/resources/workplace/paid-leave/state-paid-familyleave-laws.pdf.

237. William A. Vega, Maria P. Aranda, and Francisca S. Rodriguez, "Millennials and Dementia Caregiving in the United States," YouthAgainstAlzheimer's (2017): 3, https://www.usagainstalzheimers.org/sites/default/files/ Dementia\%20Caregiver\%20Report_Final.pdf.

238. Stephanie Monroe, Mary Bissell, and Tiffany Allen, "A New Frontier in Paid Leave: Supporting Family Caregivers Providing Alzheimer's and Dementia Care," UsAgainstAlzheimer's (September 2018): 4-5, https:// www.usagainstalzheimers.org/sites/default/files/201809/A_New_Frontier_In_Paid_Leave.pdf.

239. Howard Gleckman, "Will Paid Leave for Family Caregivers Catch on In the US," Forbes, (September 5, 2018), https://www.forbes.com/sites/ howardgleckman/2018/09/05/will-paid-leave-for-familycaregivers-catch-on-in-the-us/\#4b8499c8110a.

240. Lynn Friss Feinberg, "Breaking New Ground: Supporting Employed Family Caregivers with Workplace Leave Policies," AARP Public Policy Institute (September 2018), https://www.aarp.org/content/dam/aarp/ ppi/2018/08/breaking-new-ground-supportingemployed-family-caregivers-with-workplace-leavepolicies.pdf.

241. Stephanie Monroe, Mary Bissell, and Tiffany Allen, "A New Frontier in Paid Leave: Supporting Family Caregivers Providing Alzheimer's and Dementia Care," USAgainstAlzheimer's (September 2018): 7, https://www. usagainstalzheimers.org/sites/default/files/2018-09/A_ New_Frontier_In_Paid_Leave.pdf.

242. Ibid, 3.
243. "US Department of Veterans Affairs Announces Formation of New Veterans' Family, Caregiver, and Survivor Advisory Committee; Names Senator Elizabeth Dole Chair," US Department of Veterans Affairs, https://www.va.gov/ADVISORY/docs/PressReleaseVeteransFamilyMembership.pdf.

244. Jason Resendez, "Milken Institute and AARP Roundtable Discussion," (July 22, 2019), used with permission.

245. Stephanie Monroe, Mary Bissell, and Tiffany Allen, "A New Frontier in Paid Leave: Supporting Family Caregivers Providing Alzheimer's and Dementia Care," UsAgainstAlzheimer's (September 2018): 3-7, https:// www.usagainstalzheimers.org/sites/default/files/201809/A_New_Frontier_In_Paid_Leave.pdf.

246. Janet Walsh, "Dementia and Caregiving in the US: Time for Paid Family Leave," Human Rights Watch, (February 8, 2019), https://www.hrw.org/ news/2019/02/08/dementia-and-caregiving-us-timepaid-family-leave.

247. "Caregiving in the US 2015," National Alliance for Caregiving and AARP Public Policy Institute, (June 2015): 61, http://www.caregiving.org/wp-content/ uploads/2015/05/2015_CaregivingintheUS_Final-ReportJune-4_WEB.pdf.

248. "The Aging of the Baby Boom and the Growing Care Gap: A Look at Future Declines in the Availability of Family Caregivers," AARP Public Policy Institute (2013): 1, https:// www.aarp.org/content/dam/aarp/research/public_policy_ institute/Itc/2013/baby-boom-and-the-growing-caregap-in-brief-AARP-ppi-Itc.pdf.

249. "Paid Family and Medical Leave: By the Numbers," The Women's Initiative, Center for American Progress, (September 27, 2017), https://www.americanprogress.org/ issues/women/reports/2017/09/27/439527/paid-familymedical-leave-numbers/.

250. Lynn Friss Feinberg, "Breaking New Ground: Supporting Employed Family Caregivers with Workplace Leave Policies," AARP Public Policy Institute, (September 4, 2018), 12, https://www.aarp.org/ppi/info-2018/breakingnew-ground-supporting-employed-family-caregiverswith-workplace-leave-policies.html. 
SUPPORTING ORGANIZATIONS

$$
{ }_{\text {Real Possibilities }}
$$

BANK OFAMERICA Biogen

A. BrightFocus $^{\circledR}$

Cure in Mind. Cure in Sight.
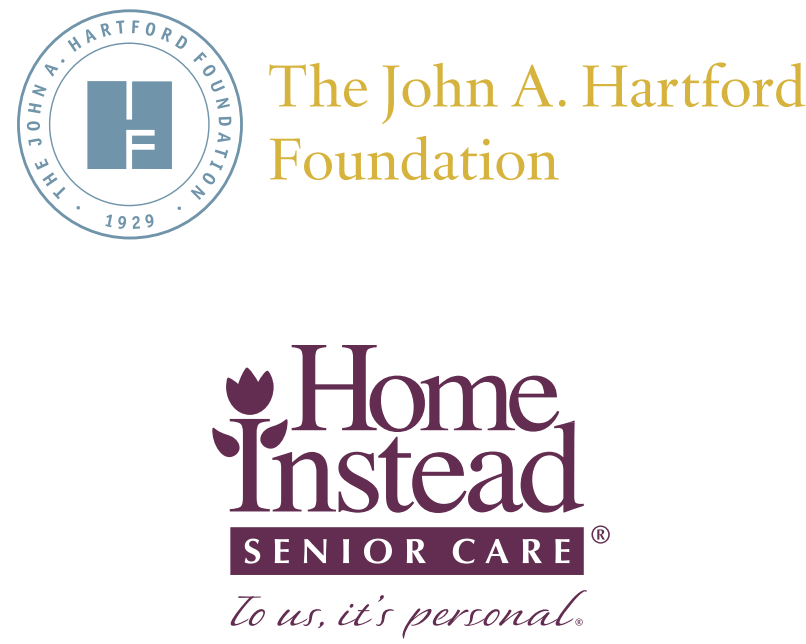

USAgainstAlzheimer's 


\section{ACKNOWLEDGMENTS}

Our work depends on the efforts of many colleagues who share our aspirations. A special thanks to our sponsors and collaborators, AARP, Bank of America, Biogen, BrightFocus Foundation, Home Instead Senior Care, The John A. Hartford Foundation, and UsAgainstAlzheimer's.

Thank you to our colleague, Ken Sagynbekov from the health economics research team, for analyzing data and updating projections on the prevalence and economic impact of dementia. We especially appreciate our Center for the Future of Aging colleague, Cara Levy, for her valuable research assistance. We also appreciate our colleagues Jill Posnick, Karen Rogers, Emily Ball, Kelsey Biggins, Heather Fields, and Bridget Wiegman for their editing and design help.

To our friends in the field-Matthew Baumgart, Ellen Blackwell, Jisella Dolan, Robert Egge, Howard Fillit, Molly French, Terry Fulmer, Carolyn Jones, Melinda Kelley, Brooks Kenny, Surya Kolluri, lan Kremer, Jill Lesser, Sarah Lock, Erin Long, Holly Massett, Lisa McGuire, Kelly O'Brien, Jason Resendez, Mark Roithmayr, Robyn Stone, George Vradenburg, Joan Weiss, Grace Whiting, and Jennifer Ann Zimmer-we greatly appreciate your insights and feedback during our review process. Your comments helped make our report a much better product.

To the many experts from government, the private sector, and academia with whom we consulted, we appreciate your time and valuable input in helping us develop our recommendations for action. We thank Norma Coe for her contributions to helping us better understand the economic value of caregiving. Finally we thank, as always, our Chairman Paul Irving and the members of our Center for the Future of Aging Business Council and Academic and Policy Advisory Board. Their support, ideas, and shared commitment to a better future motivate our work in many ways. 
Nora Super serves as senior director of the Milken Institute Center for the Future of Aging, whose mission is to improve lives and strengthen societies by promoting healthy, productive, and purposeful aging. In this role, she oversees all programs and policies related to aging-related initiatives and is responsible for managing and creating data-driven research, meaningful policy initiatives, and impactful convenings in the United States as well as internationally. Prior to joining the Milken Institute, Super held several key leadership roles in the public and private sectors. Most recently, she served as the chief of program and services at the National Association of Area Agencies on Aging. In 2014, Super was appointed by President Obama as executive director of the White House Conference on Aging, where she received wide recognition for her nationwide efforts to improve the quality of life of older Americans. In 2015, Super was recognized as one of America's top 50 "Influencers in Aging" by PBS Next Avenue and was the Honoree for Outstanding Service to Medicare Beneficiaries by the Medicare Rights Center. She has also held leadership roles at the US Department of Health and Human Services, AARP, and Kaiser Permanente. Super serves on several advisory boards, including the Board of Directors of the Long-Term Quality Alliance, the Bipartisan Policy Center's Advisory Committee on Improving Care Delivery for Individuals with Serious IIIness, the Better Medicare Alliance Beneficiary Education Technical Advisory Council, the Brookings Institution and Kellogg School of Management Retirement Security Advisory Board, and the Editorial Board of the Gerontological Society of America's Policy and Aging Report. A frequent speaker on health and policy issues, Super has also taught in the MBA program at Georgetown University, leading a faculty track on health care and the budget process. A native of New Orleans, Super studied political science at Tulane University and completed her master's work in public administration, with a concentration in health policy, at George Washington University.

Rajiv Ahuja is an associate director in the Milken Institute Center for the Future of Aging. His work focuses on researching and evaluating effective aging policies that promote healthy longevity. Ahuja helps build awareness for evidence-based programs that promote prevention and wellness for longer, healthier lives. Ahuja also works with Milken Institute leadership to develop and market test innovative solutions that address health disparities. Ahuja is interested in building crossdisciplinary partnerships to develop policy, business, and technology-based solutions to domestic and global aging issues. Before joining the Institute, Ahuja worked as a health-care consultant, supporting health plan and provider clients serving members in Medicare, Medicaid, and commercial health programs. Ahuja holds a master's in health-care policy and management from Carnegie Mellon University's Heinz School of Public Policy and a JD from American University.

Kevin Proff is an associate at the Center for the Future of Aging. He assists with the Center's Business of Aging and Healthy Longevity work. Proff previously served as health education and outreach manager of Pacific Region Oasis, where he developed programs for older adults that emphasized physical, mental, and social engagement. Proff was also an associate founder of Join our Story, an online platform focused on increasing engagement and reducing isolation. He has bachelor degrees in philosophy and psychology from the University of California, Irvine, and a master of science from the University of Southern California Leonard Davis School of Gerontology. 
